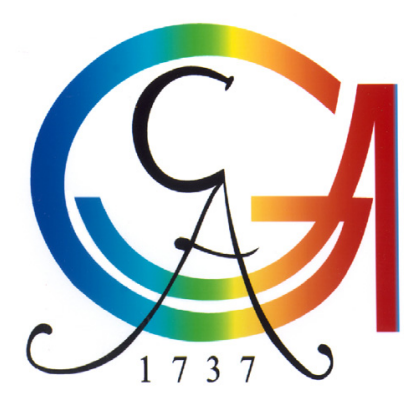

\title{
Differentiation of Flk-1 positive multipotent adult germline stem cells into endothelial cells in vitro and in vivo
}

\author{
Dissertation \\ zur Erlangung des mathematisch-naturwissenschaftlichen \\ Doktorgrades „Doctor rerum naturalium“ \\ der Georg-August-Universität Göttingen
}

\author{
vorgelegt von \\ I-Fen Cheng \\ aus Taoyuan (Taiwan)
}

Göttingen, Germany, 2010 
D7

Referent: $\quad$ Prof. Dr. med. Wolfgang Engel

Korreferent: $\quad$ Prof. Dr. Sigrid Hoyer-Fender

Tag der mündlichen Prüfung: 


\section{Certificate of authorship/originality}

I hereby declare that the Ph.D. thesis entitled "Differentiation of Flk-1 positive multipotent adult germline stem cells into endothelial cells in vitro and in vivo" has been written independently. All information sources and literatures used are indicated in the thesis.

I certify that the work in this thesis has not previously been submitted for a degree nor has it been used as part of requirements for a degree except as fully acknowledged within the text.

I-Fen Cheng 


\section{Table of Contents}

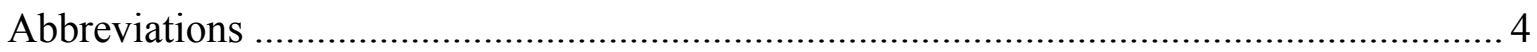

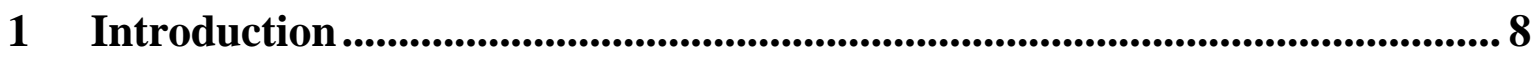

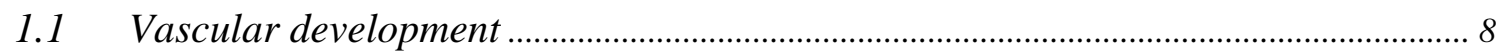

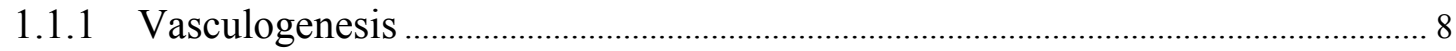

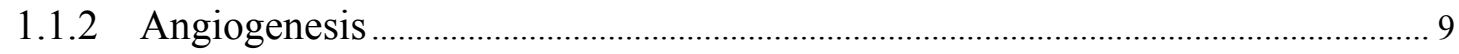

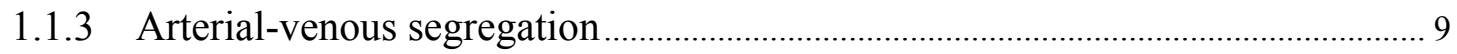

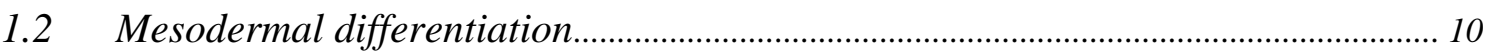

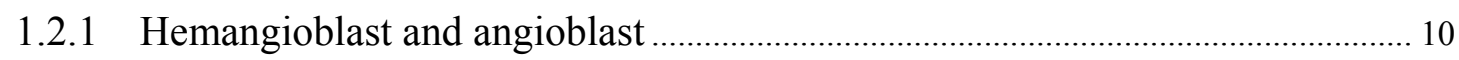

1.2.2 Cardiovascular progenitor cells ............................................................................ 11

$1.3 \quad$ Stem cells, Precursors/Progenitor cells .......................................................................... 12

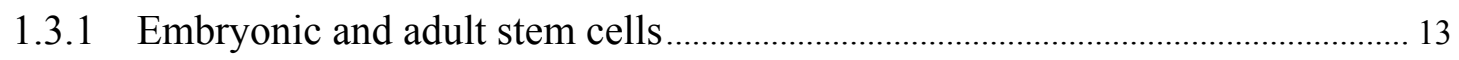

1.3.2 Spermatogonial stem cells and multipotent adult germline stem cells............... 13

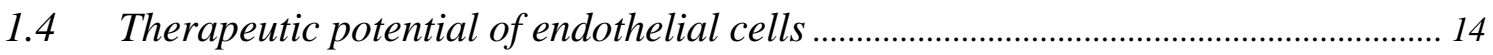

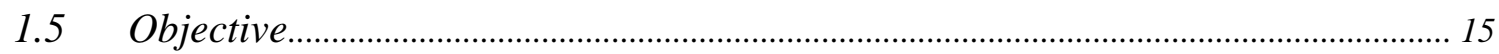

2 Materials and Methods .......................................................................................... 16

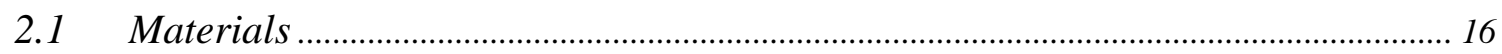

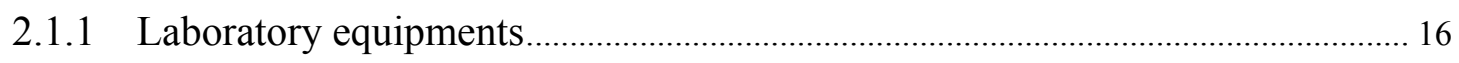

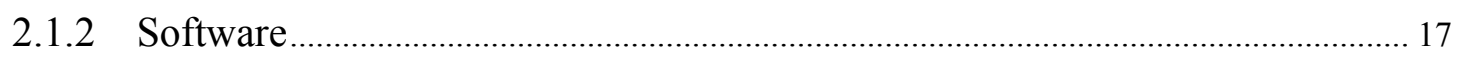

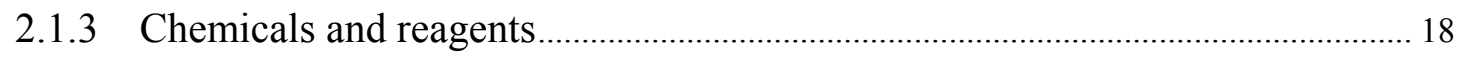

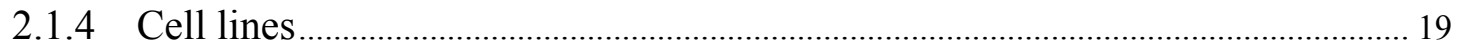

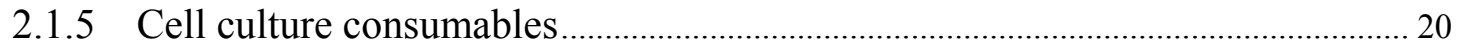

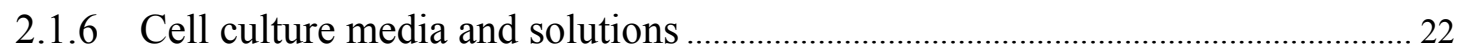

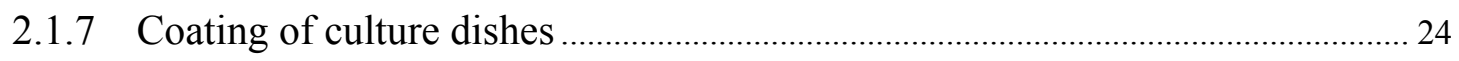

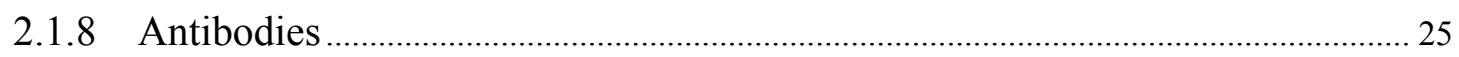

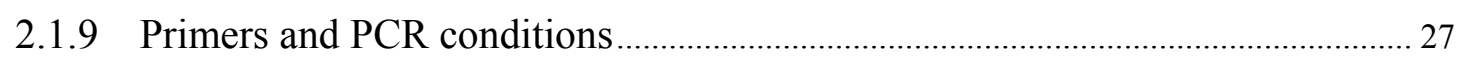

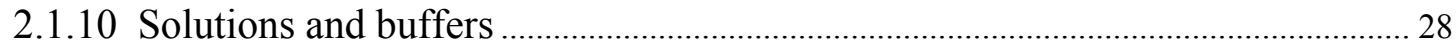

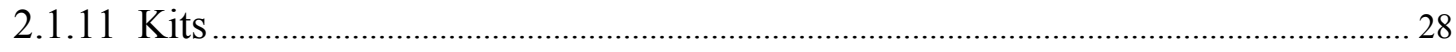

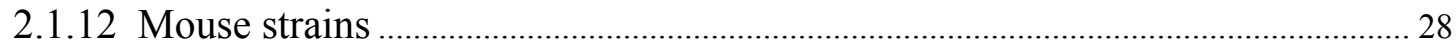

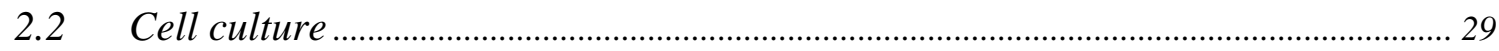




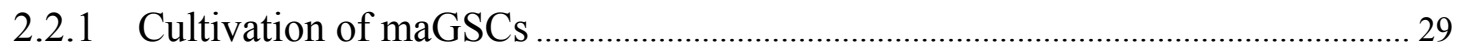

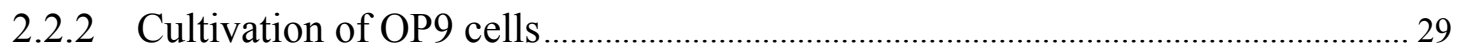

2.2.3 Cultivation of SVEC4-10 cells ...................................................................................... 30

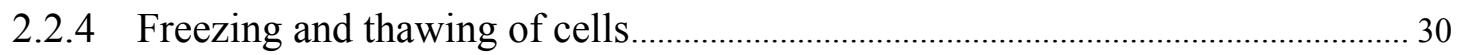

2.2.5 Induction of Flk- $1^{+}$progenitor cells from maGSCs ................................................ 31

2.2.6 Maintenance of Flk- $1^{+}$cardiovascular progenitor cells ............................................. 31

2.2.7 Induction of endothelial differentiation from Flk- $1^{+}$progenitor cells ................. 31

2.2.8 Spontaneous differentiation of Flk $-1^{+}$progenitor cells ........................................... 32

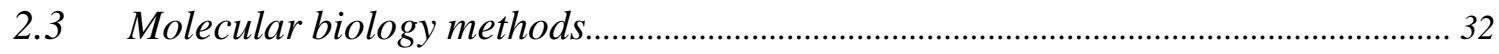

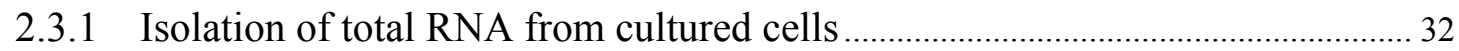

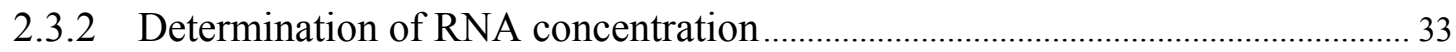

2.3.3 Reverse transcription polymerase chain reaction (RT-PCR) ….............................. 33

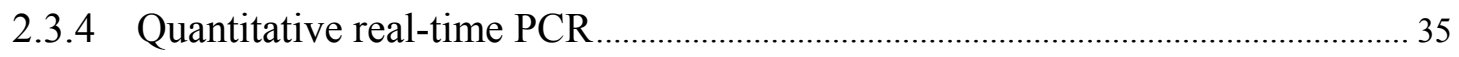

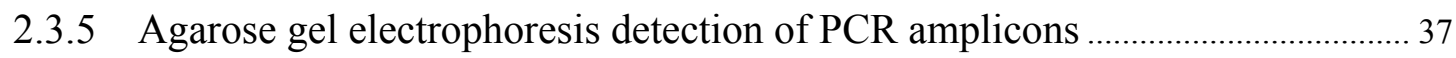

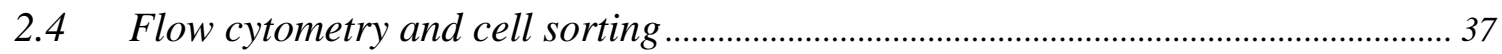

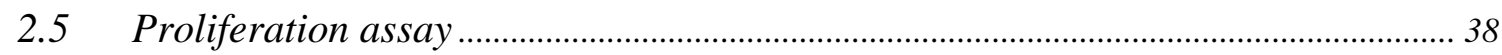

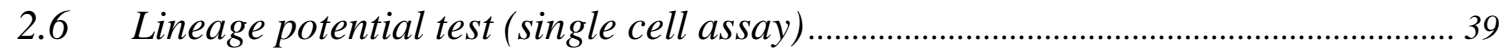

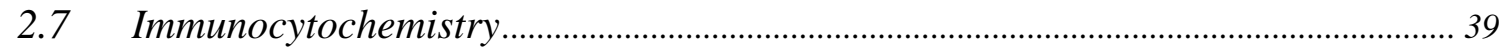

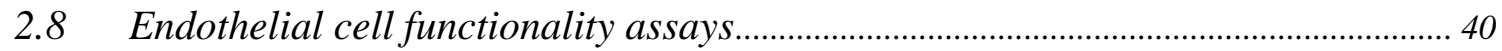

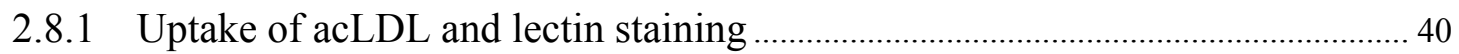

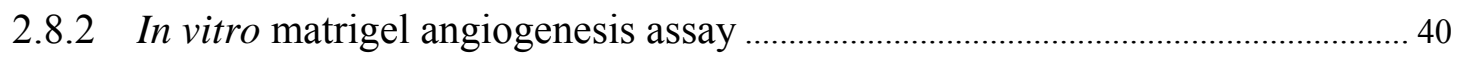

2.8.3 In vitro 3-dimensional spheroid angiogenesis assay ............................................. 41

2.9 In vivo spheroid-based matrigel plug angiogenesis assay ......................................... 42

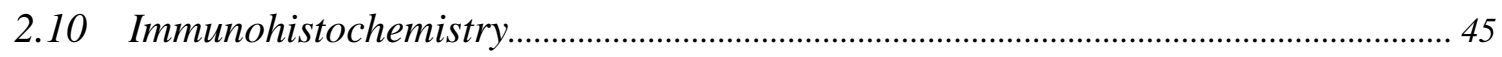

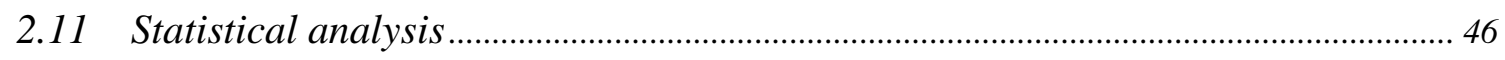

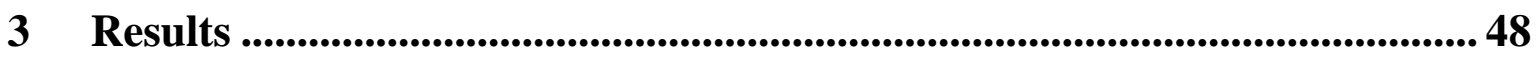

3.1 Generation of maGSC-derived Flk- $1^{+}$cardiovascular progenitor cells ................... 48

3.2 In vitro screening for candidate ECM proteins ............................................................. 49

3.3 In vitro characterization of Flk- $1^{+}$progenitor cells ………………………………...... 58

3.3.1 Gene expression analysis of Flk $-1^{+}$progenitor cells .............................................. 58 
3.3.2 Angiogenic potential of Flk-1 $1^{+}$progenitor cells

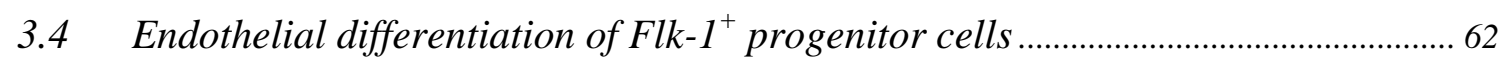

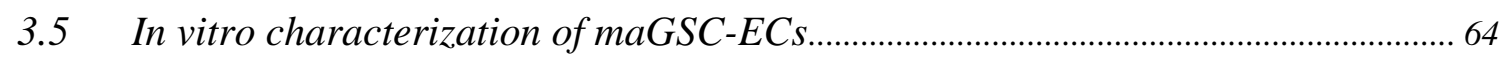

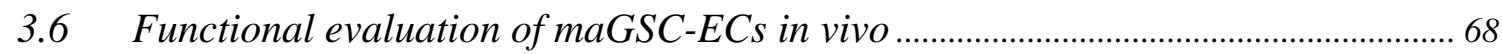

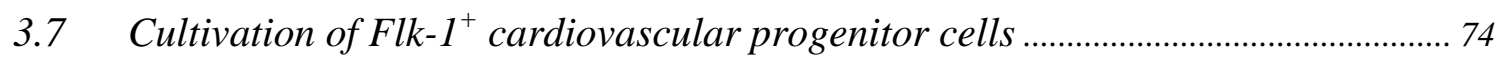

3.7.1 Screening culture conditions for long-term culture of Flk- $1^{+}$progenitor cells 74

3.7.2 In vitro characterization of long-term cultured Flk- $1^{+}$progenitor cells ............. 82

3.7.3 Protein expression of Flk-1 and Isl1 in long-term cultured Flk- $1^{+}$progenitor

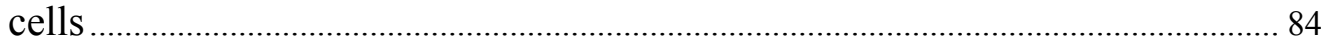

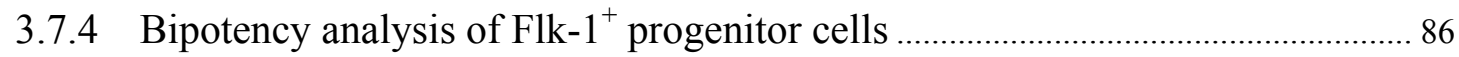

3.7.5 Angiogenic potential of the presumptive Flk- $1^{+}$progenitor cells ........................ 86

3.7.6 Presumptive Flk- $1^{+}$progenitor cells spontaneously differentiate into three cardiovascular lineages

4 Discussion.

4.1 MaGSCs may be useful as alternative cell source for the generation of cardiovascular progenitor and endothelial cells.

4.2 Collagen type IV is superior in supporting endothelial cell differentiation ............ 92

4.3 VEGF promotes endothelial cell differentiation ............................................................ 94

4.4 In vitro endothelial differentiation from maGSCs....................................................... 97

4.5 MaGSC-ECs are not yet clinically applicable in vivo ............................................... 100

4.6 In vivo detection system for tracking cell fate after transplantation ....................... 102

4.7 Long-term cultivation of Flk-1 ${ }^{+}$cardiovascular progenitor cells ............................. 103

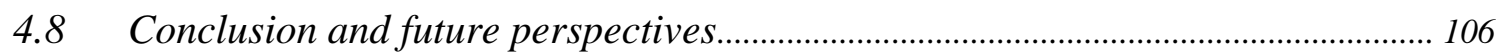

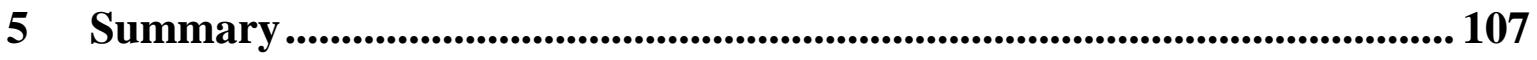

6 References ........................................................................................................... 109

7 Acknowledgements..................................................................................... 125

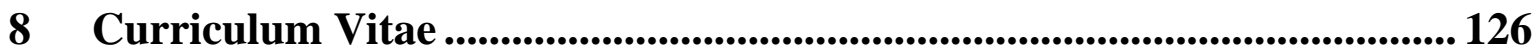




\section{Abbreviations}

AcLDL

Ang

$\square$-SMA

bFGF

$\mathrm{BL}-\mathrm{CFC}$

BSA

$\square-\mathrm{ME}$

cDNA

CM-DiI

$\mathrm{CO}_{2}$

COLIV

$\mathrm{Ct}$

cTnT

DAPI

$\mathrm{ddH}_{2} \mathrm{O}$

DEPC

DMEM

DMSO

DNase

dNTP

DPBS

dpc

EB

EC

ECBM

ECGS/H

ECM

EDTA

EGF
Acetylated Low-Density Lipoprotein

Angiopoietin

$\square$-Smooth Muscle Actin

basic Fibroblast Growth Factor

Blast Colony-Forming Cell

Bovine Serum Albumin

$\square$-Mercaptoethanol

complementary Deoxyribonucleic Acid

Chloromethylbenzamido-DiI (a carbocyanine dye)

Carbon dioxide

Collagen type IV

Cycle threshold

cardiac Troponin T

Diamidino-2-Phenylindole dihydrochloride

double distilled water

Diethylpyrocarbonate

Dulbecco's Modified Eagle Medium

Dimethyl Sulfoxide

Deoxyribonuclease

deoxynucleotide Triphosphate

Dulbecco's Phosphate Buffered Saline

day post coitus

Embryoid Body

Endothelial Cell

Endothelial Cell Basal Medium

Endothelial Cell Growth Supplement/Heparin

Extracellular Matrix

Ethylene Diamine Tetraacetic Acid

Epidermal Growth Factor 


\begin{tabular}{|c|c|}
\hline EGFP & Enhanced Green Fluorescent Protein \\
\hline EHS & Engelbreth-Holm-Swarm \\
\hline eNOS & endothelial Nitric Oxide Synthase \\
\hline EPC & Endothelial Progenitor Cell \\
\hline ESC & Embryonic Stem Cell \\
\hline FACS & Fluorescence Activated Cell Sorting \\
\hline FBS & Fetal Bovine Serum \\
\hline FITC & Fluorescein Isothiocyanate \\
\hline Flk-1 & Fetal liver kinase-1 \\
\hline Flt & Fms-like tyrosine kinase \\
\hline $\mathrm{FN}$ & Fibronectin \\
\hline GAPDH & Glyceraldehyde-3-Phosphate Dehydrogenase \\
\hline GFP & Green Fluorescent Protein \\
\hline GFR matrigel & Growth Factor Reduced matrigel \\
\hline $\mathrm{HCl}$ & Hydrochloric acid \\
\hline $\mathrm{ICM}$ & Inner Cell Mass \\
\hline IGF-1 & Insulin-like Growth Factor-1 \\
\hline $\operatorname{IgG}$ & Immunoglobulin $\mathrm{G}$ \\
\hline IMDM & Iscove's Modified Dulbecco's Medium \\
\hline iPS cell & induced Pluripotent Stem cell \\
\hline Isl1 & Islet-1 \\
\hline LIF & Leukemia Inhibitory Factor \\
\hline M199 & Medium 199 \\
\hline maGSC & multipotent adult Germline Stem Cell \\
\hline M-CSF & Macrophage Colony-Stimulating Factor \\
\hline $\mathrm{MEF}$ & Mouse Embryonic Fibroblast \\
\hline MEM $\square$ & Minimum Essential Medium alpha \\
\hline Mesp1 & Mesoderm posterior 1 \\
\hline $\mathrm{mGC}$ & multipotent Germ Cell \\
\hline $\mathrm{MgCl}_{2}$ & Magnesium Chloride \\
\hline $\mathrm{MMC}$ & Mitomycin $\mathrm{C}$ \\
\hline $\mathrm{MnCl}_{2}$ & Manganese Chloride \\
\hline mRNA & messenger Ribonucleic Acid \\
\hline MTG & Monothioglycerol \\
\hline
\end{tabular}


MTS

$\mathrm{NaCl}$

$\mathrm{NaOH}$

NEAA

NKX2.5

Oct4

$\mathrm{P} / \mathrm{S}$

PCR

PE

PECAM-1

PFA

$\mathrm{pH}$

RT

RT-PCR

SCID

$\mathrm{SMC}$

SSC

Stra8

$\mathrm{T} / \mathrm{E}$

TAE

Taq

TGF

Tie-2

Tris

UV

v/v

VE-cad

VEGF

VEGFR

vWF 3-(4,5-dimethylthiazol-2-yl)-5-(3-

carboxymethoxyphenyl)-2-(4-sulfophenyl)-2H-

tetrazolium

Sodium Chloride

Sodium Hydroxide

Non-Essential Amino Acid

NK2 transcription factor related, locus 5

Octamer binding transcription factor 4

Penicillin/Streptomycin

Polymerase Chain Reaction

Phycoerythrin

Platelet Endothelial Cell Adhesion Molecule-1

Paraformaldehyde

prepondirance of Hydrogen ions

Room Temperature

Reverse Transcription Polymerase Chain Reaction

Severe Combined Immunodeficiency

Smooth Muscle Cell

Spermatogonial Stem Cell

Stimulated by retinoic acid 8

Trypsin/EDTA

Tris-Acetate-EDTA

Thermus aquaticus

Transforming Growth Factor

Tyrosine kinase with immunoglobulin-like and epidermal growth factor-like domains-2

Tris-(hydroxymethyl)-aminomethane

Ultraviolet

volume pro volume

Vascular Endothelial cadherin

Vascular Endothelial Growth Factor

Vascular Endothelial Growth Factor Receptor

von Willebrand Factor 


\section{Units}

$\begin{array}{ll}{ }^{\circ} \mathrm{C} & \text { Degree Celsius } \\ \mathrm{bp} & \text { Base pair } \\ \mathrm{E} & \text { Embryonic day } \\ \mathrm{g} & \text { Gram } \\ \mathrm{M} & \text { Molar } \\ \mathrm{mg} & \text { Milligram } \\ \mathrm{ml} & \text { Milliliter } \\ \mathrm{mM} & \text { Millimolar } \\ \mathrm{mm} & \text { Millimeter } \\ \square \mathrm{g} & \text { Microgram } \\ \square 1 & \text { Microliter } \\ \square \mathrm{M} & \text { Micromolar } \\ \mathrm{ng} & \text { Nanogram } \\ \mathrm{nm} & \text { Nanometer } \\ \mathrm{OD} & \text { Optical density } \\ \mathrm{rpm} & \text { Rounds per minute } \\ \mathrm{U} & \text { Unit }\end{array}$




\section{Introduction}

\subsection{Vascular development}

The cardiovascular system, which is derived from mesoderm, is the first functional organ system that develops in the embryo; it provides nutrition and oxygen to growing tissues and removes waste products (Cleaver and Melton, 2003; Jussila and Alitalo, 2002). Blood vessels are critical not only for supporting organ growth in the embryo but also for wounded tissue repair after birth (Velazquez, 2007). Blood vessels consist of two cell types: endothelial cells (ECs) and mural cells (vascular smooth muscle cells and pericytes), and the interaction between ECs and mural cells is essential during vascular development and maintenance (Darland and D'Amore, 1999; Folkman and D'Amore, 1996). There are mainly two processes mediating new blood vessel formation, namely vasculogenesis and angiogenesis (Risau and Lemmon, 1988). The major difference between the two processes is the source of endothelial progenitor cells (EPCs). In vasculogenesis the source of precursors are undifferentiated cells of the mesoderm. In angiogenesis, new vessel formation occurs via proliferation of ECs from existing vessels (Drake et al., 1998).

\subsubsection{Vasculogenesis}

Risau was the first scientist who used the term "vasculogenesis" to describe de novo blood vessel formation occurring in embryonic stem cell (ESC)-derived embryoid bodies (EBs) (Risau et al., 1988). Vasculogenesis involves the differentiation of angioblasts (endothelial progenitor cells, EPCs) into ECs and their assembly into endothelial cords. This is the mechanism by which the primitive vascular plexus is formed (Cox and Poole, 2000). Essential steps in this process are 1) the generation of angioblasts from mesoderm; 2) the assembly of angioblasts into vascular structures; 3) the formation of a vascular lumen and 4) the organization of continuous vascular networks. Notably, blood vessels formed by the process of vasculogenesis are immature, meaning that they are free of pericytes, smooth muscle cells (SMCs) and other associated cells (Drake, 2003). 


\subsubsection{Angiogenesis}

Angiogenesis is the formation of new capillaries from pre-existing blood vessels (Risau, 1997). In contrast to vasculogenesis, angiogenesis involves vascular growth and maturation. Following the initial formation of a primitive embryonic and extra-embryonic vasculature during vasculogenesis, these vascular systems are rapidly expanded and remodelled (Figure 1). This process involves EC sprouting, vessel branching, and intussusception from existing blood vessels (Flamme et al., 1997; Patan, 2004). During the process of maturation and remodelling, peri-endothelial support cells are recruited to build the vessel wall. Pericytes ensheath capillary ECs, whereas SMCs surround ECs in arteries, arterioles, venules and veins (Augustin et al., 2009). Angiogenesis is essential during tissue

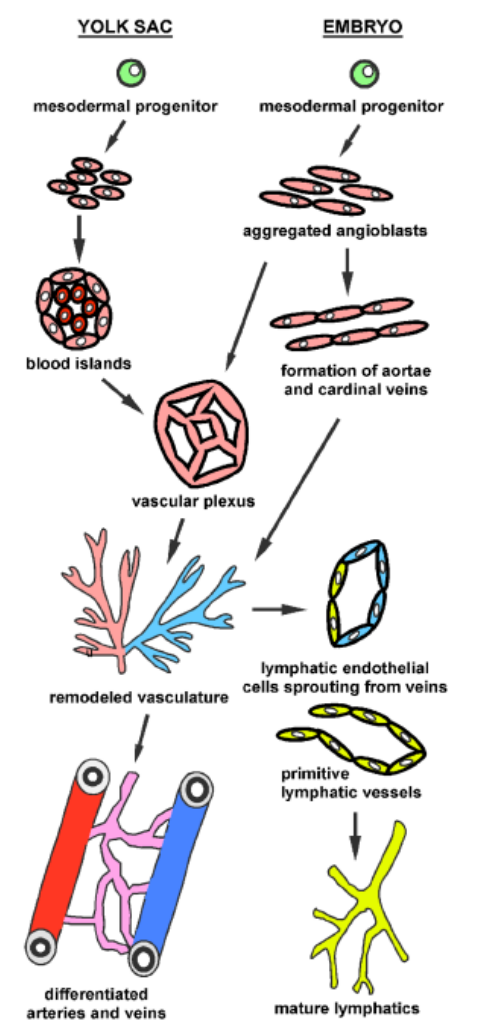

repair, fetal development and the female reproductive cycle. In contrast, dysregulated vessel growth can have a serious impact on health. For example, excessive angiogenesis promotes tumor formation or inflammatory conditions, such as arthritis and atherosclerosis; insufficient vessel growth or abnormal vessel regression may also lead to ischemic diseases, hypertension, neurodegeneration, and other disorders (Carmeliet, 2003; Carmeliet, 2005; Couffinhal et al., 2009).

Figure 1. Scheme showing the endothelial development from mesodermal progenitors. ECs develop in the yolk sac within blood islands, from which a primitive vascular plexus is formed. Within the embryo itself, the primitive embryonic vasculature is formed from angioblasts. The primitive embryonic and extraembryonic vasculature is then extensively remodelled via angiogenesis. Adapted from (De and Black, 2009).

\subsubsection{Arterial-venous segregation}

Herbert et al., while studying zebrafish vascular development recently uncovered a third mode of blood vessel formation. They found that the first embryonic artery and vein arise from a common precursor vessel. The directional control of progenitor migration leads to arterial-venous segregation and is regulated by the ligand EphrinB2 and its receptor EphB4 (Herbert et al., 2009). 


\subsection{Mesodermal differentiation}

Endothelial and hematopoietic cell lineages are the first to originate from mesoderm in the early vertebrate embryo. In the mouse embryo, mesoderm is generated from the epiblast or embryonic ectoderm, which is initiated at approximately day 6.5 of gestation. The process of gastrulation involves highly coordinated cell and primary tissue movements for subsequent morphogenesis (Tam and Beddington, 1987; Tam and Behringer, 1997). During gastrulation, three germ layers, i.e. ectoderm, mesoderm and endoderm are placed in appropriate spatial contexts (McClay and Logan, 1996).

\subsubsection{Hemangioblast and angioblast}

The hemangioblast is a common progenitor cell, which gives rise to both hematopoietic and endothelial lineages. This hypothesis was based on the close proximity of cells in the yolk sac blood islands that differentiate into both blood cells and blood vessels (His, 1900; Sabin, 1920 and Murray, 1932). In the mouse, blood islands develop from aggregates of mesodermal cells that arise between embryonic day E7.0 and E7.5. Between E8.0 and E9.0, the inner cells of these blood islands give rise to embryonic hematopoietic cells, whereas the peripheral population differentiates into ECs (Haar and Ackerman, 1971) (Figure 2).
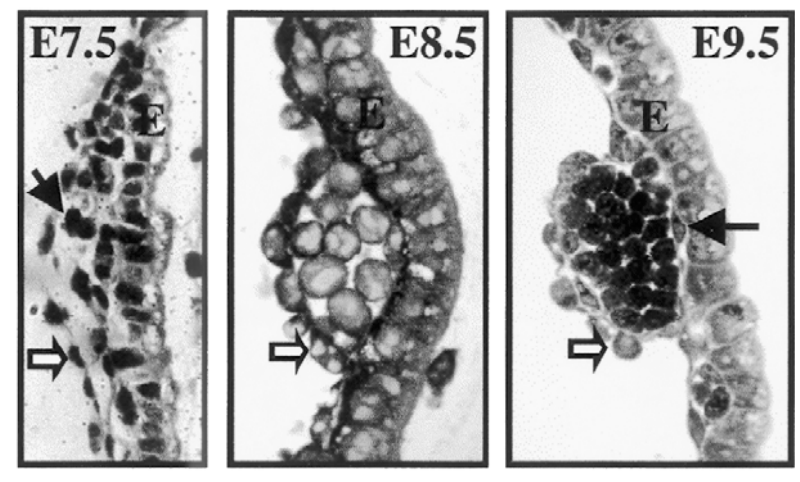

Figure 2. Development of yolk sac blood island in mouse embryo. Blood islands form between a single cell layer of endoderm cells (E) and mesothelial cells (open arrow). Closed arrow at E9.5 shows cells exhibiting endothelial morphology. Adapted from (Palis and Yoder, 2001).

The concept of the hemangioblast has gained support from studies showing that both hematopoietic and EC lineages share the expression of multiple genes, such as scl/tal1 and vascular endothelial growth factor receptor 2 (VEGFR2; Human/Mouse, KDR/Flk1) (Eichmann et al., 1997; Kallianpur et al., 1994). Gene targeting experiments demonstrating that Flk-1 is essential for blood island development added further support to the hypothesis that these lineages are derived from a common precursor (Shalaby et al., 1995). Direct evidence for the existence of hemangioblasts came from an in vitro blast 
colony-forming cell (BL-CFC) assay established by Choi. The authors found that BLCFCs could clonally give rise to both ECs and hematopoietic cells in the presence of VEGF (Choi et al., 1998; Kennedy et al., 1997). Thus, BL-CFC may be regarded as in vitro counterpart of the hemangioblast. Hemangioblasts can also be identified from the developing mouse embryo and express both brachyury and Flk-1 (Huber et al., 2004).

During further differentiation, hemangioblasts give rise to angioblasts (endothelial cell precursors). Angioblasts, a term first used by His in 1900 (His, 1900), refers to individual mesenchymal cells committed to the endothelial lineage (Noden, 1988). Angioblasts are identified by the expression of markers that label presumptive ECs, e.g. Flk-1, Platelet Endothelial Cell Adhesion Molecule-1 (PECAM-1), but are not fully differentiated (Risau and Flamme, 1995). Angioblast differentiation is promoted by VEGF (Carmeliet et al., 1996; Ferrara et al., 1996) and also appears to be induced by basic fibroblast growth factor (bFGF) (Cox and Poole, 2000). Following the commitment toward to EC lineage, angioblasts reorganize and migrate during the expansion and remodelling of the vascular plexus, which involves sprouting, splitting, fusion and regression (pruning) of vascular branches (Kubo and Alitalo, 2003). Both hemangioblasts and angioblasts express Flk-1 and Tie-2 (Tyrosine kinase with immunoglobulin-like and epidermal growth factorlike domains-2) in the mouse embryo (Furuta et al., 2006).

\subsubsection{Cardiovascular progenitor cells}

Flk- $1^{+}$multipotent cardiovascular progenitor cells have been identified using in vitro mouse ESC differentiation system as well as in vivo mouse embryo. Moreover, it has been shown that they can differentiate into all three cardiovascular lineages, i.e. cardiomyocytes, ECs and SMCs (Kattman et al., 2006). These progenitor cells can be defined by the expression of Flk- $1^{+} / \mathrm{Is} 11^{+} / \mathrm{Nkx} 2.5^{+}$(Moretti et al., 2006). Islet1 (Is11) and Nkx2.5 mark cell populations which contribute to myocardial cells, endocardium and aortic endothelium (Cai et al., 2003; Stanley et al., 2002). Isl1 is a LIM-homeobox transcription factor and marker for cardiac progenitor cells in postnatal mouse, rat and human myocardium (Laugwitz et al., 2005).

To summarize, Flk-1 is a marker for hemangioblasts, angioblasts and cardiovascular progenitor cells. Moreover, Flk-1 cardiovascular progenitor cells and BLCFCs represent two different $\mathrm{Flk}-1^{+}$progenitor populations and the segregation of these two progenitor cell populations that appear in a sequential fashion is consistent in vivo (Kattman et al., 2006, Figure 3). 


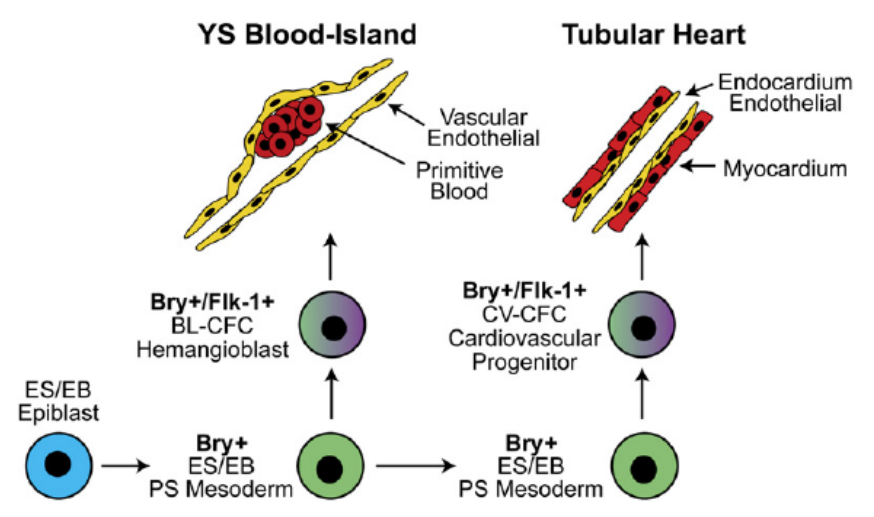

Figure 3. Model of mesodermal specification to cardiovascular and hematopoietic lineage.

Adapted from (Kattman et al., 2006)

\subsection{Stem cells, Precursors/Progenitor cells}

Stem cells are undifferentiated cells that can self-renew and give rise to one or more specialized cell types with specific cell functions in the body (McKay, 2000). Selfrenewal is the ability to generate daughter cells with identical genome and phenotype as their mother cells. Stem cells can be categorized by their potentials. Both zygote and morula are totipotent meaning their ability to generate an entire organism independently. Embryonic stem cells (ESCs) originated from inner cell mass (ICM) of a blastocyst. Both ESCs and ICM are pluripotent meaning that they can develop into all cell types of the embryo proper, excluding extraembryonic tissues (Czyz et al., 2003). During development, pluripotent ESCs become increasingly restricted in their lineage potential and generate multipotent stem cells. Adult stem cells are multipotent and self-renewing cells that sit at the top of the lineage hierarchy (van der and Weiss, 2000). They have the ability to differentiate into more committed cells that comprise specific, mature tissue (Eckfeldt et al., 2005). The best example of an adult stem cell is the bone marrow stem cell, which is unspecialized and capable of differentiating into different blood cells. In vivo, stem cells reside in specific cellular microenvironments, so called niches, that constitute appropriate settings for the support of self-renewal (Watt and Hogan, 2000).

Stem cells generate an intermediate cell type before they reach a fully differentiated state. The intermediate cell is known as a precursor or progenitor cell. Progenitor cells in fetal or adult tissues are partly differentiated cells that give rise to differentiated cells (Robey, 2000). The difference is that a stem cell is an unspecialized cell, which can replicate itself (self-renewal) and produce at least one identical daughter cell. A progenitor cell is an unspecialized or partially specialized cell that can undergo cell 
division, yielding two or more specialized cells (Zech, 2004). In contrast to stem cells, progenitor cells are limited in their proliferative ability, cannot self-renew, and may or may not be multipotent (Bull and Bartlett, 2005).

\subsubsection{Embryonic and adult stem cells}

Mouse ESCs were first isolated from the inner cell mass of mouse blastocysts at 3.5 days post coitum (dpc) in 1981 (Evans and Kaufman, 1981; Martin, 1981). ESCs have attracted particular interest in regenerative medicine, because of their almost unlimited capacity to self-renew and potential to differentiate into all derivatives of three embryonic germ layers and germ line cells. However, for their application in regenerative medicine, their maintenance and in vitro differentiation must be tightly controlled due to the high risk of teratoma formation. Moreover, the use of ESCs confronts ethical barriers, and the creation of human embryos for obtaining ESCs is prohibited by the Council of Europe. Pluripotent stem cells derived from adult organisms would circumvent the abovementioned ethical problems and hold the possibility of autologous transplantation. In recent years, several studies have shown that adult stem cells are present in a wide range of tissues. For example, they could be isolated from the central nervous system (Okano, 2002), liver (Theise et al., 1999) and pancreas (Ramiya et al., 2000). However, the number of adult stem cells obtained from these tissues is often limited.

\subsubsection{Spermatogonial stem cells and multipotent adult germline stem cells}

In females, all of the immature germ cells enter meiosis during fetal development and become oocytes, thereby ending their stem cell potential (Adams and McLaren, 2002; McLaren and Southee, 1997). In the male, immature germ cells migrate to the basement membrane of the seminiferous tubules, where they differentiate into spermatogonial stem cells (SSCs). SSCs are the male germline stem cells in the testis (Brinster, 2002). The mammalian testis has a high cell turnover rate, and SSCs are a self-renewing cell population and capable of producing progeny cells for sperm production throughout the lifetime of the male (Caires et al., 2010). The presence of a stem cell population responsible for continual sperm production in the testis was demonstrated in 1994, when the first successful SSC transplantation in mice resulting in donor-derived spermatogenesis (Brinster and Zimmermann, 1994). 
SSCs isolated from mouse testis acquire pluripotency under certain culture conditions in vitro. Multipotent germ cell (mGC) lines have been generated from neonatal mouse (Kanatsu-Shinohara et al., 2004) and mGC lines could also be generated from adult mouse testis and become so-called multipotent adult germline stem cells (maGSCs). MaGSCs are able to spontaneously differentiate into derivatives of the three embryonic germ layers in vitro and generate teratomas in immunodeficient mice. When injected into an early blastocyst, maGSCs contribute to the development of various organs and show germline transmission (Guan et al., 2006).

\subsection{Therapeutic potential of endothelial cells}

ECs or EPCs are of great interest due to their cell-based therapeutic potential for cardiovascular diseases, including the rescue of ischemic tissues (Kalka et al., 2000; Soker et al., 2000). Moreover, EC loss is a major contributing factor to postangioplasty restenosis or graft failure (Schwartz, 1998). Thus, ECs are needed in many tissue-engineering applications such as lining the lumen of synthetic vascular grafts or pre-vascularized beds (Hibino et al., 2005; Seifalian et al., 2002). Also, ECs line the inner lumen of blood vessels and their contact with circulating blood makes them an ideal carrier for drug or gene delivery (Ding et al., 2006).

Although fully mature ECs can be isolated primarily, they have a very low proliferation rate which limits their usefulness for therapeutic applications (Alsberg et al., 2006). Therefore, alternative sources of progenitor cells that can differentiate into functional, proliferating ECs are important and would have therapeutic implications in cardiovascular medicine.

As mentioned above, Flk-1 is a marker for cardiovascular progenitor cells (Kattman et al., 2006). Both hemangioblasts and angioblasts express Flk-1 thus further supporting the idea of using Flk-1 expression for selection of endothelial committedprogenitor cells.

There are two widely used approaches for mesodermal lineage induction in vitro for both human and mouse cultures. To induce mesodermal differentiation, stem cells are differentiated on collagen type IV (COLIV) (Carmeliet et al., 1996; Gerecht-Nir et al., 2003; Li et al., 2007; McCloskey et al., 2006; Nishikawa et al., 1998; Yamashita et al., 2000) or by co-culture with feeder layer OP9 stromal cells (Baba et al., 2007; Hirashima et al., 1999; Kelly and Hirschi, 2009; Nakano et al., 1994; Vodyanik et al., 2005). OP9 stromal cells are frequently used because this cell line does not express functional 
macrophage colony-stimulating factor (M-CSF), known to have inhibitory effects on the differentiation of ESCs to blood cell lineage (Nakano T et al., 1994). Furthermore, a study could demonstrate that Flk-1 expression was prolonged and EC maturation was better supported by OP9 cells compared to mouse ES cells differentiation via EB differentiation system (Zhang et al., 2005).

At the stage of endothelial differentiation, the VEGF signaling pathway is essential. VEGF is generally referred to as VEGF-A (Dai and Rabie, 2007). VEGF is a survival factor for ECs (Gerber et al., 1998) and the primary angiogenic molecule during development (Tammela et al., 2005). Cultures without VEGF generated mostly mural cells expressing $\square$-smooth muscle actin ( $\square \square$ SMA), but no ECs (Lanner et al., 2007; Yamashita et al., 2000). Moreover, depletion of VEGF expression results in a nearly complete block to vascular development (Carmeliet et al., 1996).

Based on these former studies, Flk-1 can be used as a selection marker for cardiovascular progenitor cells and the OP9 co-culture system may be employed to promote mesodermal differentiation. Endothelial differentiation may be induced by supplementation of the culture medium with VEGF.

\subsection{Objective}

The aim of this study was to isolate and expand Flk- $1^{+}$cardiovascular progenitor cells from maGSCs and to further differentiate these cells into morphological and functional ECs. Different culture conditions were examined and compared for their potential to induce endothelial differentiation and to support the growth and maintenance of $\mathrm{Flk}-1^{+}$progenitor cells. The multipotency of maGSC-derived Flk- $1^{+}$progenitor cells were addressed and the functionality of maGSC-derived endothelial-like cells (maGSCECs) was examined both in vitro and in vivo. 


\section{Materials and Methods}

\subsection{Materials}

\subsubsection{Laboratory equipments}

$0.22 \square \mathrm{m}$ filter unit, Millex-GS Millipore (GLGS0250S)

$70 \square$ m cell strainers, BD Biosciences (352350)

ABI PRISM ${ }^{\circledR} 7900 H T$ Real Time PCR System

Autoclave, Tuttnauer 5075 ELV, Biomedis

Biosafety cabinet with aspirator for tissue culture, CA/RE5, W. Krannich

Cell-counting chamber, Thoma neu, Carl Roth (T733.1)

Chemical fume hood, Norddeutsche Laborbau

$\mathrm{CO}_{2}$ incubator, SANYO, W. Krannich

DNA electrophoresis set, Bio-Rad

Drying oven, Heraeus

ELISA reader, Bio-Tek

Embedding cassette, Medite Medizintechnik (47-1102-00)

Embedding machine TP1020, Leica

Eppendorf centrifuge 5415D

Eppendorf centrifuge 5810R

Eppendorf mastercycler gradient

FACS $5 \mathrm{ml}$ polystyrene round-bottom tube, 12 X $75 \mathrm{~mm}$, BD Falcon

FACSAria II cell sorter, BD Bioscience

FACSVantage SE system, BD Biosciences

Fluorescence microscope (AXIO ZEISS) coupled to a digital camera

Freezing container Nalgene Labware (5100-0001)

Gel photo printer, SEIKO Precision DVP-1200, Biozym

Glass Pasteur pipettes, $230 \mathrm{~mm}$

Injection needle 0.6 X $30 \mathrm{~mm}, 23 \mathrm{G}$ 1/4"-Nr.14

Labcycler, Sensoquest, Biotechnica 
Laminar flow hood with a HEPA filter

Microscope coverglasses, 18 X18 mm, Gerhard Menzel GmbH

Microscope glass slides, Gerhard Menzel GmbH

Microtome RM2165, Leica

Microwave oven

Multilmage light cabinet, Alpha Innotech Corporaton

Multi-micropipette, Eppendorf AG

Pipette tips for volumes $0.1-1000 \square 1$

Pipettes for volumes $0.1-1000 \square 1$

Reaction tubes (1.5 and $2 \mathrm{ml})$

Reaction tubes (15 and $50 \mathrm{ml})$

Slide storage boxes

Spectrophotometer, Eppendorf AG

Standard plastic pipettes $(2,5,10,25 \mathrm{ml})$

Syringe, Omnifix 40 Solo, $1 \mathrm{ml} / 40$ I.U. B.Braun (for matrigel injection)

Upright microscope for fluorescence or DIC microscopy, Olympus BX51

Vacuum Filtration System with $0.22 \square$ m filter, Millipore (SCGP00525)

Vortex-Genie 2, Schuett Labortechnik

Water bath set at $37^{\circ} \mathrm{C}$

Water bath with accurate temperatures between 15 and $99^{\circ} \mathrm{C}$

\subsubsection{Software}

$\begin{array}{lll}\text { ABI Prism SDS } & \text { Version 2.1 } & \text { Applied } \\ & & \text { Biosystems } \\ \text { AxioVision } & \text { Version 3.1 } & \text { Carl Zeiss } \\ \text { CellQuest } & \text { Version 3.3 } & \text { Becton } \\ & & \text { Dickinson } \\ \text { C-View } & \text { Version 2.1.010703 } & \text { Digital Video } \\ & & \text { Camera } \\ & & \text { Company } \\ \text { GraphPad Prism } & \text { Version 4.01 } & \text { GraphPad } \\ & & \text { Software }\end{array}$


Image-Pro Plus

Version 4.5.0.29

$\mathrm{KC} 4$

Refenence Manager

WinMDI
Version 3.4

Version 11

Version 2.9
Media

Cybernetics

Bio-Tek

Thomson

Reuters

open source, the

Scripps Research

Institute

\subsubsection{Chemicals and reagents}

\begin{tabular}{|c|c|c|}
\hline 2-propanol & Sigma & 278475 \\
\hline Acetic acid $96 \%$ & Carl Roth & $\mathrm{T} 179.2$ \\
\hline Acetone & Merck & 8.22251 .1000 \\
\hline Agarose & Invitrogen & $15510-027$ \\
\hline Chloromethylbenzamido & Molecular Probes & $\mathrm{V}-22888$ \\
\hline \multicolumn{3}{|l|}{-DiI (CM-DiI) } \\
\hline Collagen, Type I & BD Biosciences & 354236 \\
\hline $\begin{array}{l}\text { Diamidino-2-Phenylindole } \\
\text { dihydrochloride (DAPI) }\end{array}$ & Sigma & D-9542 \\
\hline DiI Acetylated Low- & Mo Bi Tec & L3484 \\
\hline \multicolumn{3}{|c|}{ Density Lipoprotein (AcLDL) } \\
\hline Embedding medium & McCormick & 502004 \\
\hline Eosin Y alcoholic & Thermo Shandon & 6766007 \\
\hline Ethanol 99\% & Chemie-Vertrieb & UN1170 \\
\hline Fibrinogen & Calbiochem & 341576 \\
\hline FITC-Griffonia lectin I & Vector & FL-1101 \\
\hline Forene $100 \%$ & Abbott & 2594.00 .00 \\
\hline Hydrochloric acid (HCl), & Fluka/Sigma & 84422 \\
\hline \multicolumn{3}{|l|}{$37 \%$} \\
\hline Ketamin $10 \%$ & Medistar & 13690.00 .00 \\
\hline Matrigel & BD Biosciences & 354234 \\
\hline Mayer's hematoxylin & Sigma & MHS32 \\
\hline Methanol & J.T.Baker & 8402 \\
\hline Methyl cellulose & Sigma & M0512 \\
\hline
\end{tabular}




\begin{tabular}{|c|c|c|}
\hline Mounting medium for & Vector & H-1000 \\
\hline Sodium Chloride $(\mathrm{NaCl})$, & Braun & 6697366.00 .00 \\
\hline $0.9 \%$ & & \\
\hline Sodium Hydroxide & Merck & 1.09136 .1000 \\
\hline$(\mathrm{NaOH}), 2 \mathrm{~N}$ & & \\
\hline Paraformaldehyde (PFA) & Sigma & P6148 \\
\hline PCR nucleotide mix & Promega & $\mathrm{C} 114 \mathrm{H}$ \\
\hline Thrombin & Calbiochem & 605190 \\
\hline $\begin{array}{l}\text { Tris-(hydroxymethyl)- } \\
\text { aminomethane (TRIS) }\end{array}$ & Paesel+Lorei & 100840 \\
\hline Triton X-100 & Fluka/Sigma & 93426 \\
\hline Xylariem(Xylazine) & Riemser & 400177.00 .00 \\
\hline Xylene & J.T.Baker & 8080 \\
\hline Xylene substitute & Thermo Shandon & 9999122 \\
\hline
\end{tabular}

\subsubsection{Cell lines}

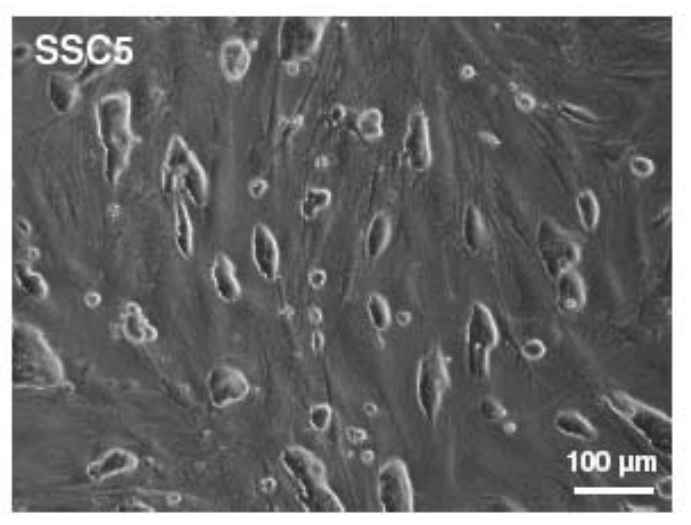

SSC5. SSC5 is a subline of mouse maGSCs. SSC5 were isolated from testis tissues of adult transgenic (Stra8EGFP/Rosa26) mice (4-6 weeks old). Stra8 (stimulated by retinoic acid 8) is a spermatogonia-specific marker (OuladAbdelghani et al., 1996). This cell line was established in 2006 (Guan et al., 2006).

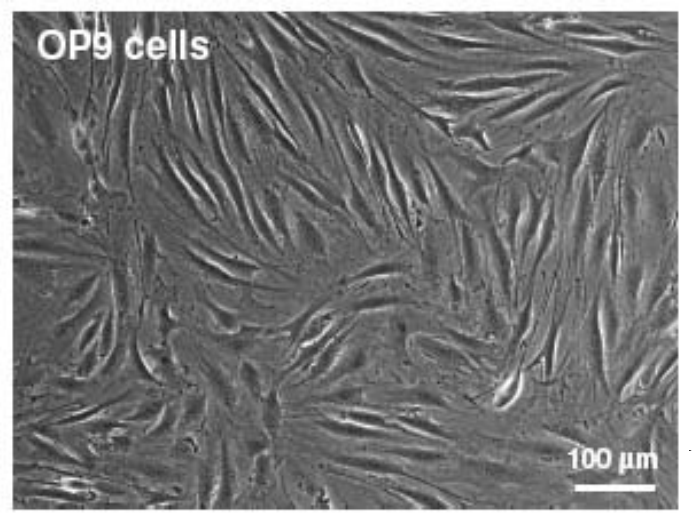

OP9 cells. The OP9 stromal cell line was purchased from RIKEN bioresource center cell bank, Japan (cell no. RCB1124). This line was established from newborn calvaria mouse that lacks functional M-CSF because 
of a mutation in the M-CSF gene (Yoshida et al., 1990).

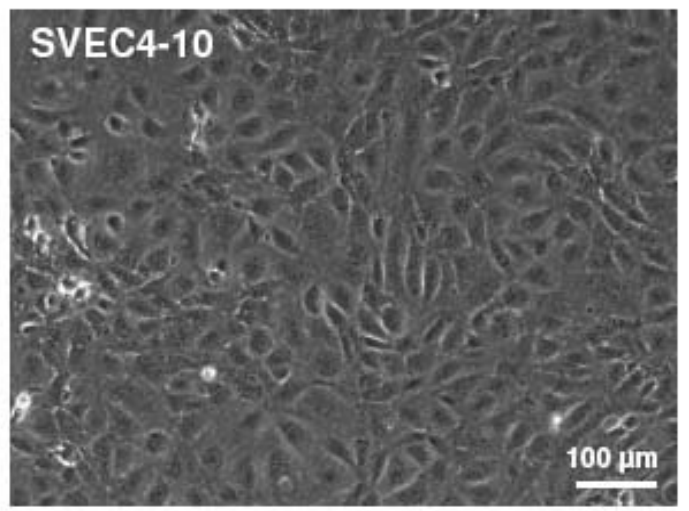

SVEC4-10. SVEC4-10 is a murine EC line derived by SV40 (strain 4A) transformation of ECs from axillary lymph node vessels. This line retains morphological and functional characteristics of normal ECs (O'Connell and Edidin, 1990). This cell line was purchased from ATCC, ATCC number: CRL-2181.

\title{
2.1.5 Cell culture consumables
}

\section{$\underline{\text { Product }}$}

Growth media

Dulbecco's Modified Eagle

Medium (DMEM)

Endothelial Cell Basal Medium

(ECBM) 2

Iscove's Modified Dulbecco's

Medium (IMDM)+ GlutaMAX ${ }^{\mathrm{TM}}-1$

Minimum Essential Medium

MEM) Alpha

Medium 199 (M199)+

GlutaMAX $^{\mathrm{TM}}-1$

M199 10X

\section{Medium supplements}

$\square$-Mercaptoethanol ( $\square$-ME)

SERVA

Invitrogen

Promocell

B-27 Supplement (50X), without vitamin A

Endothelial Cell Growth

\section{Cat. number}

11960

C-22211

Invitrogen

31980

Invitrogen

22561

Invitrogen

41150

Sigma

M0650

\author{
Promocell
} 28625

$12587-010$ 
Supplement/Heparin (ECGS/H)

Endothelial Cell Growth Medium 2 Promocell

kit, containing

ECBM 2

C-22211

Supplement Pack

C-39211

Fetal Bovine Serum (FBS)

Lonza

DE14-801F

Human VEGF $_{165}$

Peprotech

$100-20$

L-Glutamine

Invitrogen

25030024

Leukemia Inhibitory Factor

Millipore

ESG1107

(LIF)

MEM Non-Essential Amino Acid

Invitrogen

11140

(NEAA) 10mM, 100X

Monothioglycerol (MTG)

Sigma

M6145

N-2 Supplement (100X)

Invitrogen

17502-048

Penicillin/Streptomycin (P/S)

Invitrogen

15140-148

10000 units/10000 $\square \mathrm{g} / \mathrm{ml}$

\section{Other reagents}

COLIV

Dimethyl Sulfoxide (DMSO)

Dulbecco's Phosphate Buffered

Saline (DPBS)

Ethylene Diamine Tetraacetic Acid

(EDTA)

Gelatin

Growth Factor Reduced (GFR)

Matrigel $^{\mathrm{TM}}$

Human Fibronectin (FN)

Mitomysin C (MMC)

Trypsin
Sigma

Sigma

Invitrogen

Sigma

Fluka / Sigma

BD Biosciences

Tebu-Bio

SERVA

Invitrogen
E6758

48720

354230

2003

29805

C5533

D2650

14190

27250-018 


\section{$\underline{\text { Tissue culture plates and dishes }}$}

NUNC tissue culture dish

$100 \times 15 \mathrm{~mm}$

NUNC tissue culture dish

$60 \times 15 \mathrm{~mm}$

NUNC multidishes 6-well plate

NUNC multidishes 24-well plate

NUNC multidishes 12-well plate

Plastic square petri dishes

$120 \times 120 \times 17 \mathrm{~mm}$

Suspension culture plate 24-well

Tissue culture plate 96-well, round

bottom suspension cells
NUNC, Thermo

150679

Fisher Scientific

Inc.

NUNC, Thermo

150288

Fisher Scientific

Inc

NUNC, Thermo

140685

Fisher Scientific

Inc

NUNC, Thermo

150628

Fisher Scientific

Inc

NUNC, Thermo

142475

Fisher Scientific

Inc

NUNC, Thermo

167008

Fisher Scientific

Inc

Greiner bio-one

688102

Greiner bio-one

662102

Sarstedt

83.1837 .500

\subsubsection{Cell culture media and solutions}

\section{Cell type-dependent medium}

Mouse Embryonic Fibroblast

(MEF) growth medium

\section{Medium}

DMEM 
MaGSCs growth medium

OP9 growth medium

OP9 and maGSCs co-culture medium

SVEC4-10 growth medium

Endothelial differentiation medium
DMEM

MEM Alpha

IMDM+

GlutaMAX $^{\mathrm{TM}}-1$

DMEM

ECBM 2

ECBM 2

Endothelial progenitor growth

medium ( $2 \%$ medium III)
$15 \%$ FBS

$1 \%$ NEAA $(0.1 \mathrm{mM})$

$1 \% \square-\mathrm{ME}$

$1 \%$ L-Glutamine

$10^{3} \mathrm{U} / \mathrm{ml} \operatorname{LIF}(\mathrm{v} / \mathrm{v})$

$20 \%$ FBS

$1 \% \square-\mathrm{ME}$

$20 \%$ FBS

$1 \% \operatorname{NEAA}(0.1 \mathrm{mM})$

$450 \square \mathrm{M}$ MTG

$10 \%$ FBS

4 mM L-glutamine

$20 \%$ FBS

$1 \% \square-\mathrm{ME}$

0.4\% ECGS/H

EGF

$5 \mathrm{ng} / \mathrm{ml}$

Hydrocortisone

0.2

VEGF $_{165}$

bFGF

$\mathrm{g} / \mathrm{ml} 50$

IGF-1

$\mathrm{ng} / \mathrm{ml}$

Ascorbic acid $10 \mathrm{ng} / \mathrm{ml}$ $20 \mathrm{ng} / \mathrm{ml}$

$1 \square \mathrm{g} / \mathrm{ml}$

$2 \%$ FBS

$1 \% \square-\mathrm{ME}$

0.4\% ECGS/H

EGF

$10 \mathrm{ng} / \mathrm{ml}$ 


$\begin{array}{ll}\text { Hydrocortisone } & 0.2 \square \\ \text { VEGF }_{165} & \mathrm{~g} / \mathrm{ml} \\ \text { bFGF } & 10 \mathrm{ng} / \mathrm{ml} \\ \text { IGF-1 } & 10 \mathrm{ng} / \mathrm{ml} \\ \text { Ascorbic acid } & 20 \mathrm{ng} / \mathrm{ml} \\ \text { N2 } & 1 \square \mathrm{g} / \mathrm{ml} \\ \text { B27 } & 1 \mathrm{X} \\ & 1 \mathrm{X}\end{array}$

1x T/E solution

$0.1 \%(\mathrm{w} / \mathrm{v}) \quad$ stored at $4^{\circ} \mathrm{C}$

Trypsin- $0.01 \%$

$(w / v)$ EDTA

in PBS

MMC stock solution

$200 \square \mathrm{g} / \mathrm{ml}$

stored at $-20^{\circ} \mathrm{C}$

dissolved in PBS

$\square$-ME stock solution (100X)
$7 \square 1 \square$-ME $\quad$ filtered through a $0.22 \square \mathrm{m}$
stock solution in strainer and stored at $4^{\circ} \mathrm{C}$
$50 \mathrm{ml}$ PBS

Freezing medium

$5 \mathrm{ml} \mathrm{FBS}$
$2 \mathrm{ml} \mathrm{DMSO}$

filtered through a $0.22 \square \mathrm{m}$

$18 \mathrm{ml}$ DMEM

\subsubsection{Coating of culture dishes}

Gelatin

The reconstituted gelatin was diluted with $\mathrm{ddH}_{2} \mathrm{O}$ to a concentration of $1 \%$, autoclaved and stored at $4^{\circ} \mathrm{C} .0 .1 \%$ gelatin was used to coat dishes at RT for 1 hour or $4^{\circ} \mathrm{C}$ overnight. Plates were used 
directly without rinsing before cell seeding.

FN

COLIV

GFR matrigel
The reconstituted $\mathrm{FN}$ was diluted with sterile physiological saline to a concentration of 10

$\mathrm{g} / \mathrm{ml}$ and stored at $-20^{\circ} \mathrm{C}$.

Culture dishes were coated with $1.4 \square \mathrm{g} / \mathrm{cm}^{2}$ at RT for 1 hour and rinsed with PBS once before seeding of cells.

COLIV was reconstituted to a concentration of 1 $\mathrm{mg} / \mathrm{ml}$ in $0.25 \%$ acetic acid, incubated overnight, aliquoted and stored at $-20{ }^{\circ} \mathrm{C}$. This solution was further diluted into $20 \square \mathrm{g} / \mathrm{ml}$ for coating to obtain a concentration of $2.8 \square \square \mathrm{g} / \mathrm{cm}^{2}$. Coated dishes were placed at $4^{\circ} \mathrm{C}$ overnight or several hours at $37^{\circ} \mathrm{C}$ and rinsed with PBS twice.

0.5 mg GFR matrigel (ready-to-use) was aliquoted in $15 \mathrm{ml}$ centrifuge tubes and stored at $80^{\circ} \mathrm{C}$. Prior to coating dishes, GFR matrigel was kept on ice and thawed by adding $6 \mathrm{ml}$ of ice-cold IMDM medium. Culture dishes were coated with GFR matrigel at a concentration of 11.6 $\mathrm{g} / \mathrm{cm}^{2}$ at $4^{\circ} \mathrm{C}$ overnight. Culture dishes were not rinsed before the addition of cells.

\subsubsection{Antibodies}

\section{Primary antibodies}

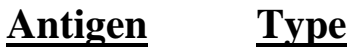

Supplier

Cat. number 


$\begin{array}{lll}\square \text {-SMA } & \text { monoclonal mouse } & \text { Sigma } \\ & \text { anti-mouse } & \\ \text { cTnT } & \text { monoclonal mouse } & \text { Abcam } \\ & \text { anti-mouse } & \\ \text { Flk-1 } & \text { monoclonal PE- } & \text { BD Biosciences } \\ & \text { conjugated rat anti- } & \\ & \text { mouse } & \\ \text { Isl1 } & \text { polyclonal anti- } & \text { Developmental Studies } \\ & \text { mouse } & \text { Hybridoma Bank } \\ \text { VE- } & \text { monoclonal rat anti- } & \text { eBioscience } \\ \text { cadherin } & \text { mouse } & \\ & & \\ \text { vWF } & \text { polyclonal rabbit } & \text { Dako } \\ & \text { anti-human/mouse } & \end{array}$

\section{Isotype controls}

PE-conjugated rat IgG2a,

BD Biosciences

553930

Rabbit IgG

Dako

X0936

\section{Secondary antibodies}

Alexa Fluor 488 goat anti-rabbit IgG Mo Bi Tec

A11070 $(\mathrm{H}+\mathrm{L})$

Cy3 goat anti-mouse IgG+IgM

Jackson

$115-165-068$

$(\mathrm{H}+\mathrm{L})$, affinity-purified

ImmunoResearch

FITC goat anti-mouse $\operatorname{IgG}(\mathrm{H}+\mathrm{L})$,

Jackson

$115-095-062$

affinity-purified

ImmunoResearch

FITC goat anti-rabbit $\operatorname{IgG}(\mathrm{H}+\mathrm{L})$,

Jackson

111-095-045

affinity-purified

ImmunoResearch

MFP488 goat anti-rat IgG $(\mathrm{H}+\mathrm{L}) \quad$ Mo Bi Tec

MFP-A1006

MFP555 goat anti-mouse IgG $(\mathrm{H}+\mathrm{L}) \quad$ Mo Bi Tec

MFP-A2422

MFP555 goat anti-rabbit IgG $(\mathrm{H}+\mathrm{L}) \quad$ Mo Bi Tec

MFP-A2428 


\subsubsection{Primers and PCR conditions}

Gene Primer Sequence (5' to 3’)

$\square$-SMA

For- CTACTGCCGAGCGTGAGATT

Rev- GTAGACAGCGAAGCCAAGATG

For- GCTGTGACTGCCTACCAGAAT

Brachyury

Rev- GAGAGAGAGCGAGCCTCCAAA

For- CCTTCCGCTACCAGCCAGA

eNOS

Rev-CAGAGACCTTCACTGCATTGG

For- CCTACCCCACACATTACATGG

Flk-1

GAPDH

Isl-1

Rev- TTTTCCTGGGCACCTTCTATT

For- GCAGTGGCAAAGTGGAGATT

Rev- TCTCCATGGTGGTGAAGACA

For- ACGTCTGATTTCCCTGTGTGTTGG

Rev- TCGATGTGGTACACCTTAGAGCGG

Mesp1

For- CCTGACCAAGATCGAGACG

Rev-ACGACACCCCGCTGCAGA

For- AGGGTCTGCTACTGAGATGCTCTG

Nanog

Rev-CAACCACTGGTTTTTCTGCCACCG

For- CAGTGGAGCTGGACAAAGCC

Nkx 2.5

Rev- TAGCGACGGTTCTGGAACCA

PECAM-1

For- GTCATGGCCGTCGAGTA

Rev- CTCCTCGGCATCTTGCTGAA

For- GTGAAGCCAGATGGGACAGT

Tie-2

Rev- TTGGCAGGAGACTGAGACCT

Tie-2 For- AAGCATGCCCATCTGGTTAC

(for qPCR) Rev- GTAGGTAGTGGCCACCCAGA
Size Annealing Cycle

(bp) Temp.

$\left({ }^{\circ} \mathrm{C}\right)$

$449-60$

31

$231 \quad 52$

33

$105 \quad 60 \quad 35$

$201 \quad 55$

35

250

56

31

275

63

34

202

60

34

363

66

34

$217 \quad 65$

35

261

55

35

$499 \quad 60$

32

238

60

40 


$\begin{array}{lllll}\text { VE-cad } & \begin{array}{l}\text { For- CCTTCTGCAGGGGACTATCGA } \\ \text { Rev- CATCTCATGCACCAGGGTCAC }\end{array} & 282 & 60 & 35 \\ \text { VE-cad } & \text { For-AGGACAGCAACTTCACCCTCA } & 70 & 60 & 40 \\ \text { (for qPCR) } & \text { Rev- AACTGCCCATACTTGACCGTG } & & & \\ & \text { For- TGGTGGGCATGATGGAGAGGTTA } & 485 & 65 & 36 \\ \text { vWF } & \text { Rev- GCAAGGTCACAGAGGTAGCTGACT } & & & \\ & \text { For-GCTTGAACTGTTTGACGGAGAGG } & & & 40 \\ \text { vWF } & \text { (for qPCR) } & \text { Rev- TGACCCAGCAGCAGGATGAC } & 105 & 60\end{array}$

\subsubsection{Solutions and buffers}

50 X TAE buffer

$4 \%$ PFA

\author{
$242 \mathrm{~g}$ Tris base \\ $57.1 \mathrm{ml}$ glacial acetic acid \\ $100 \mathrm{ml} 0.5$ M EDTA (pH 8.0) \\ $\mathrm{ddH}_{2} \mathrm{O}$ was added to a final volume of 1 liter \\ $2 \mathrm{~g}$ PFA dissolved in $50 \mathrm{ml}$ of PBS \\ The solution was heated at $80{ }^{\circ} \mathrm{C}$ with a stir \\ bar in a chemical hood until it became clear
}

\subsubsection{Kits}

SV Total RNA isolation kit Promega, Z3105

Transcriptor High Fidelity cDNA Synthesis kit Roche, 05081955001 In vitro Angiogenesis Assay kit Chemicon, ECM625

\subsubsection{Mouse strains}

CD-1 mouse Crl:CD1 (ICR)(outbred)

Female CD-1 mice were from the animal facility of the University of Goettingen.

SCID mouse Female SCID mice were from the animal facility of the University of Goettingen. SCID is the abbreviation of 
the severe combined immunodeficiency. Animals homozygous for the SCID mutation have impaired T and B cell lymphocyte development.

\subsection{Cell culture}

\subsubsection{Cultivation of maGSCs}

Undifferentiated maGSCs were initially maintained on MMC-treated primary MEF in DMEM medium supplemented with $15 \%$ heat-inactivated FBS, L-glutamine, NEAA, $\square$-ME (Serva, $50 \square \mathrm{mol} / \mathrm{L}$ ) and $10^{3}$ units/ml recombinant human LIF. MEFs were treated with MMC one day before maGSC seeding. MMC treatment inhibits cell proliferation, but allows feeder cells to maintain a metabolically active state. The treatment is described in more detail below:

1.) Medium was aspirated of MEFs culture as soon as they reached $80 \%$ confluence on $60 \mathrm{~mm}$ culture dishes

2.) $3 \mathrm{ml}$ of MEF growth medium and $150 \square 1$ of MMC stock solution were added

3.) Cells were incubated for 3 hours in a $37^{\circ} \mathrm{C}$ incubator

4.) Medium was aspirated and cells were washed 3 times with $3 \mathrm{ml}$ of PBS to get rid of all the MMC

5.) MMC-treated MEFs were cultured for 24 hours for recovery.

MaGSCs were subcultured every day in a ratio of 1:4 to 1:8. For subculture, old culture medium was removed and cells were rinsed briefly once with pre-warmed T/E solution. Cells were detached with T/E solution for 30 seconds at RT and the digestion was stopped by adding maGSCs culture medium. The cultures were incubated at $37^{\circ} \mathrm{C}$ in humidified air with $5 \% \mathrm{CO}_{2}$.

\subsubsection{Cultivation of OP9 cells}

OP9 cells were cultured in OP9 complete growth medium on $0.1 \%$ gelatin-coated $100 \mathrm{~mm}$ culture dishes. The cultures were incubated at $37^{\circ} \mathrm{C}$ in humidified air with $5 \%$ $\mathrm{CO}_{2}$. Medium was changed every 2 days. After the culture reached $80 \%$ of confluent density, the cells were subcultured with a ratio of 1:4 to 1:5. Cell density is important. At low cell density, OP9 cells adopt a spindly morphology, whereas over-confluent OP9 cells 
will differentiate into adipocytes producing large vacuole containing cells (Wolins et al., 2006). Such cells are not able to induce stem cells into mesodermal differentiation. For subculture, old culture medium was removed and cells were rinsed briefly once with $4 \mathrm{ml}$ pre-warmed T/E solution. T/E solution was removed and cells were incubated with another fresh $4 \mathrm{ml}$ of $\mathrm{T} / \mathrm{E}$ solution for 30 seconds at RT to allow detachment. T/E solution was aspirated and neutralized by adding complete growth medium. Then, the cell suspension was transferred to $0.1 \%$ gelatine-coated dishes. Cell cultures were incubated at $37^{\circ} \mathrm{C}$ in humidified air with $5 \% \mathrm{CO}_{2}$.

\subsubsection{Cultivation of SVEC4-10 cells}

SVEC4-10 cells were cultured in SVEC4-10 growth medium and incubated at $37^{\circ} \mathrm{C}$ in humidified air with $5 \% \mathrm{CO}_{2}$. Medium was changed every 2 days. After the culture reached confluent density, cells were subcultured with a ratio of 1:4 to 1:5. For subculture, old culture medium was removed and the cells were rinsed briefly once with pre-warmed $\mathrm{T} / \mathrm{E}$ solution. T/E solution was aspirated and cells were incubated with another change of T/E solution for 30 seconds at RT for cell detachment. T/E solution was aspirated and trypsin was neutralized with complete growth medium. Then, the cell suspension was transferred to new culture dishes.

\subsubsection{Freezing and thawing of cells}

Cells to be preserved were detached by T/E solution at RT until all the cells had detached from the surface of the dishes. Trypsin was neutralized by the addition of cell type-dependent culture medium. Cells were spun down at $1500 \mathrm{rpm}$ for $5 \mathrm{~min}$, the supernatant was discarded and the cell pellets were resuspended in freezing medium. The cell suspension was gently mixed and transferred into polypropylene cryovials $(1 \mathrm{ml}$ per vial). The vials were transferred to a freezing container and kept at $-80^{\circ} \mathrm{C}$ at least overnight before being transferred to liquid nitrogen storage tanks for long-term storage.

Cells should be thawed rapidly and then diluted slowly into pre-warmed cell type-dependent growth medium. Cells in cryovials were thawed at $37^{\circ} \mathrm{C}$ in a water bath for approximately 1 minute and transferred to a $15 \mathrm{ml}$ centrifuge tube containing $10 \mathrm{ml}$ of prewarmed $\left(37^{\circ} \mathrm{C}\right)$ growth medium. Cells were centrifuged at $1500 \mathrm{rpm}$ for 5 minutes. Supernatant was discarded and the cell pellets were resuspended gently with pre-warmed growth medium. Cells were then transferred to new culture dishes. Cell cultures were incubated at $37^{\circ} \mathrm{C}$ in humidified air with $5 \% \mathrm{CO}_{2}$. 


\subsubsection{Induction of Flk-1 ${ }^{+}$progenitor cells from maGSCs}

To initiate mesodermal differentiation of maGSCs, OP9 stromal cells (passage less than 30 ) at $80 \%$ confluence were treated with MMC the previous day as described in 2.2.3. On the day of differentiation, the feeder layer MEFs were first removed from maGSC culture by using the so-called preplating method. Briefly, maGSCs were trypsinized with $\mathrm{T} / \mathrm{E}$ solution for 30 seconds, neutralized and replated on $0.1 \%$ gelatincoated dishes, and incubated at $37^{\circ} \mathrm{C}$ for 1 hour. MEFs attached to the dishes within 1 hour, and maGSCs in suspension were collected for differentiation. $3 \times 10^{4}$ maGSCs were replated on a layer of OP9 stromal cells for 5 days in $100 \mathrm{~mm}$ culture dishes with IMDM supplemented with $20 \%$ heat-inactivated FBS and NEAA. MTG (final concentration 450 mol/l, Sigma) was added freshly from the day of co-culture as well as on day 3 , while half of medium was changed. Flk-1 $1^{+}$cells were purified by FACS on day 5 .

\subsubsection{Maintenance of Flk-1 ${ }^{+}$cardiovascular progenitor cells}

FACS-sorted Flk- $1^{+}$cells were replated onto COLIV-coated dishes at cell density of 1 to1.2 $\times 10^{4}$ cells $/ \mathrm{cm}^{2}$ in endothelial progenitor growth medium. These cells were split every 1 week after adding $0.5 \mathrm{x}$ T/E solution. After neutralization with growth medium, the cells were replated on new COLIV-coated culture dishes at a concentration of $1 \times 10^{4}$ per well in 24-well plates. Culture medium was changed on the third day after seeding and every 2 days thereafter. The medium was prepared and used at dark and protected from light at all times. Viable cells were observed under an inverted phase contrast light microscope for morphological examinations.

\subsubsection{Induction of endothelial differentiation from Flk-1 ${ }^{+}$progenitor cells}

FACS-sorted Flk- $1^{+}$cells were plated onto COLIV-coated culture dishes at cell density of 1 to $1.2 \times 10^{4}$ cells $/ \mathrm{cm}^{2}$ in endothelial differentiation medium. Culture medium was changed on the third day after seeding and every 2 days afterwards. For passaging, cells were detached by $\mathrm{T} / \mathrm{E}$ solution and trypsin was neutralized by addition of endothelial differentiation medium. Cells were replated at split ratios of $1: 2$ to $1: 3$ on fresh COLIVcoated culture dishes. Passage 5-6 endothelial differentiated cells were used for in vitro characterization. 


\subsubsection{Spontaneous differentiation of Flk-1 $\mathbf{1}^{+}$progenitor cells}

Flk $-1^{+}$progenitor cells were detached by $0.5 \mathrm{x}$ T/E solution and trypsin was neutralized by OP9 and maGSCs co-culture medium. $5 \times 10^{4}$ cells were cultivated on a layer of MMC-treated OP9 stromal cells in $60 \mathrm{~mm}$ culture dishes. Cells were cultured in OP9 and maGSCs co-culture medium for 10 days with medium change every 2 days.

\subsection{Molecular biology methods}

\subsubsection{Isolation of total RNA from cultured cells}

RNA was extracted using the SV Total RNA isolation kit (Promega) according to the manufacturer's instructions. First, cells were detached and washed with PBS once. After centrifugation at $1500 \mathrm{rpm}$ for 5 minutes, cell pellets were dispersed with 200 ice-cold RNA lysis buffer by vortexing and/or pipetting utill the lysate appeared clear. Lysed cells could be stored at $-20^{\circ} \mathrm{C}$ for weeks.

On the day of isolation, cell lysate was thawed on ice. $100 \square$ 1 of $95 \%$ ethanol were added to cleared lysate and mixed well by pipetting. The mixtures were transferred to a Spin Basket Assembly and centrifuge for 1 minute. $600 \square 1$ of RNA Wash Solution were added into each tube and centrifuged for additional 1 minute. Samples were treated with Deoxyribonuclease I (DNase I) by incubation at RT for 15 minutes. The $50 \square$ 1 DNase incubation mix was prepared using the table below:

$\begin{array}{lr}\text { DNase incubation mix (for one sample) } & \\ \text { Yellow Core Buffer } & 40 \square 1 \\ \mathrm{MnCl}_{2}, 0.09 \mathrm{M} & 5 \square 1 \\ \text { DNase I } & 5 \square 1\end{array}$

Then, $200 \square 1$ DNase Stop Solution were added and subjected to centrifugation for 1 minute. Samples were washed twice with 600 and $250 \square 1$ RNA Wash Solution, respectively. A Spin Basket was transferred to an Elution Tube. $100 \square$ l of nuclease-free 
water were added to membrane and RNA was eluted by centrifugation for 1 minute. RNA samples were stored at $-80^{\circ} \mathrm{C}$. The centrifugation was set as $13000 \mathrm{~g}$ during RNA isolation.

\subsubsection{Determination of RNA concentration}

The concentration of RNA was determined by spectrophotometry, according to the amount of UV irradiation absorbed by the bases. Absorbance reading at $260 \mathrm{~nm}$ allows calculation of nucleic acid concentration. 1 O.D. at $260 \mathrm{~nm}$ for RNA molecules $=40 \mathrm{ng} /$ 1 of RNA. The purity of nucleic acids was checked by the ratio of readings at 260 and 280 $\mathrm{nm}\left(\mathrm{A}_{260} / \mathrm{A}_{280}\right)$. A pure preparation of RNA has ratio of $1.8-2.0$, whereas a low ratio indicates contamination by protein (Okamoto and Okabe, 2000).

\subsubsection{Reverse transcription polymerase chain reaction (RT-PCR)}

RT or cDNA synthesis was performed using the Transcriptor High Fidelity cDNA synthesis kit (Roche). Total of 200 ng DNase-treated RNA was used for each RT reaction together with random hexamer primers (Roche). The final volume of RT reaction was $20 \square$ l. In an RNase-free $0.2 \mathrm{ml}$ microcentrifuge tube, the following reagents were prepared on ice.

cDNA synthesis

$\begin{array}{lr}\text { RNA } 200 \mathrm{ng} & \mathrm{x} \square 1 \\ \text { DEPC water } & \text { 9.4-x } \square 1\end{array}$

Random hexamer

$2 \square 1$

The above mixtures were heated to $65^{\circ} \mathrm{C}$ for 10 minutes and incubated on ice for at least 1 minute. The following reagents were added to the RNA-primer mix,

$\begin{array}{lc}\text { RT buffer, 5X } & 4 \square \text { 1 } \\ \text { dNTP mix, } 10 \mathrm{mM} \text { each } & 2 \square 1 \\ \text { DTT, 0.1 M } & 1 \square 1\end{array}$


RNase inhibitor, $40 \mathrm{U}$

Reverse Transcriptase, $20 \mathrm{U} / \square 1$
$0.5 \square 1$

$1.1 \square 1$

The mixtures of $20 \square$ l final volumes were mixed by gentle pipetting and then spun down. The contents were incubated at $50^{\circ} \mathrm{C}$ for 30 minutes. RT reaction was inactivated by heating to $85^{\circ} \mathrm{C}$ for 5 minutes. The cDNA was aliquoted into $10 \square 1$ each and stored at $20^{\circ} \mathrm{C}$ or directly used as a template for PCR amplification.

PCR was performed with GoTaq Polymerase (Promega) using $1 \square$ l of cDNA per reaction. Amplification reactions were performed in an automatic thermocycler equipped with a heatable lid. The following reagents were prepared and added to $0.2 \mathrm{ml}$ microcentrifuge tubes on ice:

\section{$\underline{\text { PCR reaction }}$}

cDNA

$1 \square 1$

DEPC water

$13.85 \square 1$

5X GoTaq buffer

$5 \square 1$

$\mathrm{MgCl}_{2}, 25 \mathrm{mM}$

$1.8 \square 1$

dNTP mix, $10 \mathrm{mM}$ each

$1 \square 1$

Sense primer, 10

$1 \square 1$

Antisense primer, 10

$1 \square 1$

DMSO

$0.25 \square 1$

GoTaq DNA polymerase, $5 \mathrm{U} / \square 1$

$0.1 \square 1$

Final volume

$25 \square 1$

Mixtures were gently mixed and spun down prior to reaction. Primer sequences, annealing and extension conditions are shown in chapter 2.1.9 and had been carefully established 
previously. Of note, the number of PCR cycles for each set of primers was verified to be in the linear range of the amplification. The initialization step is heating the reaction to a temperature of $95^{\circ} \mathrm{C}$ for 3 minutes to ensure the template DNA is completely denatured. The final elongation step is performed at a temperature of $72^{\circ} \mathrm{C}$ for 10 minutes after the last PCR cycle to ensure the remaining single-stranded DNA is fully extended. A standard PCR program is shown as follows:

$\begin{array}{ll}\text { Initial denaturation } & 95^{\circ} \mathrm{C} \text { for } 3 \text { minutes, } 1 \text { cycle } \\ & \text { followed by } 30-36 \text { cycles of: } \\ \text { Denaturation } & 94^{\circ} \mathrm{C} \text { for } 15 \text { seconds } \\ \text { Annealing } & \text { For the temperature, refer to } 2.1 .9,30 \text { seconds } \\ \text { Extension } & 72^{\circ} \mathrm{C}, \text { time depends on the size of PCR product, } \\ & 1 \mathrm{~kb} / \mathrm{min} \\ \text { Final extension } & 72^{\circ} \mathrm{C} \text { for } 10 \text { minutes, } 1 \text { cycle } \\ \text { Soak } & 4{ }^{\circ} \mathrm{C}\end{array}$

Products were stored at $4^{\circ} \mathrm{C}$ until analysis. $20 \square 1$ of PCR products were analyzed on 1.5 or $2 \%$ agarose gels and visualized by ethidium bromide. Quantitative analysis was performed by measuring the relative pixel intensities for each band. The pixel intensity of each target gene band was then normalized to the mean pixel intensity of the respective GAPDH band.

\subsubsection{Quantitative real-time PCR}

Use of the real-time PCR (qPCR/qRT-PCR) to amplify cDNA products has become a routine tool to study and compare gene expression between groups. SYBR Green is a simple and quick way for detecting and quantitating PCR products in real-time reactions (Ponchel et al., 2003). SYBR Green is a fluorescent intercalating dye which binds to double-stranded DNA and upon excitation emits light (Giglio et al., 2003). Thus, as a PCR product accumulates, fluorescence increases. Real-time PCR record fluorescence and report the results as a $\mathrm{Ct}$ (cycle threshold). The $\mathrm{Ct}$ is defined as the number of cycles required for the fluorescent signal to cross the threshold. This threshold is a fluorescence value slightly above the background fluorescence measured before exponential growth starts. 
Total mRNA was isolated using the SV Total RNA isolation kit (Promega). A total of 200 ng mRNA were used to synthesize cDNA using the Transcriptor High Fidelity cDNA synthesis kit (Roche). Gene expression was quantified by qPCR using $2 \square 1$ of the RT reaction and the SYBR Green PCR Master Mix (Applied Biosystems). The following reagents were prepared and added to a 384 well-plate on ice:

\section{qPCR reaction}

SYBR Green PCR Master Mix

cDNA

DEPC water

Sense primer, 10

Antisense primer, 10

Final volume

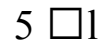

$2 \square 1$

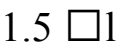

0.75

0.75

$10 \square 1$

Triplicate aliquots (each $10 \mu \mathrm{l}$ ) were carefully added into the appropriate wells and the plate was seal with adhesive film (Applied Biosystems). After a brief centrifuge spin to distribute the mixtures to the bottoms of the wells, qPCR reaction was performed using default conditions shown as follows:

Initial denaturation

Annealing and extension

Disassociation/melting curve

Soak $50^{\circ} \mathrm{C}$ for 2 minutes followed by $95^{\circ} \mathrm{C}$ for 10 minutes, 1 cycle $95^{\circ} \mathrm{C}$ for 15 seconds; $60^{\circ} \mathrm{C}$ for 1 minute, 40 cycles 15 seconds each at 95,60 , and $95^{\circ} \mathrm{C}$

$4^{\circ} \mathrm{C}$

The specificity of the SYBR Green assay was verified by melting curve analyses and the results were analyzed by comparative $C_{t}$ method (Livak and Schmittgen, 2001), with

$$
[\text { delta }][\text { delta }] C_{t}=[\text { delta }] C_{t, \text { sample }}-[\text { delta }] C_{t, \text { reference }}
$$


Fold change $=2^{[\text {delta][delta]Ct }}$

Gene expression levels were normalized to GAPDH. All experiments were done in triplicate in ABI PRISM® ${ }^{\circledR}$ 7900HT Real Time PCR System.

\subsubsection{Agarose gel electrophoresis detection of PCR amplicons}

1.5 or $2 \%$ agarose gels were prepared depending upon the size of DNA fragment. For this purpose, the required amount of agarose was measured and $1 \mathrm{X}$ TAE buffer was added. Agarose was dissolved by boiling in microwave oven until the solution appeared clear. Agarose solution was allowed to cool down till $60^{\circ} \mathrm{C}$ and ethidium bromide was added to a concentration of $0.5 \square \mathrm{g} / \mathrm{ml}$. The gels were cast in the casting chamber and were allowed to polymerize at RT. $20 \square 1$ of PCR products and DNA ladder were loaded in the wells. Electrophoresis was performed at 80-100 volts and DNA was visualised in the gel by addition of ethidium bromide and placed on an UV transilluminator. Ethidium bromide binds to both single- and double-stranded nucleic acids (DNA and RNA) by intercalating between the bases (LePecq and Paoletti, 1967) and is fluorescent meaning that it absorbs invisible UV light and transmits the energy as visible orange light.

\subsection{Flow cytometry and cell sorting}

Flow cytometry is a technology that analyzes both physical (size and granularity) and biochemical properties of single cells as they flow in a fluid stream through a beam of light. Fluorescence activated cell sorting (FACS) is an advanced method equipped with a cell sorter. The ability to analyze and sort live cells is one of the most important features (Herzenberg et al., 2002).

T/E solution dissociated cells were harvested and washed with PBS. If cells were to be surface-stained with Flk-1, cells were resuspended in $0.5 \%$ BSA fraction V in PBS and counted to make a cell concentration of $1 \times 10^{6}$ cells per ml. $100 \square 1$ of the cells $\left(1 \times 10^{5}\right)$ were transferred to $5 \mathrm{ml}$ FACS tubes and PE-conjugated anti-Flk-1 antibody $(1: 100$ dilution) or isotype control (PE-conjugated rat IgG2aא, 1:100 dilution) was added. Incubation was performed at $4^{\circ} \mathrm{C}$ in the dark for 30 minutes. 
For VE-cad or Isl1 staining, PBS washed cells were fixed with 4\% paraformaldehyde (PFA)/PBS (w/v) at RT for 15 minutes. Cells were washed once with PBS and permeabilized with $0.05 \%$ Triton $\mathrm{X}-100$ in $0.5 \%$ BSA fraction V/PBS for 5 minutes at RT. Then, cells were incubated in blocking solution (4\% BSA fraction V/PBS) for 30 minutes at $37^{\circ} \mathrm{C}$. Primary anti-VE-cad antibody (1:100 dilution) or anti-Isl1 antibody (without dilution) was added and incubated for 35 minutes at $4{ }^{\circ} \mathrm{C}$. After washing with $0.5 \%$ BSA fraction $\mathrm{V} / \mathrm{PBS}$, PE-conjugated anti-rat and anti-mouse secondary antibody was added (1:200 dilution), respectively, and cells were incubated for 30 minutes at $4^{\circ} \mathrm{C}$ in the dark.

For intracellular protein staining to detect vWF and $\square$-SMA, cells were first fixed with methanol:acetone $(7: 3)$ at $-20^{\circ} \mathrm{C}$ for 10 minutes, with intermittent vortexing in order to maintain a single cell suspension. Following fixation, cells were washed twice with $0.5 \%$ BSA fraction V in PBS. $100 \square$ l of the cells $\left(1 \times 10^{5}\right)$ were transferred to $5 \mathrm{ml}$ FACS tubes and primary antibodies were applied. Polyclonal rabbit anti-mouse vWF (1:20 dilution) or monoclonal anti-mouse $\square$-SMA (1:2000 dilution) antibody were added and incubated for 35 minutes at $4^{\circ} \mathrm{C}$, followed by incubation with fluorescein-isothiocyanate (FITC)-conjugated anti-rabbit or anti-mouse secondary antibodies (dilution for both, $1: 200)$, respectively, for 30 minutes in the dark.

Following the staining procedures, cells were washed once and resuspended in $200 \square 1$ of PBS buffer for flow cytometric analysis. Each analysis included 10,000 total events. Cells for FACS sorting were washed with culture medium and flew through 70 $\mathrm{m}$ strainers before being subjected to sorting analysis in the core facility.

\subsection{Proliferation assay}

Cell proliferation rate was examined usinig the CellTiter $96^{\circledR}$ AQueous One Solution Cell Proliferation Assay (Promega). The provided reagent contains a tetrazolium salt known as MTS. Measurement of mitochondrial metabolic rate using MTS indirectly reflecting the number of viable cells has been widely applied. Since these enzymes are inactivated shortly after cell death, this is a reliable method for the detection of viable cells (Buttke et al., 1993; Cory et al., 1991). The absorbance of the formazan product can be measured directly from a 96-well plate. 
Cells were detached by T/E solution and counted, suspended at a density of $2 \times 10^{5}$ cells/ml and $100 \square 1$ cell suspension were transferred to each well of a COLIV-coated 96well plate. Then, $100 \square$ l of cell type-dependent growth medium were added as blanks. 2 hours before the measurement, $20 \square 1$ of CellTiter $96^{\circledR}$ AQueous One Solution Reagent were carefully added into each well to avoid air bubbles. Plates were swirled briefly and incubated for 2 hour in a $37^{\circ} \mathrm{C}$ incubator under humidified air with $5 \% \mathrm{CO}_{2}$. The absorbance at $490 \mathrm{~nm}$ was recorded using a 96-well plate reader and $\mathrm{KC} 4$ software at 24 , 48, 72 and 96 hours. This assay was run in duplicate.

\subsection{Lineage potential test (single cell assay)}

To assess the potential of long-term cultured cardiovascular progenitor cells to differentiate into vascular lineages, single cell assay was performed by seeding single presumptive Flk-1 ${ }^{+}$progenitor cell into each well of COLIV-coated 96-well plates. Cells were dissociated with $0.5 \mathrm{x}$ T/E solution and counted. One single cell was incubated in 100

1 endothelial differentiation medium for 1 week. Culture medium was changed every 2 days and the cells were used for immunocytochemistry. Cells cultured in 96-well plates were directly stained with VE-cad or $\square$-SMA to verify the differentiation potential to EC or SMC lineage, respectively.

\subsection{Immunocytochemistry}

Immunocytochemistry is used to visualize the presence of a specific protein or antigen in cells. First, the cells used for immunofluorescence staining were cultured on acid-treated coverslips. Coverslips should be acid washed in order to remove spots of dirt or detergent and to facilitate subsequent extracellular matrix (ECM) coating (Andrew $\mathrm{H}$ et al., 2008). The acid-treated coverslips were prepared by placing the coverslips in a glass beaker filled with $0.1 \mathrm{M} \mathrm{HCl}$ overnight. The acid-treated coverslips were washed extensively with distilled water, immersed in $70 \% \mathrm{EtOH}$ at least overnight and then dried with filter papers. The acid-treated coverslips were autoclaved before using.

Cells were washed 3 times with PBS and fixed by either freshly prepared (up to 1 week) 4\% PFA/PBS (w/v) at RT for 20 minutes, for detection of cell surface marker, VEcad; or freshly mixed methanol and acetone (in the ratio of $7: 3$ ) at $-20^{\circ} \mathrm{C}$ for 10 minute, for 
the detection intracellular markers, vWF and $\square$-SMA. After gentle washing with PBS 3 times, cells were blocked with 4\% BSA fraction V/PBS (v/v) overnight. For staining with VE-cad antibody, the permeabilization was carried out for 20 minutes at RT by adding $0.05 \%$ Tritox X-100 in blocking buffer to improve antibody penetration. Cells were rinsed with staining buffer containing $0.5 \%$ BSA fraction V in PBS. The cells were incubated with monoclonal anti-mouse VE-cad antibody (1:100 dilution), polyclonal anti-mouse antibodies against vWF (1:100 dilution) or monoclonal anti-mouse $\square$-SMA antibody (1:12000 dilution) at $37^{\circ} \mathrm{C}$ for 1 hour or $4^{\circ} \mathrm{C}$ overnight, followed by washing with three changes of PBS. Cells were then incubated with FITC-conjugated anti-rat or anti-rabbit or Cy3-conjugated anti-mouse secondary antibodies (1:300 dilution), respectively for 40 minutes at $37^{\circ} \mathrm{C}$. After washing with PBS 2 times, cells were counterstained with DAPI (1:5000 dilution) at RT for 10 minutes in the dark. Stained cells were washed 3 times with PBS and once with distilled water, followed by mounting to $70 \%$ EtOH cleaned slides. Images were analyzed using fluorescence microscopy.

\subsection{Endothelial cell functionality assays}

\subsubsection{Uptake of acLDL and lectin staining}

Cells cultured in 24-well tissue culture plate were incubated with $2.5 \square \mathrm{g} / \mathrm{ml}$ DiIlabelled acLDL in $37^{\circ} \mathrm{C}$ incubator for 1 hour. Cells were then washed with PBS twice and fixed with 2\% PFA/PBS (w/v) for 10 minutes at RT. After washing cells 3 times with PBS, cell nuclei were stained by DAPI for 10 minutes at RT in the dark. After washing 2 times with PBS, cells were incubated with $10 \square \mathrm{g} / \mathrm{ml}$ FITC-labelled lectin at RT for 1 hour. Cells were washed with PBS twice and fluorescence images were acquired using a fluorescence microscope.

\subsubsection{In vitro matrigel angiogenesis assay}

The angiogenic potential was assessed by plating $1 \times 10^{4}$ cells in a 96-well tissue culture plate, which had been evenly coated with $50 \mu 1$ ECMatrix $^{\mathrm{TM}}$ (Chemicon). One day before cell seeding, ECMatrix ${ }^{\mathrm{TM}}$ was thawed on ice overnight. Pre-cooled pipettes, plates and tubes were also prepared. 10X Diluent Buffer was mixed with ECMatrix ${ }^{\mathrm{TM}}$ solution gently to avoid air bubbles. The diluted ECMatrix ${ }^{\mathrm{TM}}$ was kept on ice at all times to avoid premature solidification. $50 \mu$ diluted ECMatrix ${ }^{\mathrm{TM}}$ were transferred to each well of a pre- 
cooled 96-well plate. The plate was incubated in a $37^{\circ} \mathrm{C}$ incubator for 30 minutes to allow the matrix to solidify. $1 \times 10^{4}$ cells in $100 \mu \mathrm{l}$ cell type-dependent culture medium were added on top of the gel and incubated at $37^{\circ} \mathrm{C}$. For the comparison of three FACS-sorted cell populations, cells were cultured for up to 15 days with half of the medium exchanged every 2 days and photographed. The ability to form tubes, branch and develop vascularlike networks was manually determined in five randomly selected microscope fields (at 100x magnification). To verify the angiogenic properties of the differentiated endotheliallike cells, the cells were analyzed 8 hours after seeding.

\subsubsection{In vitro 3-dimensional spheroid angiogenesis assay}

The 3-dimensional spheroid angiogenesis assay was established by Thomas Korff (Korff and Augustin, 1998; Korff et al., 2001; Korff et al., 2004). It is a functional assay to test whether cells can form a vascular structure. This assay takes two main steps:

Generation of spheroids To generate spheroids, cells were detached and resuspended in cell type-dependent growth medium containing $20 \%$ methyl cellulose solution. The methyl cellulose stock solution was prepared by dissolving autoclaved $7 \mathrm{~g}$ of methyl cellulose in preheated $500 \mathrm{ml}$ of $\mathrm{M} 199$ medium $\left(60^{\circ} \mathrm{C}\right)$. The solution was mixed using a magnetic stirrer for 30 minutes, and then in the cold room overnight. Penicillin/Streptomycin (P/S) was added and the methyl cellulose stock solution was aliquot in $50 \mathrm{ml}$ each. The solution was spun down at $4000 \mathrm{rpm}$ for 2 hours at $4^{\circ} \mathrm{C}$. After centrifugation, the clear gel-like supernatant was used for experiments. Cells were counted and adjusted to a concentration of $4 \times 10^{4}$ cells in $10 \mathrm{ml}$ (for one 96-well plate) of growth medium containing $20 \%$ methyl cellulose solution. Cells were seeded in non-adherent round-bottom 96-well plates using a 12-channel pipette (100 $\square \mathrm{l} /$ well) and incubate at $37^{\circ} \mathrm{C}$. Under these conditions, cells formed a single spheroid within 24 hours.

Culture in collage type I After 24 hours, cell spheroids were collected and embedded into collagen gels. Humidified 24-well suspension culture plates were prepared in advance and pre-warmed in $37^{\circ} \mathrm{C}$ incubator. Type I rat tail collagen (BD Biosciences) was diluted 1:1 with $0.22 \square \mathrm{m}$ strainer filtered $0.1 \%$ acetic acid. Diluted collagen was mixed with 
yellowish 10X M199 medium, and neutralized with $0.22 \square$ m strainer filtered $0.2 \mathrm{~N} \mathrm{NaOH}$ immediately before use. Spheroids were harvested by $1 \mathrm{ml}$ of pipette tips with 1-2 $\mathrm{mm}$ of their ends cut to avoid hurting of the spheroid structures. After centrifugation at $1200 \mathrm{rpm}$ for 3 minutes, spheroid pellets were overlaid with methylcellulose stock solution supplemented with $20 \%$ FBS and gently diluted (1:1) with neutralized collagen working solution. The spheroid containing gel was mixed gently and rapidly transferred in duplicates into pre-warmed 24-well plates by adding $1 \mathrm{ml}$ (containing about 40 spheroids) to each well and incubated at $37^{\circ} \mathrm{C}$ for 30 minutes. After solidification of the collagen, 100 $\mu 1$ of culture medium were added to each well and incubated in a $37^{\circ} \mathrm{C}$ incubator for at least 24 hours. The cumulative sprout length of 15-20 randomly selected spheroids was measured to calculate mean sprout length for each group. Pictures were taken using Zeiss AxioVision 3.1 software and data were evaluated by Image-Pro Plus. Cumulative sprout length means the length of all sprouts grown out of an individual spheroid.

\subsection{In vivo spheroid-based matrigel plug angiogenesis assay}

The matrigel plug assay was introduced initially by Passaniti (Passaniti et al., 1992). This assay is easy to administer, requires a minimum of surgical procedures and provides a natural environment for angiogenesis initiation (Staton et al., 2004; Norrby, 2006). Matrigel is composed of basement membrane proteins extracted from the Engelbreth-Holm-Swarm (EHS) mouse sarcoma, a tumor rich in ECM proteins. Matrigel has not been completely defined regarding its chemical composition. Its major component is laminin, followed by COLIV, heparan sulfate proteoglycans, nidogen/entactin. It also contains growth factors such as EGF, TGF- $\square$, IGF, FGF, platelet-derived growth factor and nerve growth factor (Vukicevic et al., 1992). Importantly, matrigel specifically induces ECs to differentiate into blood capillaries (Baatout, 1997). The spheroid-based matrigel

plug assay in this study was based on an article published by Anna M Laib in Nature protocols (Laib et al., 2009). The principle of this assay is based on the sprouting and tubelike network formation from EC spheroids. Implanted EC-spheroids closely mimic the behavior of ECs during angiogenesis.

Briefly, cells were first labelled with CM-DiI ex vivo in order to differentiate the administered cells from the cells of the host (see below). The day before implantation, spheroids were generated from the labelled cells and incubated in a $37^{\circ} \mathrm{C}$ incubator for 24 hours. For one plug, 1000 spheroids (500 cells per spheroid) were mixed with matrigel and 
subcutaneously implanted into CD-1 mice as well as severe combined immunodeficiency (SCID) mice. These implants were removed after 3 weeks and used for immunofluorescence or immunohistochemistry. A general outline including all the steps is shown in Figure 4.
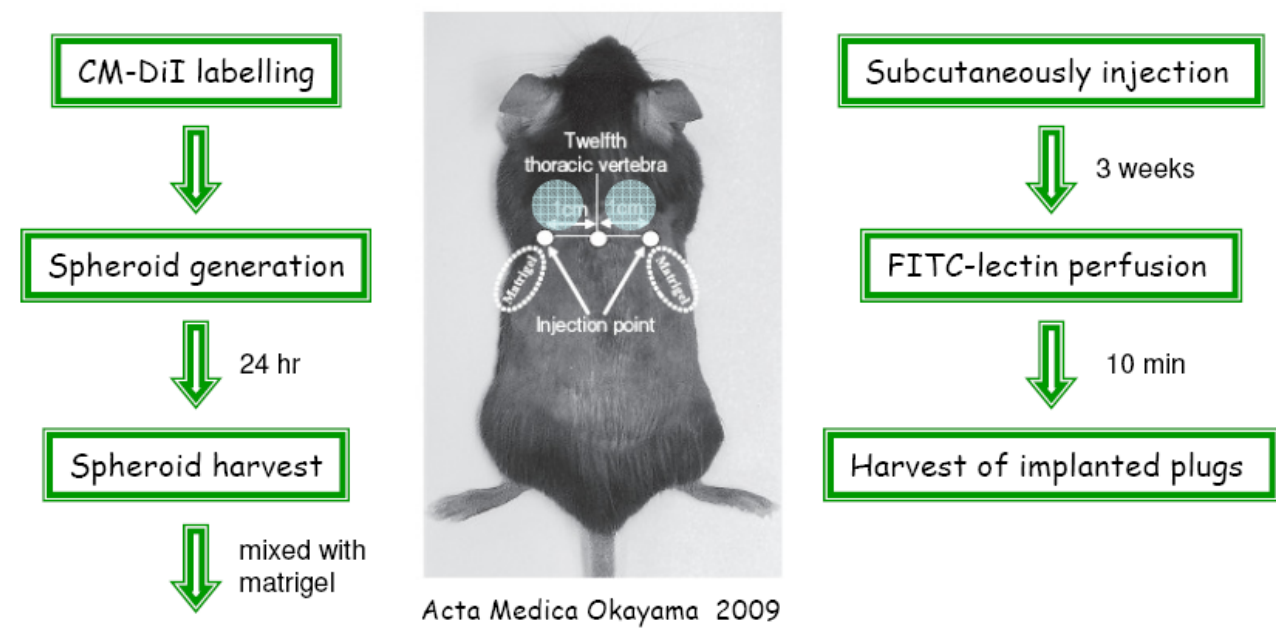

Figure 4. Flow chart of the in vivo murine matrigel plug angiogenesis assay. The photo is adapted from (Wake et al., 2009)

Cell-labelling with CM-DiI Cells were detached by T/E solution and counted. Cells were resuspended at a density of $1 \times 10^{6}$ cells $/ \mathrm{ml}$ in cell type-dependent serum free medium. $5 \square 1$ of CM-DiI solution were added per ml of cell suspension and mixed well by gentle pipetting. The labelling process was incubated in a $37^{\circ} \mathrm{C}$ incubator for 20 minutes and stabilized at $4{ }^{\circ} \mathrm{C}$ for 5 minutes. The cells were washed twice with cell type-dependent growth medium. 
Generation of spheroids Cells were suspended in a concentration of $1 \times 10^{6}$ cells in 50 ml cell type-dependent growth medium containing 20\% methocel stock solution. $25 \square 1$ cell suspension (containing 500 cells) were aliquoted to the lid of non-adherent plastic square petri dishes using a 12-channel pipette. Bottom plates of the dishes were filled with $5 \mathrm{ml}$ of sterile PBS to avoid desiccation. Lids were then placed on the bottom plates to achieve hanging drop cultures. The cultures were incubated in a $37^{\circ} \mathrm{C}$ incubator for 24 hours. 2000 spheroids were generated for 2 plugs in this protocol.

Harvesting of spheroids Before spheroid harvest, whether the cells have formed rounded spheroids was checked under a low magnification microscope. $5 \mathrm{ml}$ of $10 \%$ FBS/PBS were added on the first plastic square petri dish and spread over the plate by pipetting up and down gently. All the spheroids were collected by removing the entire spheroid-containing medium using standard $10 \mathrm{ml}$ plastic pipettes. The mixture was poured from one plate to another. Spheroid-containing medium was transferred to $50 \mathrm{ml}$ tubes when the fluid became too viscous. Spheroids were spun down by centrifugation at $300 \mathrm{~g}$ for 5 minutes, without brake. The supernatant was aspirated carefully without disturbing the spheroid pellets. The spheroid pellets were washed once with $10 \mathrm{ml}$ of endothelial cell basal medium 2 (ECBM2) and centrifuged at $300 \mathrm{~g}$ for 5 minutes without brake. The supernatant was carefully aspirated and the spheroid pellets were resuspended in $2 \mathrm{ml}$ of ECBM2 (volume: $1 \mathrm{ml}$ per plug). $1 \mathrm{ml}$ of spheroids containing ECBM was transferred to 2 $\mathrm{ml}$ sterile reaction tubes at RT. Spheroids were pooled by centrifugation at $1200 \mathrm{rpm}$ for 3 minutes and the supernatant was discarded. In the meanwhile of spheroids washing step, methocel/fibrinogen/ECBM mixture in a ratio of 1:1:1 ( $\mathrm{vol} / \mathrm{vol} / \mathrm{vol})$ was prepared in advance. 3 X $300 \quad \square \quad 1$ (prepare 1 share more for safety margin) of methocel/fibrinogen/ECBM mixture were prepared. Fibrinogen was thawed first at RT because it will precipitate on ice. ECBM and fibrinogen were mixed first and viscous methyl cellulose stock solution was added the last with a $1 \mathrm{ml}$ cut-off tip. VEGF 165 and $\mathrm{bFGF}$ were added at final concentration of $100 \mathrm{ng} / \mathrm{ml}$ to the methocel/fibrinogen/ECBM mixture and mixed well by pipetting up and down. $300 \square 1$ of the growth factor supplemented methocel/fibrinogen/ECBM mixture were added to each $2 \mathrm{ml}$ tube containing spheroid pellet. These mixtures were kept at RT prior using. 

injection of xylazine/ketamine. The first tube with the growth factor supplemented methocel/fibrinogen/ECBM mixture and spheroid pellet was placed on ice and $300 \square$ of matrigel were added on top of the mixture. $4 \square 1$ of thrombin were added and mixed well by using a syringe. A needle was attached to the syringe, and the mixture was quickly injected subcutaneously under the left or right dorsal flanks. The needle was held for 10 seconds to allow the mixtures to solidify. Usually, two plugs from different groups (e.g. OP9 cells/maGSC-ECs or SVEC4-10/maGSC-ECs) were injected into the left and right flank, respectively, of each mouse to account for potential differences in the angiogenic response of individual mice.

Dissection of implanted matrigel plugs Mice were anesthetized by intraperitoneal injection of xylazine/ketamine. They were perfused with $70 \square$ l of FITC-lectin through a catheter inserted in the jugular vein, and lectin was allowed to circulate for 20 minutes, after which mice were killed by cervical dislocation. Lectins are specific carbohydratebinding proteins that bind to ECs and have proven for visualization of blood vessels (Jilani et al., 2003). Therefore, FITC-lectin perfusion allows us to visualize the newly formed vessels in the matrigel plugs as well as their connections to the circulatory system from the host. The plugs were carefully excised, fixed with $4 \%$ PFA at $4{ }^{\circ} \mathrm{C}$ overnight and used for immunofluorescence or immunohistochemistry.

\subsection{Immunohistochemistry}

Immunohistochemistry (IHC) is a method for demonstrating the presence and location of proteins in tissue sections. The basic steps are as follows: fixation and embedding of the tissues, followed by sectioning and staining.

Paraffin embedding and sectioning Because paraffin is immiscible with water, tissue must be dehydrated before embedding with molten paraffin wax. After fixation, plugs were immersed in an ascending alcohol series for 1 hour each at RT in the following solutions: 75\% ethanol; 85\% ethanol; 96\% ethanol; isopropanol three changes; xylol two changes and finally embedded in paraffin at $60^{\circ} \mathrm{C}$ overnight. For sectioning, plugs were embedded into paraffin cassettes and stored at RT until sectioning. 5 and $30 \mu \mathrm{m}$ thick tissue blocks were sectioned using a microtome. The sections were floated in a $42^{\circ} \mathrm{C}$ water 
bath and mounted onto superfrost histological slides. The slides were dried on a $42^{\circ} \mathrm{C}$ heating plate for about 20 minutes and placed in a $37^{\circ} \mathrm{C}$ dry oven overnight to facilitate attachment of sections and to soften the paraffin. Paraffin sections were stored at RT.

Deparaffinization and rehydration of the tissue sections Before deparaffinization, the slides were kept in a $60^{\circ} \mathrm{C}$ oven for 10 minutes to facilitate paraffin melting (optional). Slides were deparaffinized in three changes of xylene for 5 minutes each under a chemical hood. Deparaffinized slides were then transferred to a descending alcohol series for 5 minutes each in the following solutions: $99 \%$ ethanol; $80 \%$ ethanol; $70 \%$ ethanol; $50 \%$ ethanol and rinse briefly in distilled water. The above solutions were prepared with distilled water.

Immunofluorescence Samples were encircled by a liquid barrier marker pen. DAPI stained tissues were mounted with mounting medium for fluorescence. Stained tissues were covered with coverslips of an appropriate size and excess mounting medium was drained with a filter paper. Slides were allowed to dry in the dark.

H\&E staining (Hematoxylin-eosin staining) H\&E staining is the standard method used in histology. It shows an overview of the tissue structure. The staining method involves application of hemalum, which is a complex formed from aluminium ions and oxidized hematoxylin. The hematoxylin solution colors nuclei of cells blue. Eosin is a fluorescent red dye and used to stain cytoplasm, collagen and muscle fibers red. After deparaffinization and rehydration, slides were stained in Mayer's hematoxylin solution for 8 minutes and differentiated in running warm tap water for $10 \sim 15$ minutes. Then, slides were counterstained in eosin Y solution for 10 seconds and rinsed in tap water by a few dips. Slides were dehydrated through $80 \%$ ethanol, 96\% ethanol, absolute ethanol, 2 minutes each. Finally, slides were cleared up in 2 changes of xylene, 5 minutes each and mounted with xylene based mounting medium. The staining was also carried out in the core facility.

\subsection{Statistical analysis}

Results are presented as mean \pm standard deviation (SD). The number of independent experiments in each analysis or assay performed is indicated in the text. Differences between groups were examined using One-way ANOVA. A $P$ value of less than 0.05 was considered statistically significant, a value $<0.01$ or $<0.001$ as highly 
significant. All statistical analyses were performed using GraphPad Prism software, version 4.01. 


\section{Results}

\subsection{Generation of maGSC-derived Flk-1 $\mathbf{1}^{+}$cardiovascular progenitor cells}

The experimental setup explaining the strategy employed to obtain Flk-1 positive $\left(\mathrm{Flk}-1^{+}\right)$cardiovascular progenitor cells from maGSCs and to differentiate these cells into functional ECs is depicted in Figure 5. Briefly, undifferentiated Stra8-EGFP ${ }^{+}$maGSCs (SSC5) were cultivated on a layer of MMC-treated OP9 stromal cells for mesodermal induction. After 5 days, predifferentiated maGSCs were replated onto three different ECM proteins in order to screen for the optimal culture condition. Accordingly, FACS-sorted Flk- $1^{+}$cells were cultured on the selected ECM protein for endothelial differentiation and for long-term Flk-1 ${ }^{+}$progenitor cell culture.

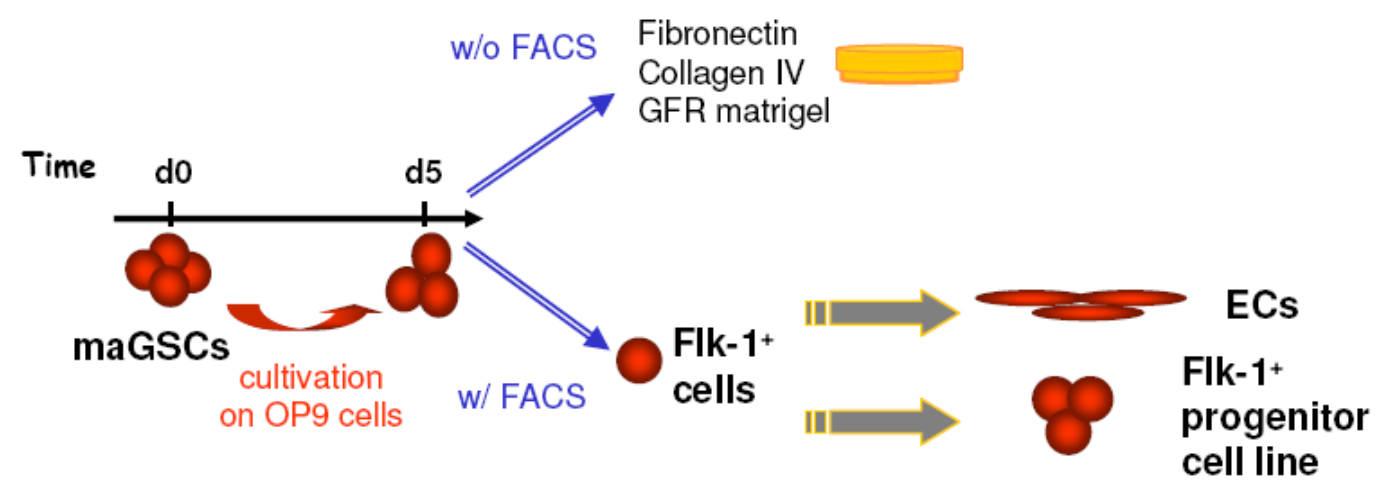

Figure 5. Schematic drawing showing the strategy to obtain Flk-1 positive cells. A co-culture system with OP9 stromal cells was used to induce $\mathrm{Flk}-1^{+}$progenitor cells. Day 5 predifferentiated maGSCs were replated on FN-, COLIV- or GFR matrigel-coated culture dishes for the screening of optimal culture conditions. FACS-sorted Flk-1 ${ }^{+}$cells were used for EC differentiation and establishment of Flk- $1^{+}$progenitor cell line.

Mesodermal differentiation of maGSCs was induced via 2D culture on MMCtreated OP9 stromal cells. The morphology was observed daily under the microscope, and the progressive change from a rounded to an extended morphology is shown below (Figure 6; arrows). 

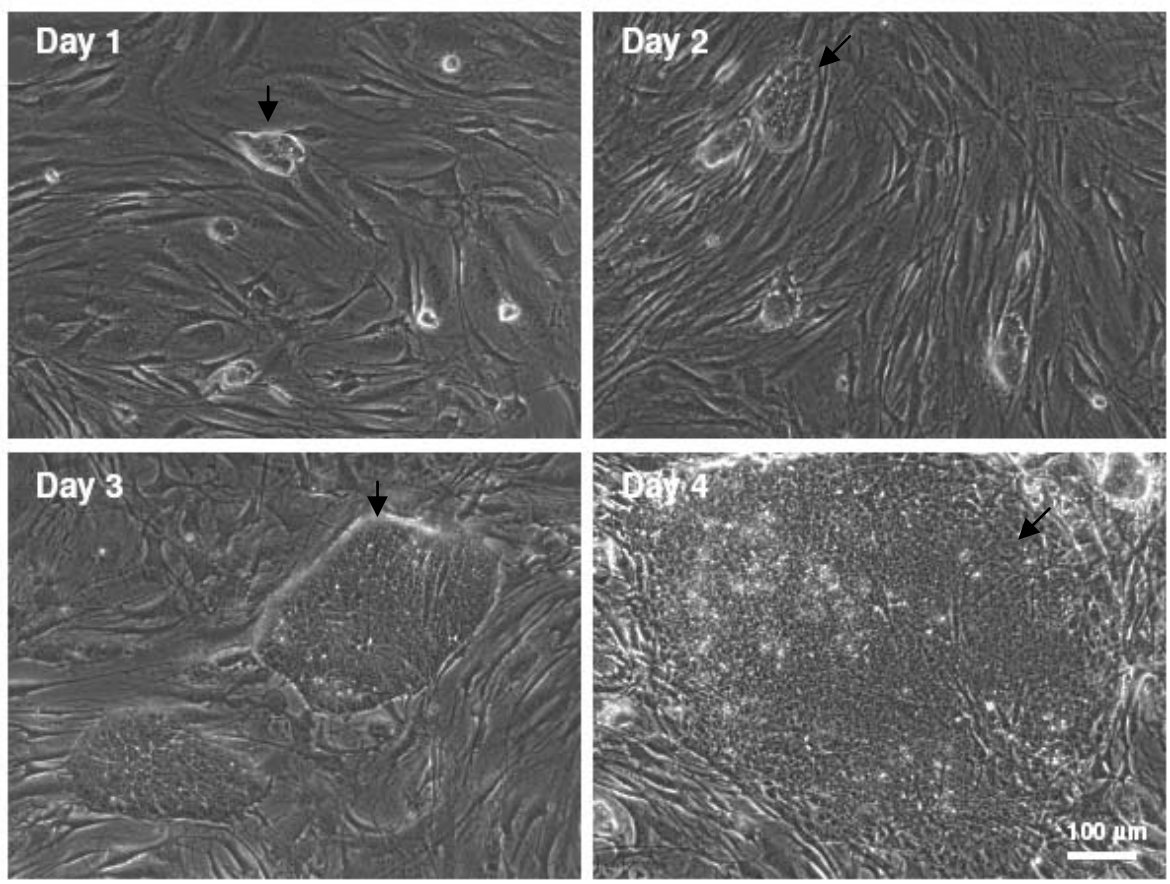

Figure 6. Morphology of maGSCs during co-culture with OP9 cells. Round undifferentiated maGSCs colonies with smooth surfaces progressively change into flat, spreading, differentiating cells when cultured on a layer of OP9 stromal cells from day 1 to day 4 .

Preliminary experiments revealed that co-cultivation of maGSCs on OP9 stromal cells yielded the highest amount of Flk-1 ${ }^{+}$cells on day 5 when compared to other time points (Kaiser, 2010). Thus, maGSCs were co-cultivated on OP9 cells for 5 days in all following experiments, before being transferred to culture dishes coated with either FN, COLIV, or GFR matrigel, or being separated by FACS based on their Flk-1 expression.

\subsection{In vitro screening for candidate ECM proteins}

First, a series of experiments were performed to optimize the culture conditions and the ability of ECM constituents to support and modulate EC differentiation was examined. After 5 days of co-culture on OP9 cells, predifferentiated cells were replated on three different ECM proteins, as explained above. After cultivation for additional 5 days, the cell morphology showed heterogeneity under all three coating conditions (Figure 7). 

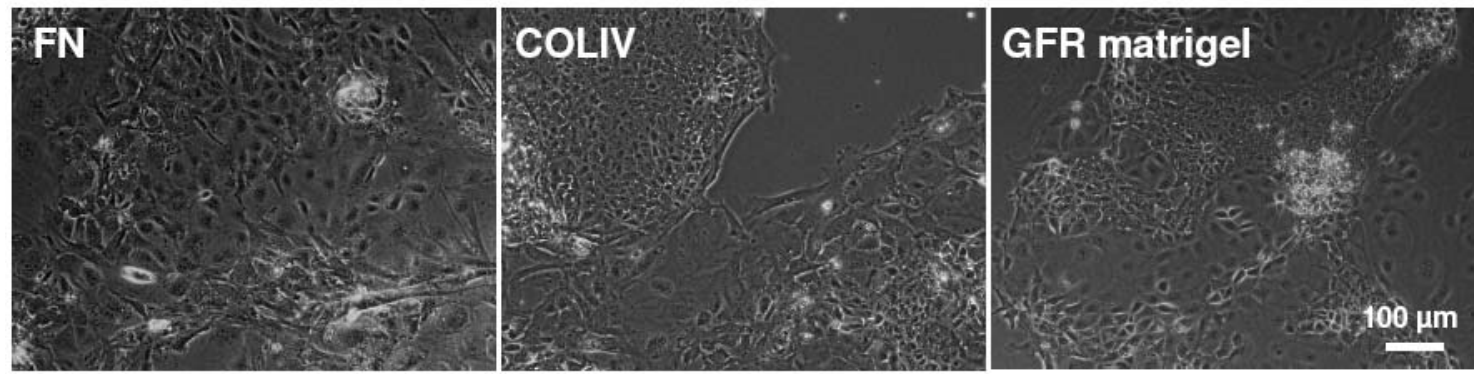

Figure 7. Morphology of maGSCs cultured on different ECM proteins on day 5+5. maGSCs were co-cultured with OP9 cells for 5 days (predifferentiated maGSCs) and then transferred to FN-, COLIV- or GFR matrigel-coated culture dishes. As can be seen, cells exhibit a heterogeneous morphology.

To evaluate the ability of the three different ECM proteins to support attachment of day 5 predifferentiated maGSCs, floating cells were collected 2 days after replating. However, no significant differences in the number of floating cells were detected (Figure 8 A). Also, treatment with VEGF did not affect the number of floating cells. In addition, the number of attached cells 5 days after replating was recorded. The data showed significantly higher number of cells attached to culture dishes coated with GFR matrigel $\left(2.7 \pm 0.3 \times 10^{5}\right)$ compared to those cultivated on COLIV $\left(1.7 \pm 0.3 \times 10^{5}\right)$ or FN $\left(1.7 \pm 0.4 \times 10^{5}\right)$, however, only in the presence of VEGF (Figure $8 \mathrm{~B}$ ).

A

\section{d $5+2$ \\ floating cell no.}

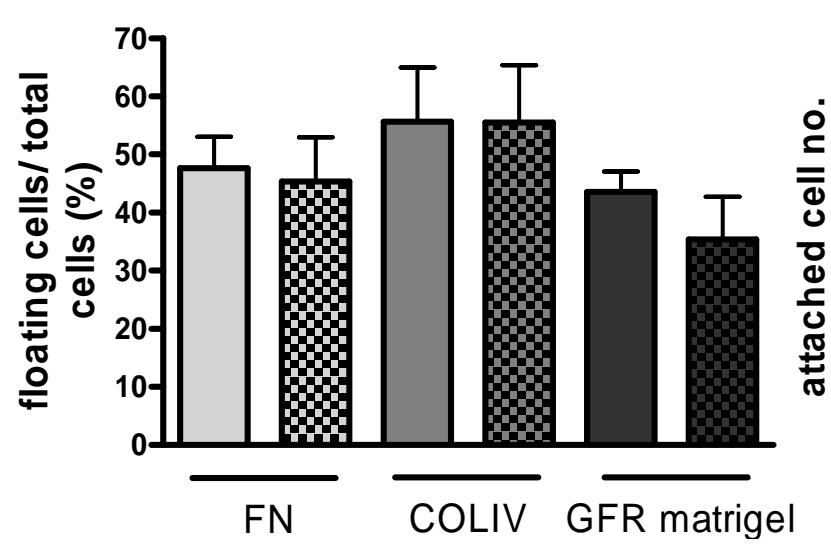

B

\section{d $5+5$}

attached cell no.
W/ VEGF

$\S$

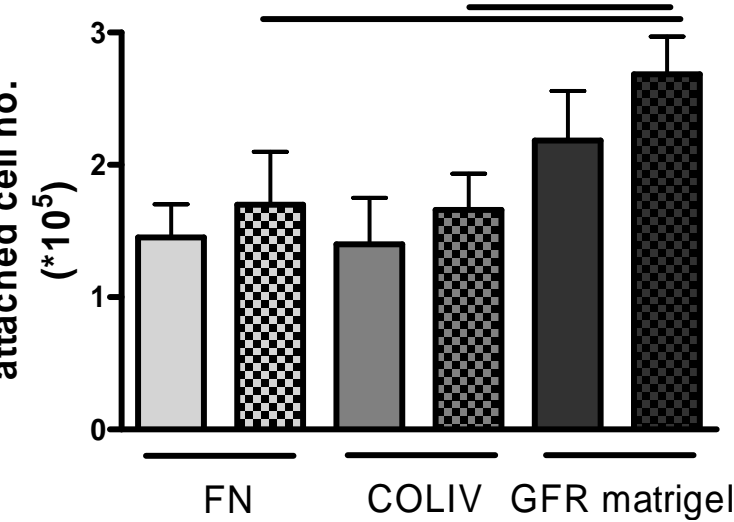

Figure 8. Effect of coating culture dishes with either FN, COLIV or GFR matrigel on the number of floating and attached cells on day 5+5. A, The number of floating cells does not differ between different ECM coating conditions and also not affected by the presence of VEGF. B, The number of attached cells is significantly elevated if the cells were cultured on GFR matrigel in the presence of VEGF compared to those grown on FN or COLIV. Data are shown as mean \pm S.D.; $\S \mathrm{P}<0.05 ; \mathrm{n}=3$ independent experiments. 
The surface expression of Flk-1 was examined using flow cytometry on day $5+5$ (Figure 9) and 5+9 (Figure 10; $n=3$ separate experiments). These analyses revealed that significantly higher numbers of $\mathrm{Flk}^{+}{ }^{+}$cells could be maintained after cultivation on COLIV $(16.5 \pm 2.3 \%)$ compared to FN $(11.4 \pm 4.5 \% ; P<0.05)$ or GFR matrigel $(8.1 \pm 1.2 \%$; $P<0.001$; and $P=0.061$ vs. FN). Stimulation with VEGF (10 $\mathrm{ng} / \mathrm{ml}$ throughout the 5 day culture period) significantly increased the number of Flk-1 ${ }^{+}$cells when compared to basal levels in all three different coating conditions ( $P<0.001$ vs. control-treated for COLIV; $P=0.001$ for $\mathrm{FN} ; P<0.001$ for GFR matrigel), suggesting that VEGF is important for maintaining Flk-1 expression. This effect was particularly pronounced in cells grown on COLIV (35.6 $\pm 3.3 \%$ ), compared to those grown on FN $(27.3 \pm 0.2 \% ; P<0.01)$ or GFR matrigel $(26.2 \pm 1.2 \% ; P<0.01)$ (Figure 9). 


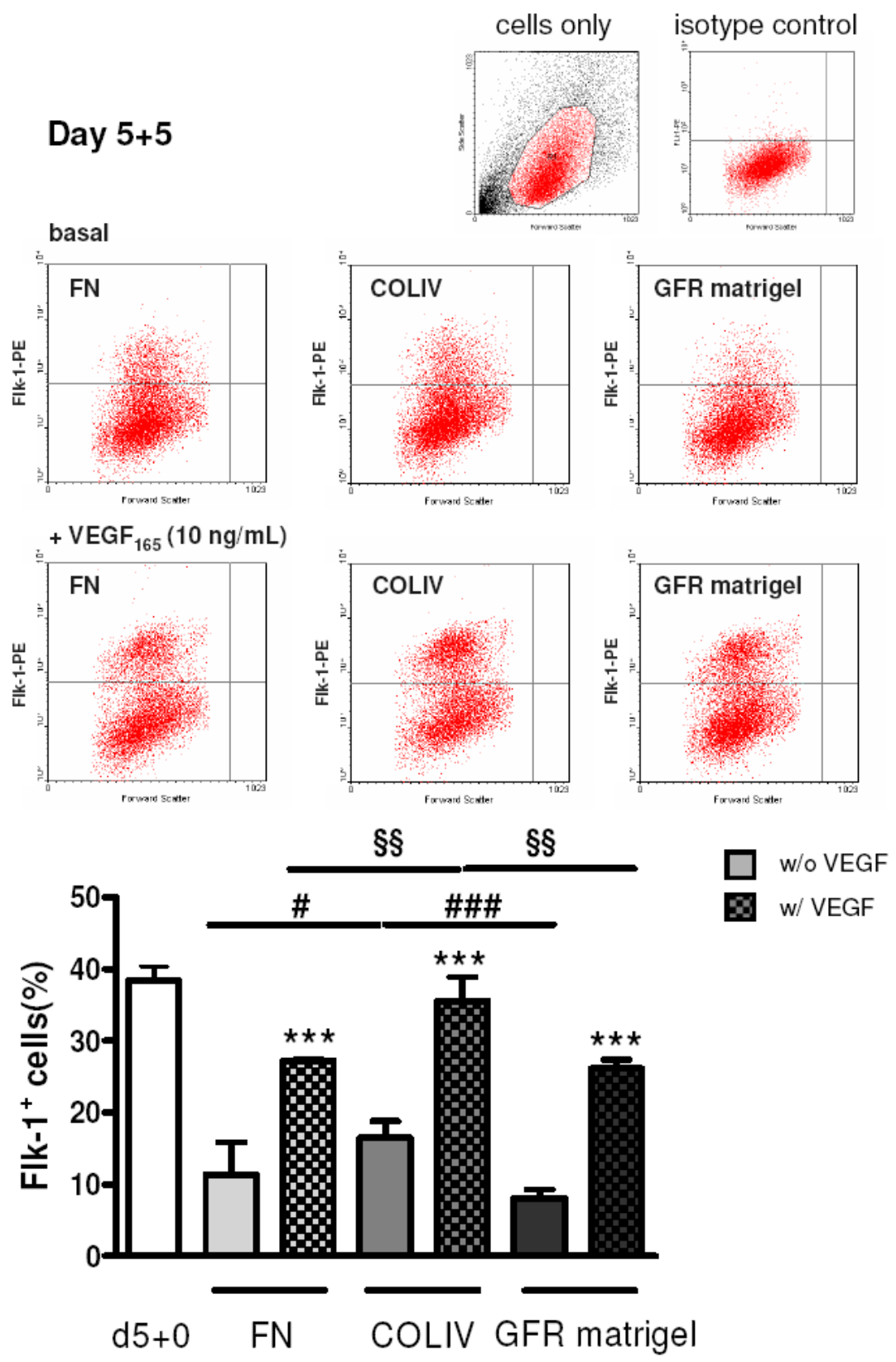

Figure 9. Determination of the number of Flk-1 ${ }^{+}$cells after cultivation on three different ECM proteins using flow cytometry. Expression of Flk-1 on day $5+5$ with or without VEGF treatment was examined by flow cytometry. A, VEGF is essential for Flk-1 expression maintenance, and COLIV supports Flk-1 expression. In all three different ECM protein-coated dishes, VEGF significantly increases the number of Flk- $1^{+}$cells compared to basal levels on day $5+5(* * *$ $\mathrm{P}<0.001$ ). In addition, cells cultured on COLIV contain significantly higher numbers of Flk $-1^{+}$cells on day $5+5$ compared to those grown on FN or GFR matrigel. Data are shown as mean \pm S.D.; * and $\S \mathrm{P}<0.05, \S \S \mathrm{P}<0.01$, *** and $\S \S \S<0.001 ; \mathrm{n}=3$ independent experiments. 
On day $5+9$, the number of Flk $-1^{+}$cells decreased when compared to day $5+5$ and there was no significant difference of Flk-1 expression among the groups without VEGF stimulation. In the groups being cultivated in the presence of VEGF, cells cultured on COLIV-coated dishes $(27.0 \pm 3.1 \%)$ again showed a significantly higher Flk-1 expression when compared to the cells grown on GFR matrigel-coated dishes $(6.0 \pm 0.6 \%$; Figure 10), whereas the difference towards cells grown on FN was not statistically significant.
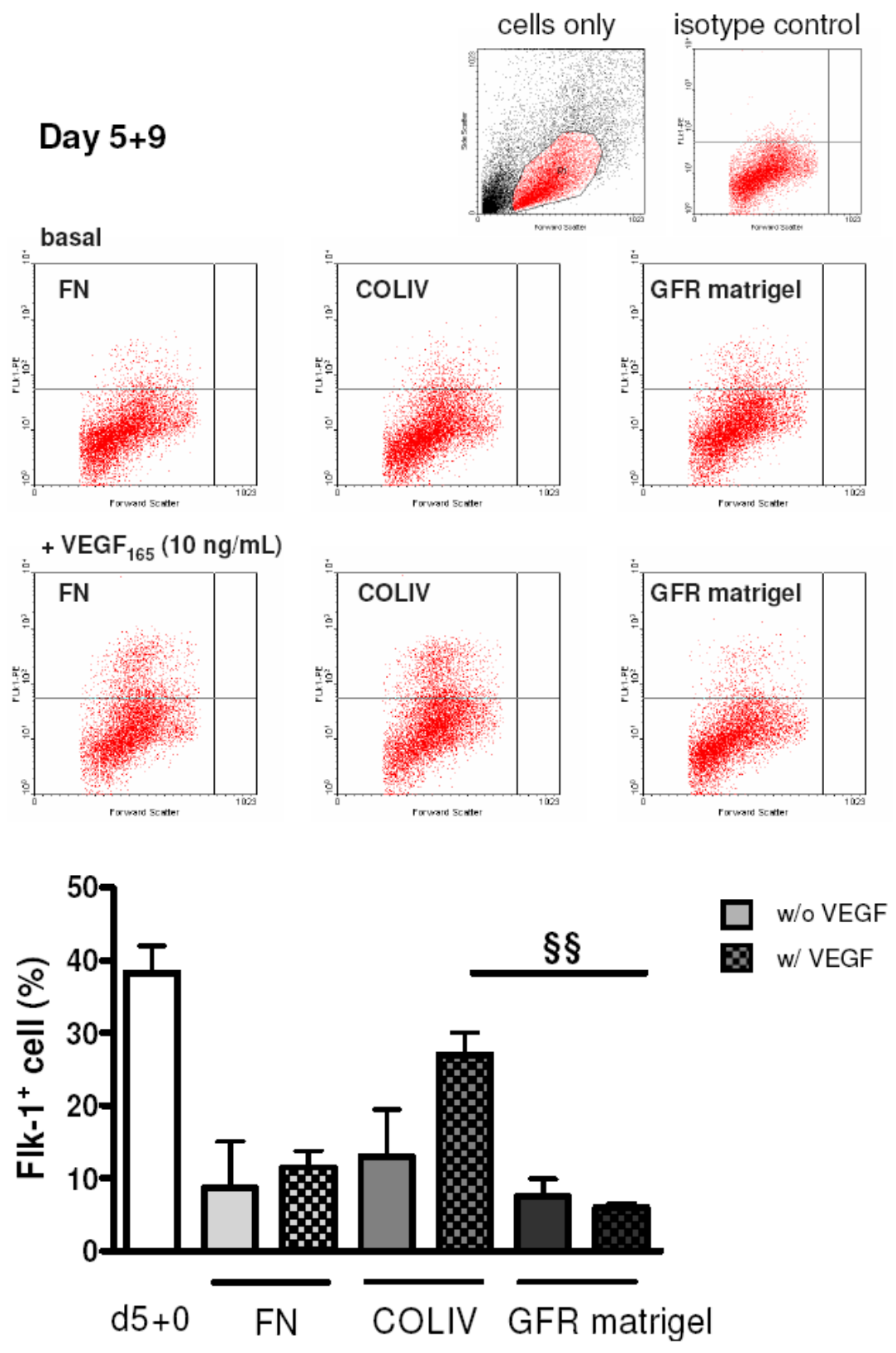

Figure 10. Determination of the number of Flk-1 $\mathbf{1}^{+}$cells after cultivation on three different ECM proteins using flow cytometry. Expression of Flk-1 on day 5+9 with or without VEGF treatment was examined by flow cytometry. Cells cultured on COLIV in the presence of VEGF contain significantly higher numbers of Flk-1 $1^{+}$cells compared to those grown on GFR matrigel. Data are shown as mean \pm S.D.; $\S \S$ $\mathrm{P}<0.05 ; \mathrm{n}=3$ independent experiments. 
Furthermore, the mRNA expression of the cells cultured on three different coating ECM proteins with or without treatment of VEGF was compared to examine the endothelial differentiation efficiency. The genes analyzed included growth factor receptors such as Flk-1 and Tie-2, adhesion molecules such as VE-cad (Lampugnani et al., 1992; Vestweber, 2008) and PECAM-1/CD31 (DeLisser et al., 1994), endothelial nitric oxide synthase (eNOS) as functional endothelial marker and vWF as the late-stage endothelial marker (Ginsburg et al., 1985). When treated with VEGF, cells cultured on COLIV showed a higher expression of endothelial markers, such as Tie-2, VE-cad and PECAM-1, as shown by conventional RT-PCR (Figure 11). These results were further confirmed by real-time PCR analysis (Figure $12 \mathrm{~A}-\mathrm{D})$.

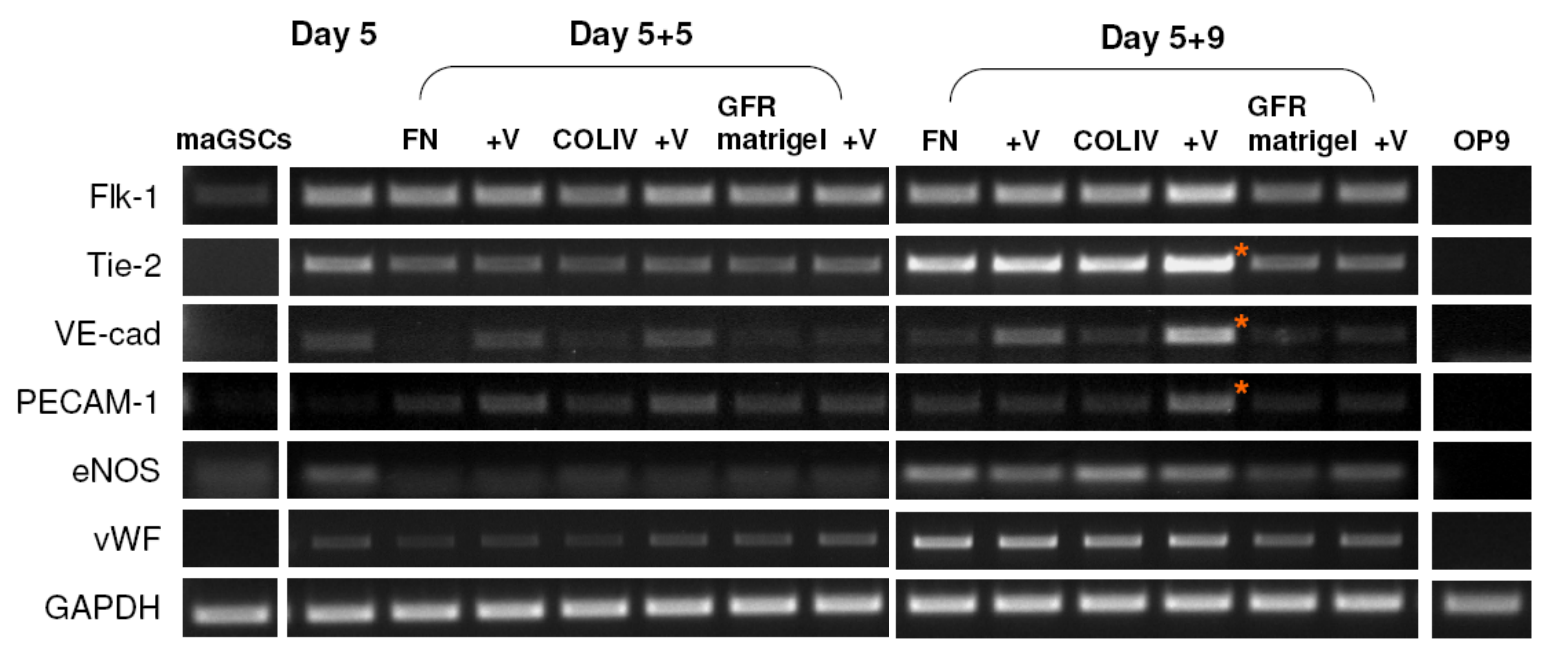

Figure 11. Gene expression patterns of predifferentiated maGSCs cultured in different conditions. MaGSCs were co-cultured with OP9 stromal cells for 5 days, transferred to FN-, COLIVand GFR matrigel-coated culture dishes and continued to be cultivated with or without VEGF. The expression of endothelial and smooth muscle cell markers on day $5+5$ and $5+9$ was examined by conventional RT-PCR. The expression of Tie-2, VE-cad and eNOS is upregulated on cells grown on COLIV-coated dishes with addition of VEGF on day 5+9. Undifferentiated maGSCs and OP9 cells served as negative control.

The mRNA expression of day 5+9 cells cultured with addition of VEGF was also analyzed by real-time PCR analysis. The results showed that cells cultured on COLIV exhibited a significantly higher expression of Flk-1 ( $P<0.05$ vs. FN and $P<0.01$ vs. GFR matrigel), Tie-2 ( $P<0.05$ vs. FN and $P<0.01$ vs. GFR matrigel) as well as VE-cad $(P<0.01$ vs. FN and 
$P<0.001$ vs. GFR matrigel). However, the expression of vWF did not differ significantly between the groups (Figure 12 A-D).
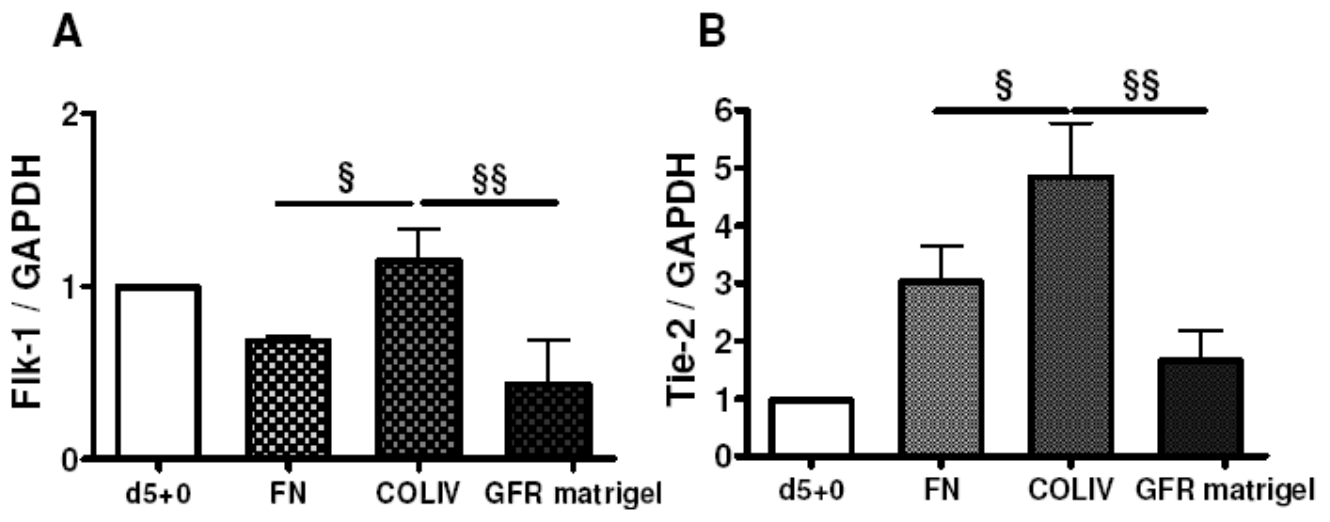

C
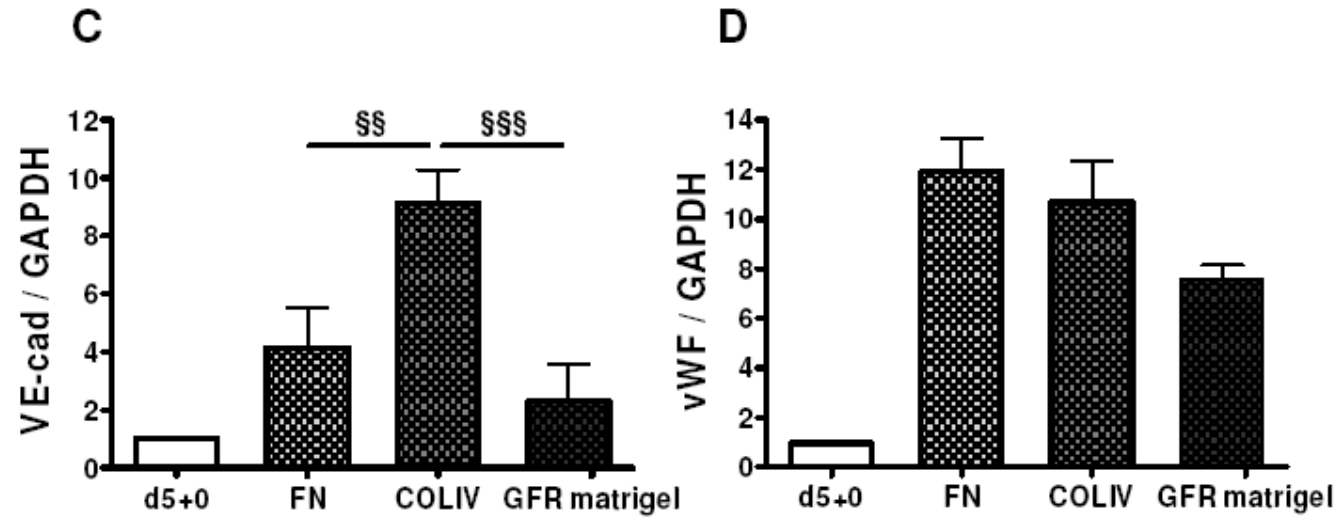

Figure 12. Real-time PCR analyses of day 5+9 cells cultured on FN-, COLIV-and GFR matrigel-coated culture dishes in the presence of VEGF. A-C, The results show that cells cultured on COLIV and stimulated with VEGF expressed significantly higher amounts of endothelial genes, such as Flk-1, Tie-2 and VE-cad. D, The expression of vWF is not significantly different among three groups. Data are shown as mean \pm S.D.; $\S \mathrm{P}<0.05, \S \S$ $\mathrm{P}<0.01, \S \S \S \mathrm{P}<0.001 ; \mathrm{n}=3$ independent experiments.

On the other hand, immunocytochemical analyses of vWF, a marker for late-stage ECs, in cells cultivated for 12 days in the presence of VEGF, revealed tubular structures formed by vWF-positive cells only in cells grown on culture dishes coated with COLIV or FN, but not in those grown on GFR matrigel-coated dishes (representative pictures shown in Figure 13). 

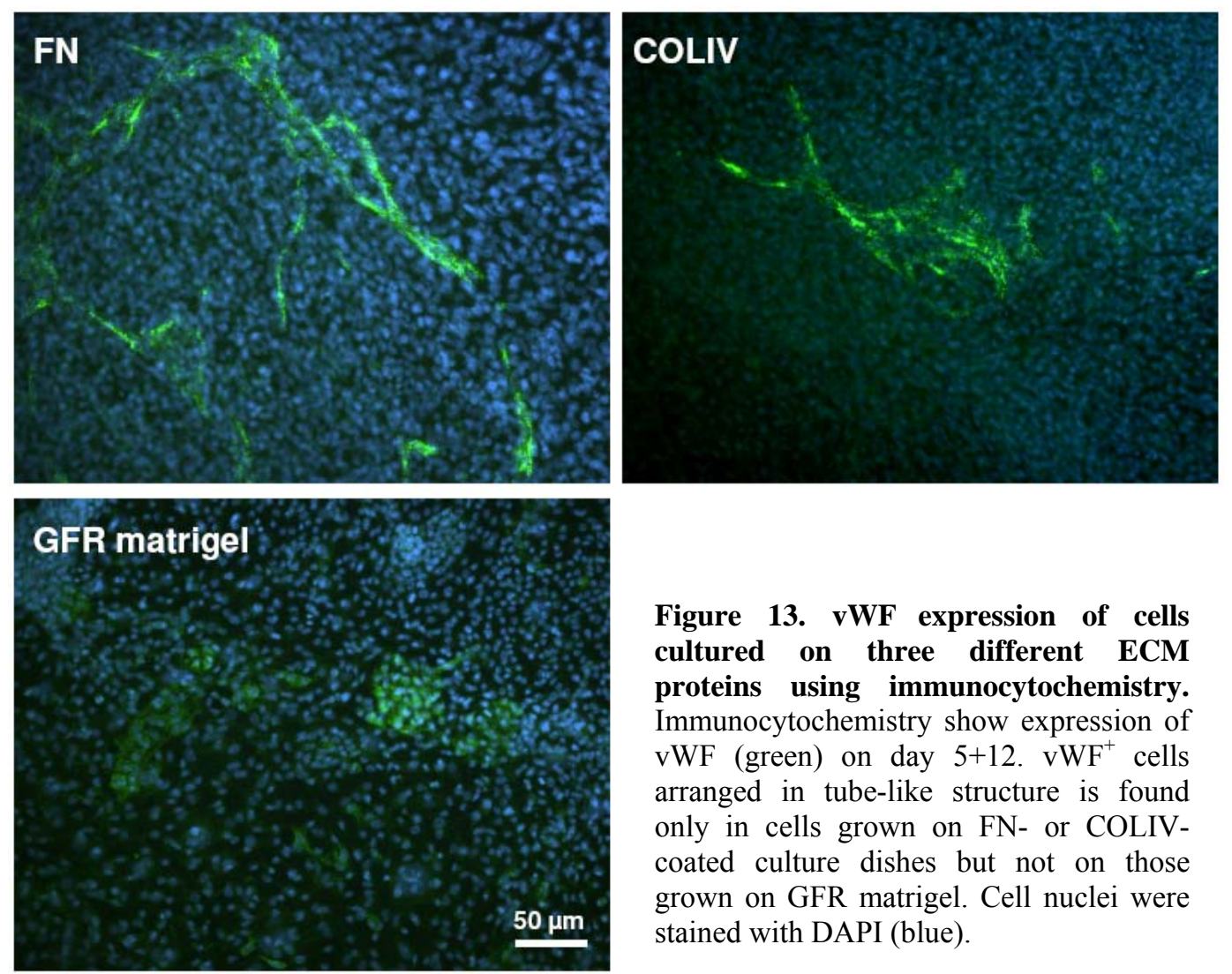

Figure 13. vWF expression of cells cultured on three different ECM proteins using immunocytochemistry. Immunocytochemistry show expression of $\mathrm{vWF}$ (green) on day $5+12 . \mathrm{vWF}^{+}$cells arranged in tube-like structure is found only in cells grown on FN- or COLIVcoated culture dishes but not on those grown on GFR matrigel. Cell nuclei were stained with DAPI (blue).

Next, we examined how different ECM proteins affect the ability of cells to also functionally behave like ECs. In order to examine the ability of ECM-differentiated cells to sprout, one of the earliest events during vessel formation, the three-dimensional (3D) in vitro spheroid angiogenesis assay was performed ( $\mathrm{n}=4$ independent experiments). Initially, spheroids were generated from cells cultured on FN-, COLIV- and GFR matrigel-coated dishes for 12 days in the presence of VEGF (10 ng/ml). As shown in Figure 14, determination of the cumulative sprout length indicated that cells cultured on COLIVcoated dishes had a higher ability to sprout $(1,497 \pm 419 \mu \mathrm{m} ; P<0.001$ vs. FN; and $P<0.001$ vs. GFR matrigel) when compared to spheroids derived from cells grown on either FN $(1,072 \pm 395 \mu \mathrm{m})$ or GFR matrigel $(498 \pm 342 \mu \mathrm{m})$. Moreover, the formation of tube-like connections between spheroids could only be observed in cells cultured on FN- or COLIVcoated dishes, but not on those derived from GFR matrigel-coated dishes (representative examples are shown in Figure 14; arrows). 

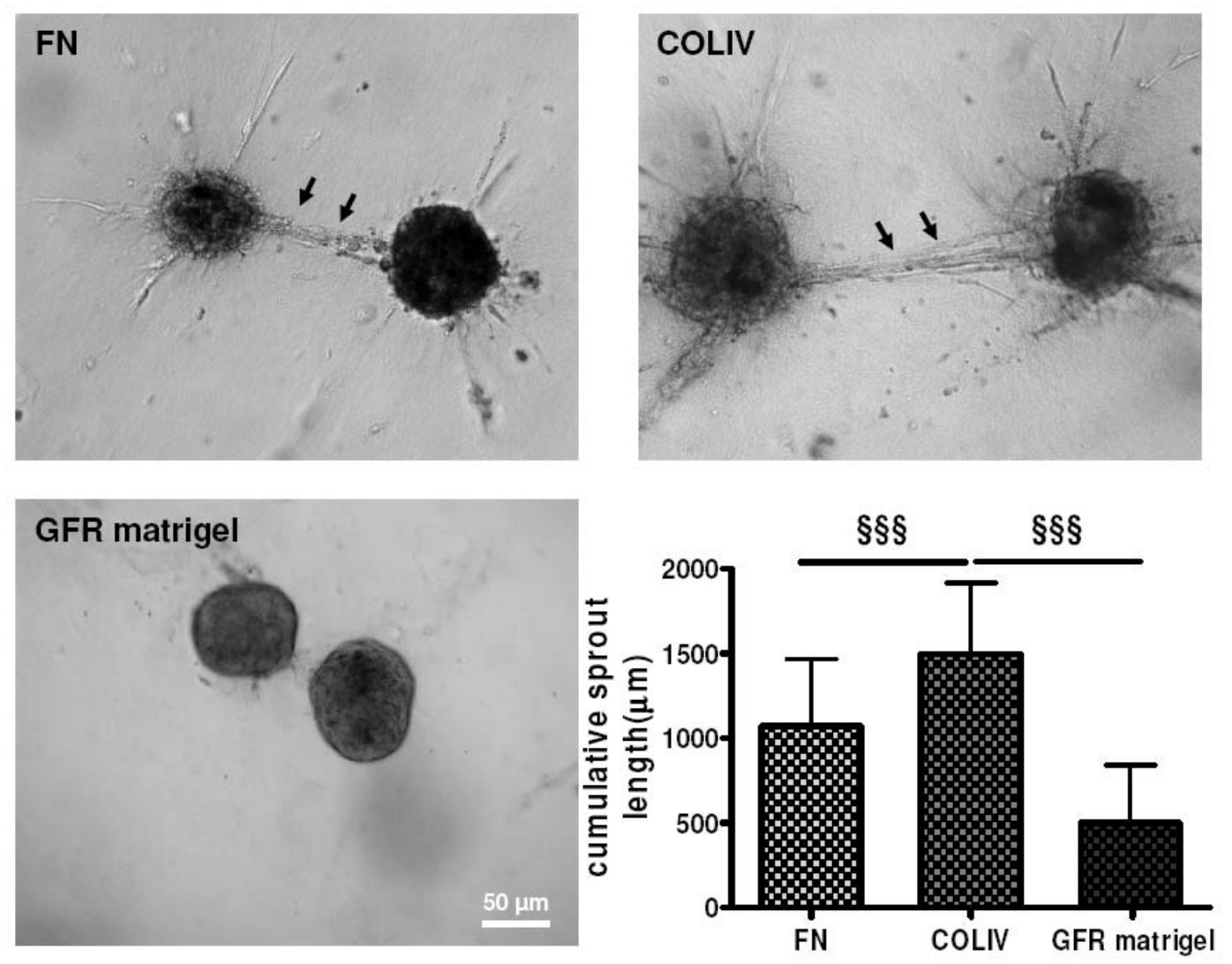

Figure 14. Comparison of angiogenic responses of cells cultured on three different ECM proteins. Day 5+12 cells were analyzed using the 3-dimensional spheroid angiogenesis assay. Measurement of the cumulative sprout length shows that cells cultured on COLIV in the presence of VEGF possess a significantly higher ability to sprout. Data are shown as mean \pm S.D.; $\S \S \S \mathrm{P}<0.001 ; \mathrm{n}=3$ independent experiments.

Taken together, the culture of cells on COLIV-coated culture dishes was found to maintain the growth of $\mathrm{Flk}-1^{+}$cells and to facilitate endothelial differentiation, as determined by the flow cytometry in Flk-1 expression and EC marker expression, respectively. Moreover, cells grown on COLIV exhibited the highest potential to sprout and to form tube-like structures when compared to cells grown on either FN or GFR matrigel. On the other hand, the number of Flk-1 ${ }^{+}$cell has reduced at later time points in all of the culture conditions, indicating that lineage selection is necessary for obtaining pure endothelial population. According to the above findings, FACS-sorted Flk- $1^{+}$cells were cultured on COLIV to support the expansion of Flk-1 ${ }^{+}$progenitor cells and to induce endothelial differentiation throughout the following experiments. 


\subsection{In vitro characterization of Flk- $\mathbf{1}^{+}$progenitor cells}

Lineage selection of $\mathrm{Flk}-1^{+}$progenitor cells was performed using FACS, three separate cell populations could be distinguished, i.e. Flk-1 ${ }^{+}, \mathrm{Flk}-1^{\text {low/- }}$ and $\mathrm{GFP}^{+}$cells (Figure 15). Flk-1 ${ }^{+}$cells represent cardiovascular progenitor cells, Flk-1 ${ }^{\text {low/- }}$ cells served as negative control and $\mathrm{GFP}^{+}$cells stand for undifferentiated stem cells. Using this approach, approximately $35 \%$ of predifferentiated maGSCs (i.e. after 5 days of co-culture with OP9 cells) were found to express Flk-1. After sorting, the purity of sorted cells was analyzed by flow cytometry (Figure 15).
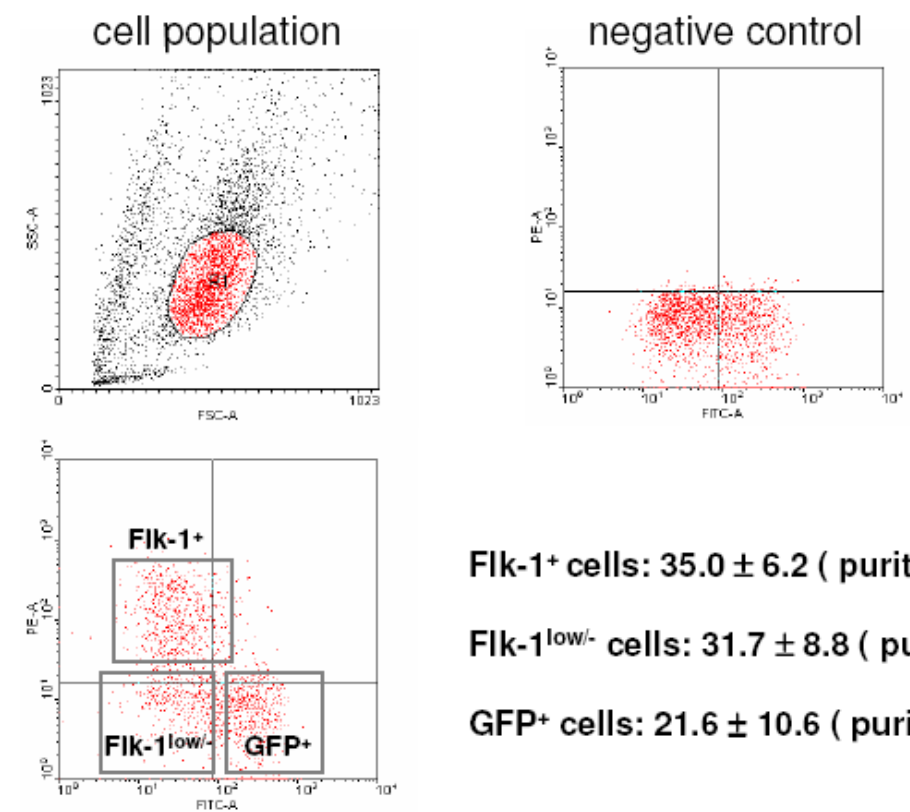

Flk-1+ cells: $35.0 \pm 6.2$ ( purity $98.2 \%$ )

Flk-1 ${ }^{\text {low/ }}$ cells: $31.7 \pm 8.8$ ( purity $96.3 \%$ )

GFP+ cells: $21.6 \pm 10.6$ ( purity $97.3 \%$ )

Figure 15. Mesodermal induction of maGSCs via co-culture with OP9 stromal cells for 5 days. Single cell suspensions were prepared from the day 5 co-culture of Stra8-EGFP ${ }^{+}$maGSCs with OP9 cells and stained with Flk-1. The predifferentiated maGSCs generate around $35 \%$ Flk- $1^{+}$cells, $32 \%$ Flk$1^{\text {low/ }}$ cells and $22 \%$ undifferentiated $\mathrm{GFP}^{+}$cells on day 5 .

\subsubsection{Gene expression analysis of Flk-1 ${ }^{+}$progenitor cells}

First, the mRNA expression of day 5 predifferentiated maGSCs was examined for early mesodermal and cardiovascular progenitor markers. RT-PCR analysis confirmed that only Flk- $1^{+}$cells expressed Flk-1 mRNA, receptor for Angiopoietin (Ang), Tie-2, the early mesodermal marker brachyury as well as markers of cardiovascular progenitor cells, such as Is11 and Nkx2.5 (Figure 16). 


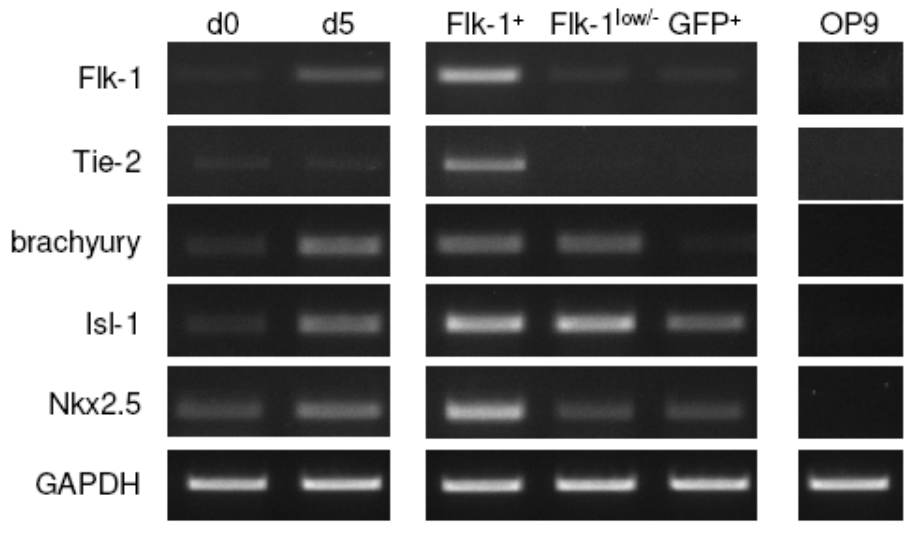

Figure 16. mRNA expression patterns of three FACS-sorted cell populations. RT-PCR analysis shows that only day $5 \mathrm{Flk}-1^{+}$cells express cardiovascular progenitor markers Flk-1, Is11, Nkx2.5 and early endothelial marker Tie-2. Negative controls included day 0 undifferentiated maGSCs and OP9 stromal cells. Results for day 5 cells immediately before sorting are also shown.

\subsubsection{Angiogenic potential of Flk-1 ${ }^{+}$progenitor cells}

To evaluate the angiogenic potential of $\mathrm{Flk}-1^{+}$cells, all three sorted cell populations were seeded on either matrigel (2D matrigel ${ }^{\mathrm{TM}}$ angiogenesis assay) or used to generate spheroids and embedded in collagen type I (3D spheroid angiogenesis assay). Using the matrigel ${ }^{\mathrm{TM}}$ angiogenesis assay, it was observed that all three sorted cell populations can form tube-like structures, although this phenomenon was observed first in Flk-1 $1^{+}$cells (day 5) and at later time points (first at day 12) also in the Flk-1 ${ }^{\text {low/- }}$ and GFP ${ }^{+}$ cells (Figure 17).

\section{Day 5}
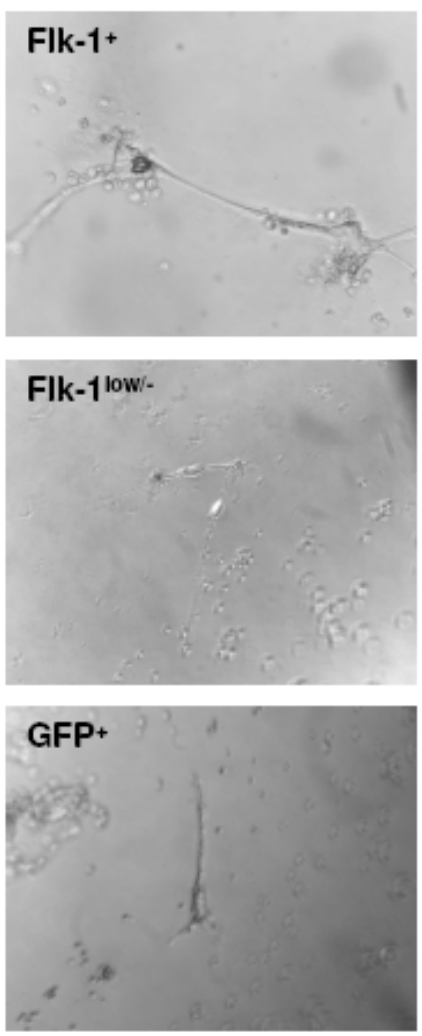

Day 12
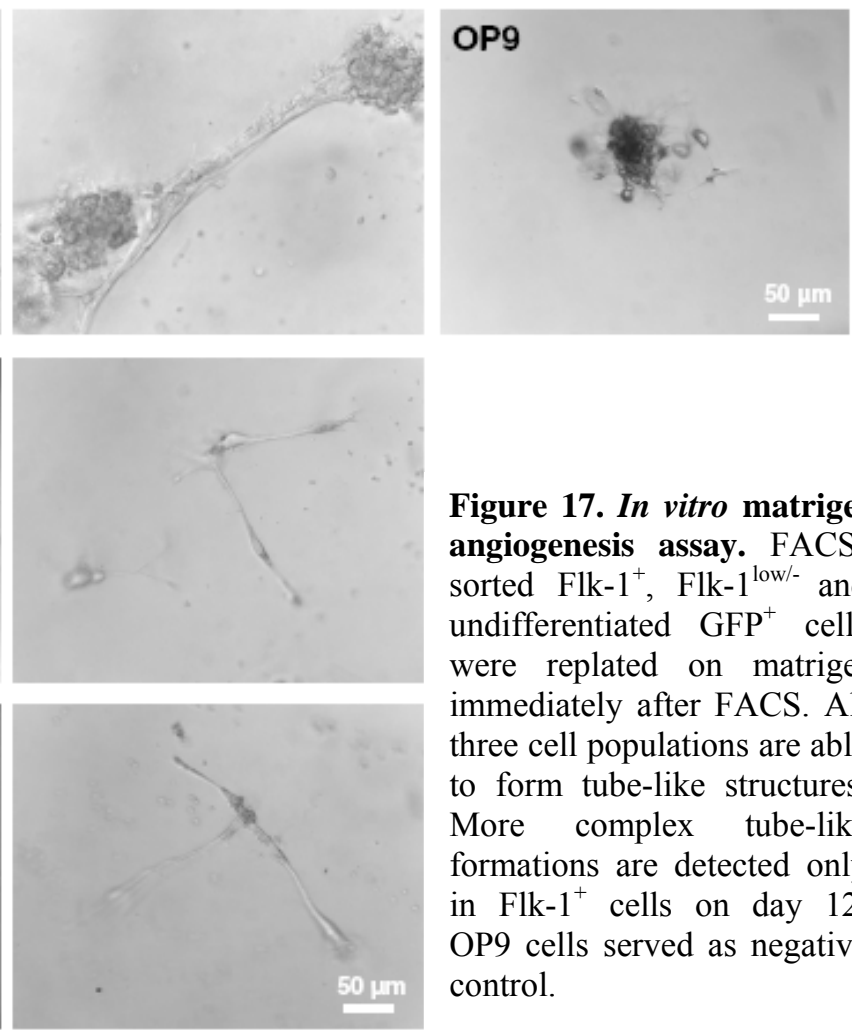

Figure 17. In vitro matrigel angiogenesis assay. FACSsorted Flk- $1^{+}$, Flk- $1^{\text {low/ }}$ and undifferentiated $\mathrm{GFP}^{+}$cells were replated on matrigel immediately after FACS. All three cell populations are able to form tube-like structures. More complex tube-like formations are detected only in $\mathrm{Flk}-1^{+}$cells on day 12. OP9 cells served as negative control. 
In addition, maturation and extension of networks was only observed in Flk-1 ${ }^{+}$ cells. For example, Flk- $1^{+}$cells developed phenotypes such as branch points, multiple tube-like structures and tube-like network formations (Figure $18 \mathrm{~A}$, representative example). Quantitative evaluation of the number of tube-like structures per microscopic field revealed that Flk-1 ${ }^{+}$cells possessed the highest ability to form tube-like structures. $\left(P<0.001\right.$ vs. Flk-1 ${ }^{\text {low/- }}$ and $\mathrm{GFP}^{+}$cell; Figure $\left.18 \mathrm{~B}\right)$.

\begin{tabular}{cccc} 
A & Day $\mathbf{5}$ & $\mathbf{1 2}$ & 15 \\
\cline { 2 - 4 } GFP+ $^{+}$ & cell extension & cell extension & $\begin{array}{l}\text { tube-like formation } \\
\text { between 2 cells }\end{array}$ \\
Flk-1 low/- $^{\text {cell extension }}$ & cell extension & $\begin{array}{l}\text { tube-like formation } \\
\text { between 2 cells }\end{array}$ \\
Flk-1+ & increasing branch point & $\begin{array}{l}\text { multiple tube-like } \\
\text { structure formation }\end{array}$ & $\begin{array}{l}\text { tube-like network } \\
\text { formation }\end{array}$
\end{tabular}

B

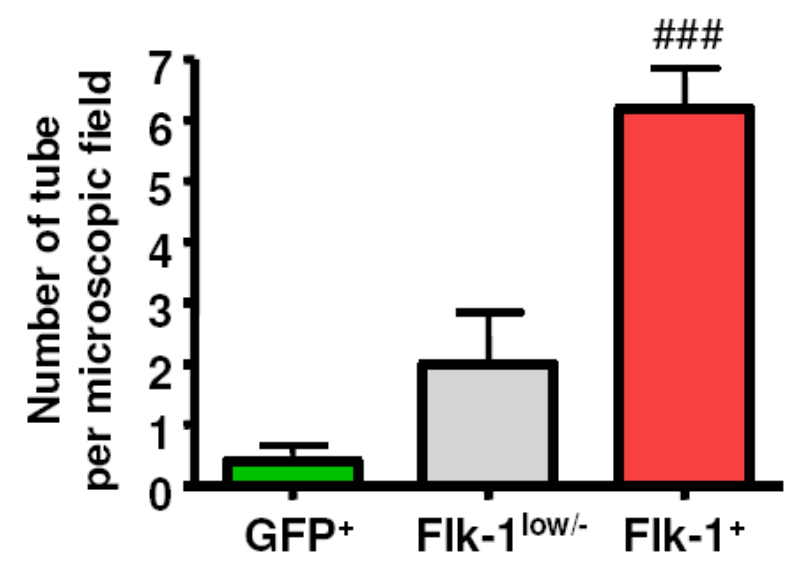

Figure 18. In vitro matrigel angiogenesis assay. FACS-sorted Flk$1^{+}$, Flk- $1^{\text {low/- }}$ and undifferentiated $\mathrm{GFP}^{+}$ cells were replated on matrigel immediately after FACS. A, Three morphologies are unique to $\mathrm{Flk}-1^{+}$ cells, such as increasing branch points (left; arrow), multiple tube-like structures (middle) and tube-like network formation (right). B, Flk- $1^{+}$ cells show the highest capacity to develop tube-like formations. Data are shown as mean \pm S.D.; \#\#\# $\mathrm{P}<0.001$; $\mathrm{n}=3$ independent experiments. 
Further analysis using the 3D spheroid angiogenesis assay revealed that among all three sorted cell populations, only Flk $-1^{+}$cells were able to sprout (Figure 19 A) and to respond to stimulation with VEGF (Figure $19 \mathrm{~B} ; P<0.01$ vs. unstimulated).

A

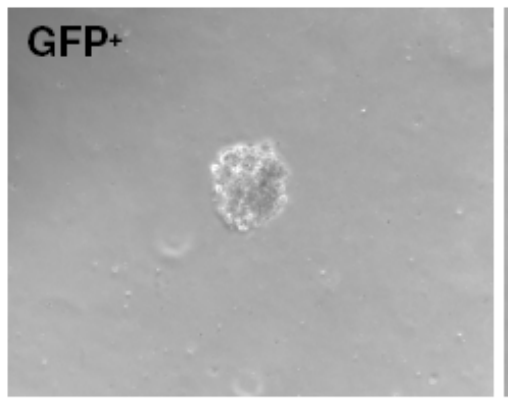

Flk-1 1ow/-

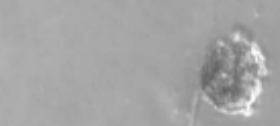

Baseline

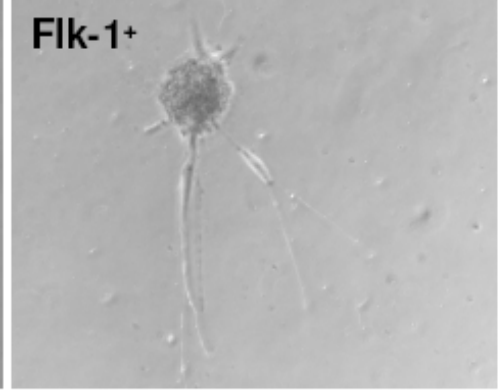

VEGF

$50 \mathrm{ng} / \mathrm{ml}$

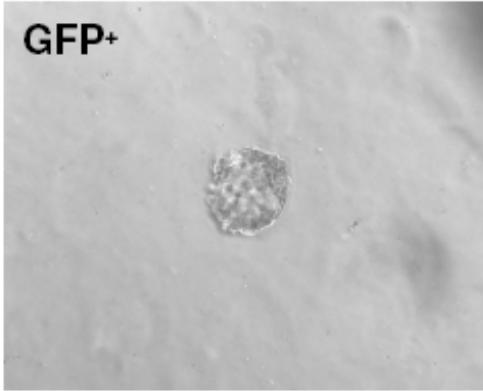

Flk-1 1ow/-

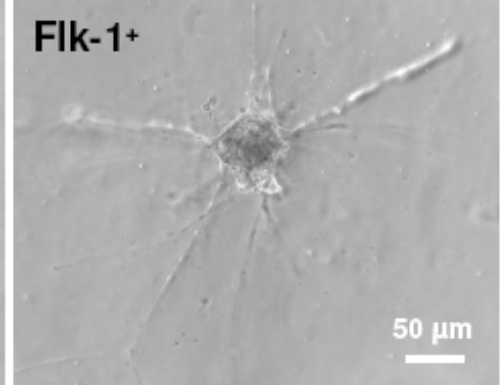

B

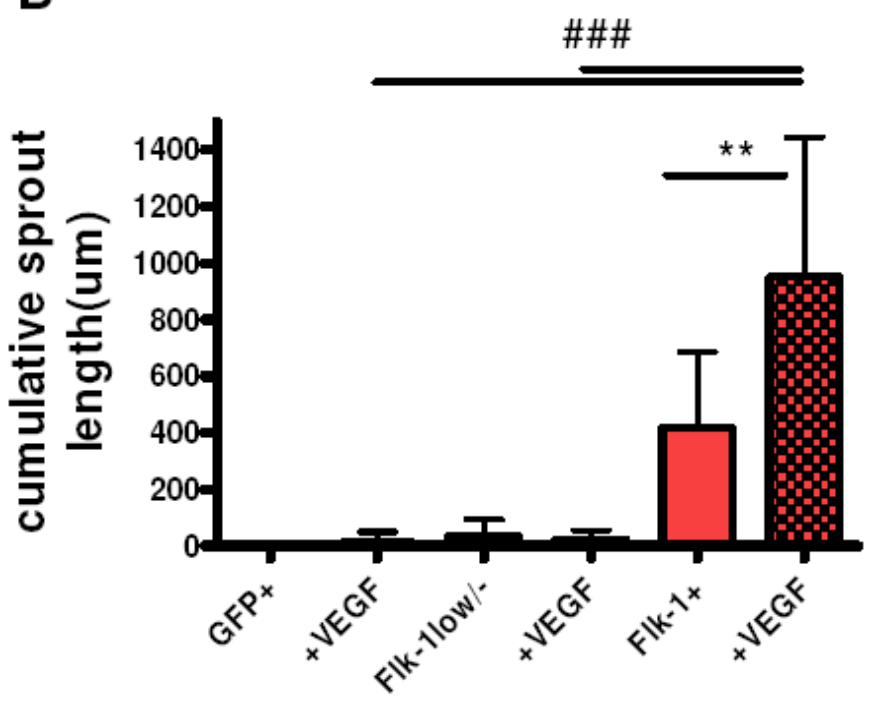

Figure 19. In vitro 3D spheroid angiogenesis assay. FACSsorted Flk-1 ${ }^{+}$, Flk-1 $1^{\text {low/- }}$ and $\mathrm{GFP}^{+}$ cells were used for spheroid generation immediately after sorting. A, Only Flk $-1^{+}$cells have the ability to sprout and VEGF promotes this process. B, Cumulative sprout length is significantly increased in Flk- $1^{+}$ cells both with and without VEGF treatment. Data are shown as mean \pm S.D.; ** $\mathrm{P}<0.01$, \#\#\# $\mathrm{P}<0.001 ; \mathrm{n}=3 \quad$ independent experiments. 


\subsection{Endothelial differentiation of Flk-1 ${ }^{+}$progenitor cells}

According to the above findings, $\mathrm{Flk}-1^{+}$progenitor cells expressed all three markers for cardiovascular progenitor cells and possessed angiogenic potential. To examine the endothelial differentiation potential of FACS-sorted Flk- $1^{+}$cells, Flk- ${ }^{+}$, Flk$1^{\text {low/- }}$ and $\mathrm{GFP}^{+}$cell populations were separately grown on COLIV-coated dishes under endothelial differentiation conditions for longer time periods. The morphologies of all three cell populations were observed 2 days (Figure $20 \mathrm{~A}$ ) and 5 days after replating (Figure $20 \mathrm{~B}$ ). Flk-1 ${ }^{\text {low/- }}$ and $\mathrm{GFP}^{+}$cells were prone to form cell clusters, whereas Flk-1 ${ }^{+}$ cells exhibited spindle-shaped structures.

\section{A Day $5+2$}
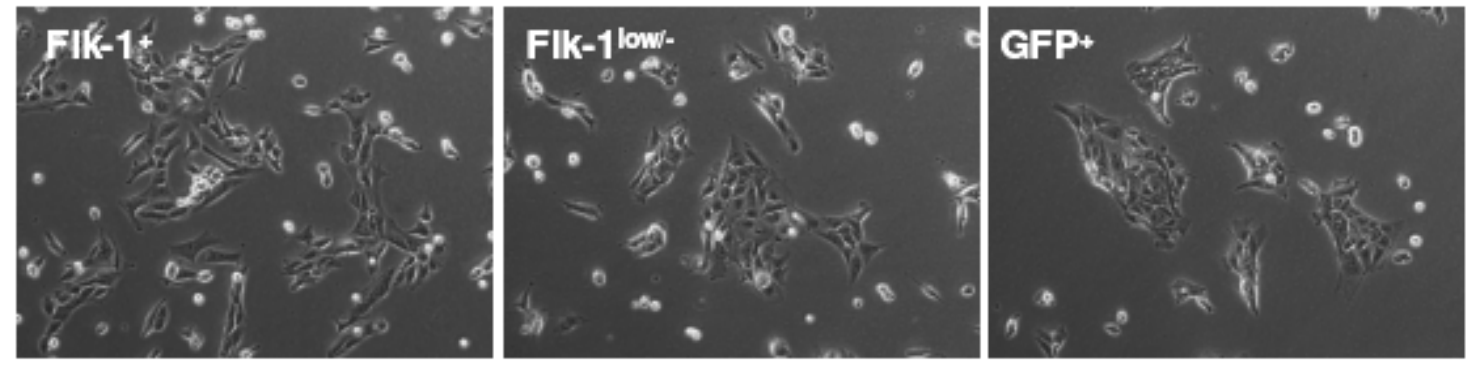

B

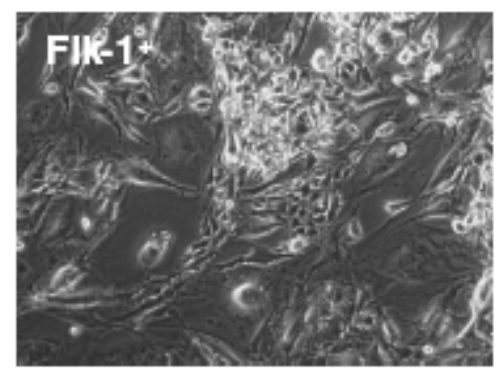

Day $5+5$

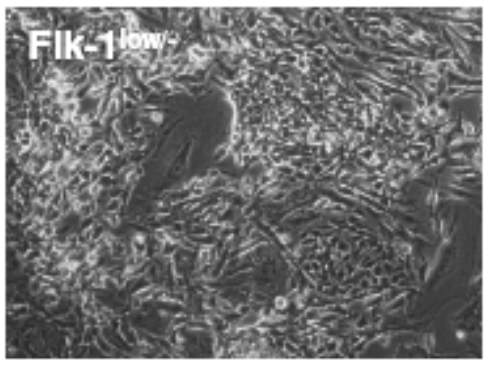

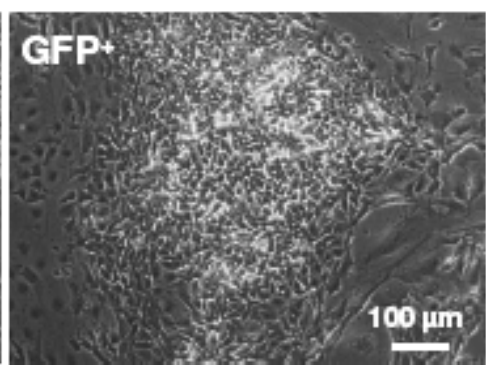

Figure 20. Morphology of FACS-sorted Flk-1 ${ }^{+}$, Flk-1 ${ }^{\text {low/- }}$ and undifferentiated GFP cells $^{+}$ cultured on COLIV-coated culture dishes. A-B, Flk- $1^{+}$cells exhibit a spindle-shaped morphology and Flk-1 ${ }^{\text {low/- }}$ and $\mathrm{GFP}^{+}$cells form cell clusters.

After further cultivation and analysis at 8, 13, and 18 days (passage 1), Flk-1 ${ }^{+}$ cells had formed cobblestone-like endothelial colonies as shown by bright field microscopy (Figure $21 \mathrm{~A}$ ) and in accordance with previous findings ( $\mathrm{Li}$ et al., 2007; Sone et al., 2007). To further characterize them, cells were collected for RNA isolation followed by RT-PCR analysis ( $\mathrm{n}=3$ independent experiments; Figure $21 \mathrm{~B}$ ). These analyses revealed that $\mathrm{Flk}-1^{+}$cells cultured in endothelial differentiation medium expressed higher level of EC markers, and the expression levels further increased with prolonged duration of culture 
(with the exception of Flk-1). On the other hand, markers for vascular SMCs (e.g. $\alpha$-SMA) (Skalli et al., 1989) were down-regulated after long-term culture, i.e. after cultivation at day 13 , passage 1 and 6 .
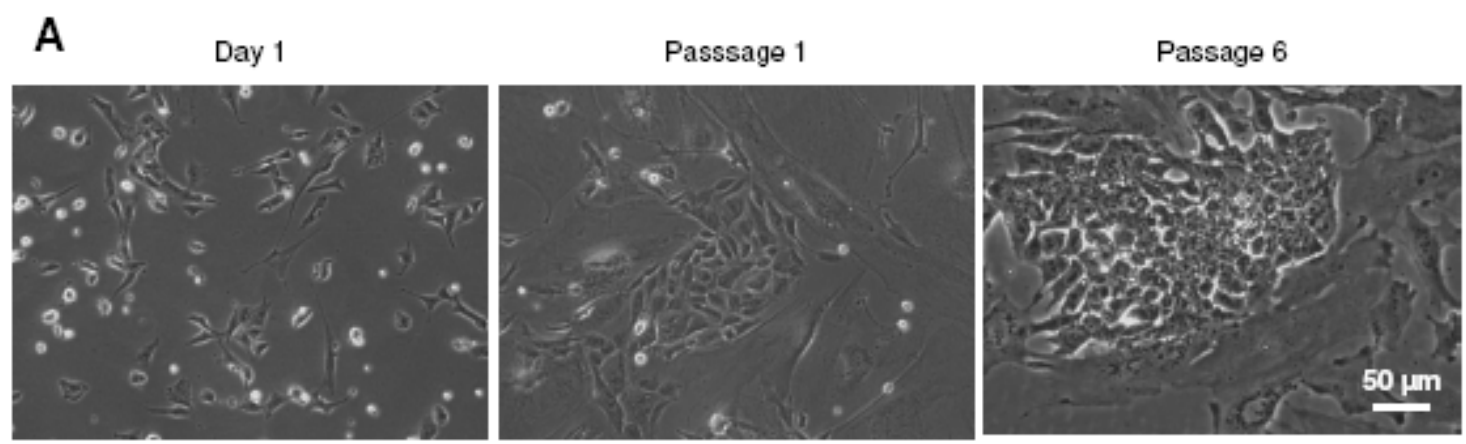

B

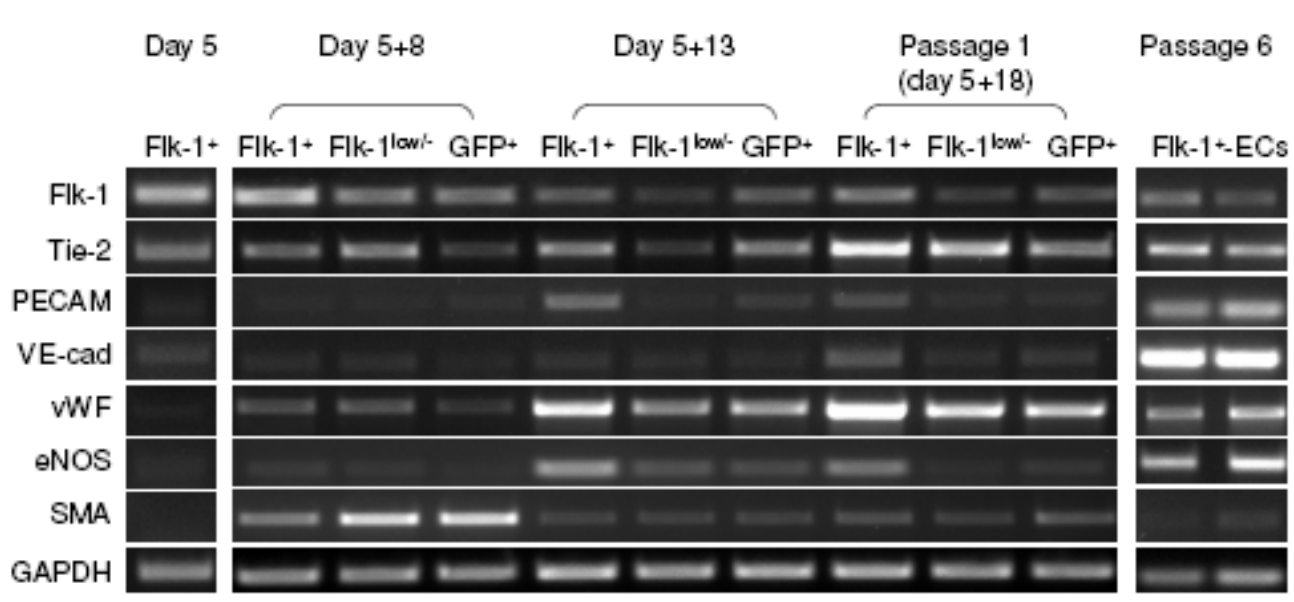

Figure 21. Cell morphology and endothelial differentiation of Flk-1 ${ }^{+}$cells. A, Flk- $1^{+}$cells exhibit a spindle-shaped morphology at subconfluence 1 day after replating and appear to be flatter and packed closer after long-term culture. B, The gene expression profile of endothelial markers was analyzed at different time points up to passage 6 . The expression of Tie-2, VE-cad and vWF is upregulated in Flk- $1^{+}$derived ECs after long- term culture. In contrast, the expression of $\square$-SMA is downregulated (see right column).

To summarize, when cultured on COLIV-coated culture dishes in endothelial differentiation medium supplemented with VEGF, maGSC-derived Flk- $1^{+}$cells were able to differentiate into endothelial-like cells as suggested both by their morphology and their gene expression profile. Next, we further examined whether these maGSC-ECs were functional. 


\subsection{In vitro characterization of maGSC-ECs}

To further characterize these differentiated endothelial-like cells, maGSC-ECs at passage 5-6 were subjected to flow cytometry analysis using antibodies against endothelial markers. FACS analyses revealed that maGSC-ECs exhibited both EC and SMC marker expression. For example, $56.1 \% \pm 3.6 \%$ of cells were found to be positive for Flk-1; $52.6 \%$ $\pm 5.2 \%$ for VE-cad and $66.3 \% \pm 4.2 \%$ for vWF, whereas $14.8 \% \pm 2.0 \%$ of the cells expressed $\square$-SMA (Figure 22). Thus, the FACS data revealed that maGSC-derived Flk-1 ${ }^{+}$ cells had differentiated into vascular lineages containing approximately 55-60\% of endothelial-like cells and 15\% of smooth muscle-like cells (Figure 22).
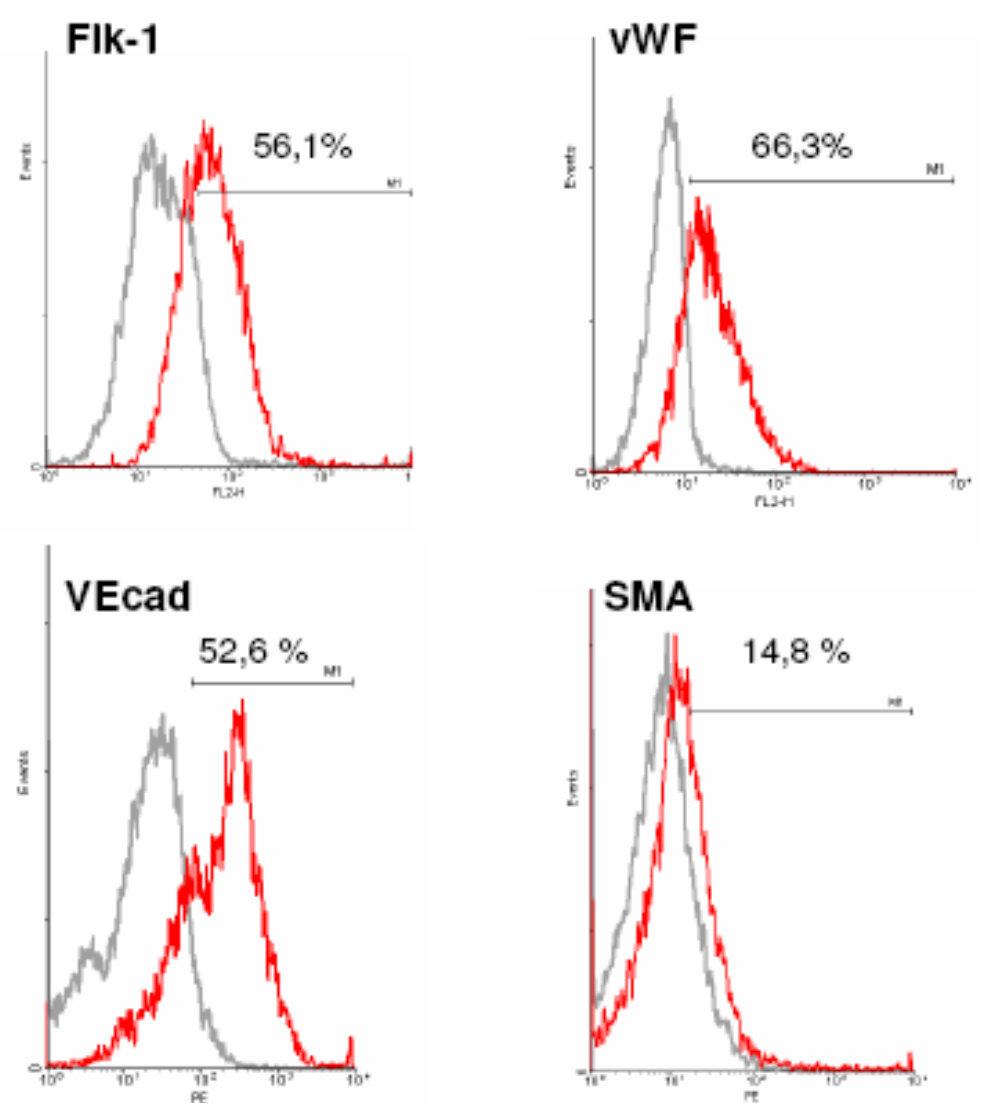

Figure 22. In vitro characterization of maGSC-ECs. Flow cytometry analyses show the expression of typical endothelial markers in differentiated maGSC-ECs. For example, about 55-60\% of the cells are positive for Flk-1, VE-cad and vWF. On the other hand, around $15 \%$ of the cells are positive for $\square$-SMA. $n=3$ independent experiments. 
Furthermore, imunocytochemical analysis of maGSC-ECs at passage 5-6 revealed that cells were positive for VE-cad, a strictly endothelial cell-specific adhesion molecule located at junctions between ECs (Vestweber, 2008), as well as vWF, stored in WeibelPalade bodies within the cytoplasm of mature ECs (Rondaij et al., 2006). On the other hand, expression of $\square$-SMA suggests the differentiation of some of the cells into smooth muscle-like cells (Figure 23).
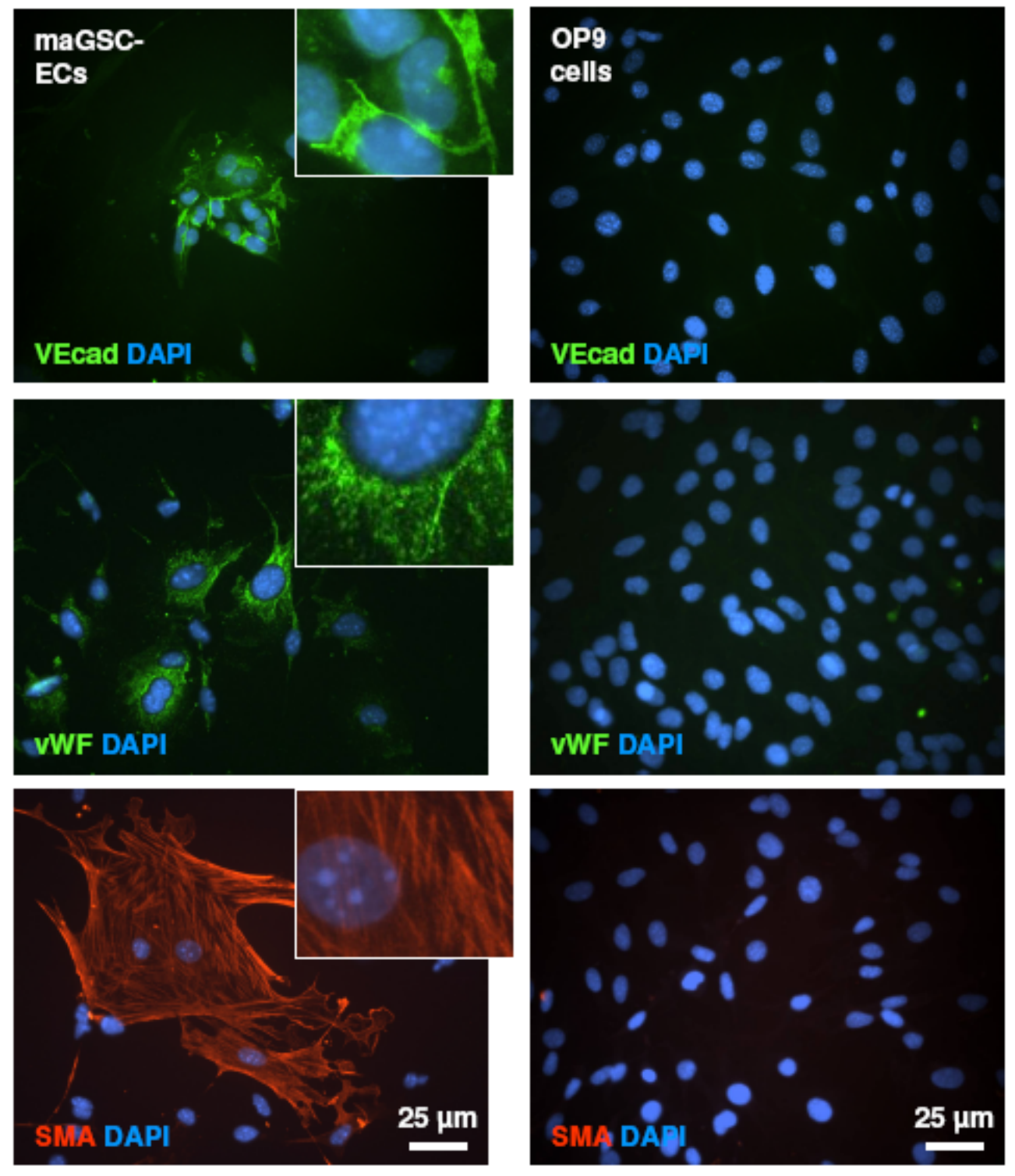

Figure 23. In vitro characterization of maGSC-ECs using immunocytochemistry. Immunostaining of maGSC-ECs (left column) shows expression of typical mature EC markers (VE-cad at the junction between ECs and vWF in the cytoplasm), but also of $\square$ SMA. Cell nuclei were stained with DAPI (blue). OP9 stromal cells served as negative control (right column). 
The ability of maGSC-ECs to take up fluorescence DiI-AcLDL, a phenomenon previously reported to characterize ECs (Levenberg et al., 2010; McCloskey et al., 2006; Voyta et al., 1984; Wang et al., 2007) was determined. MaGSC-ECs were able to endocytose acLDL and bound to a mouse EC-specific lectin (Figure 24). Lectin binding was one of the characteristics of ECs (Rafii and Lyden, 2003).
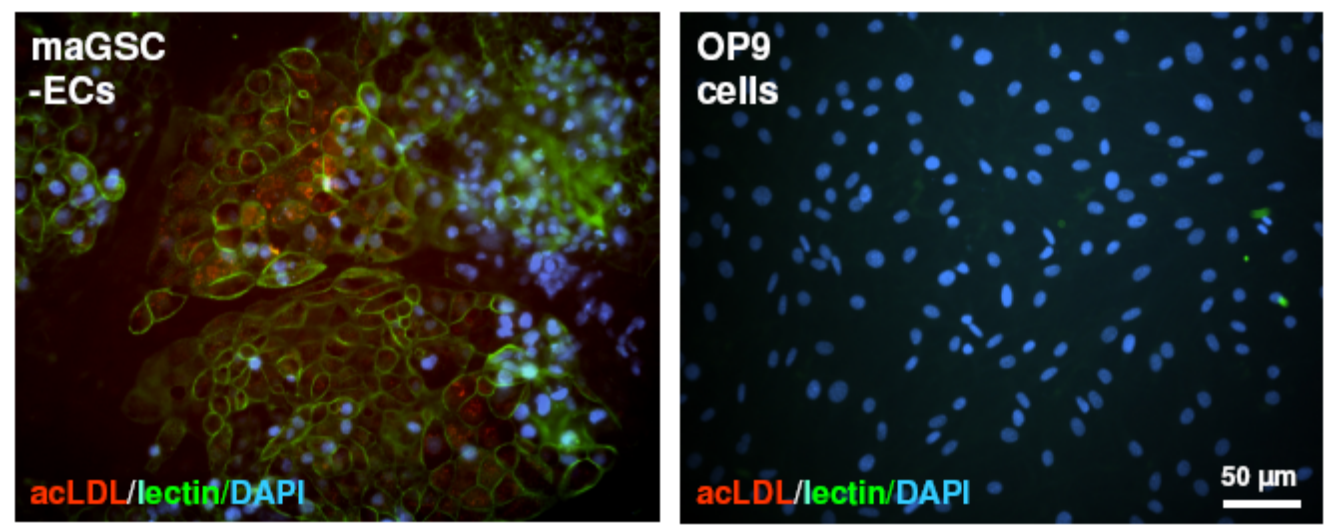

Figure 24. Ability of maGSC-ECs to take up acLDL and to bind lectin. MaGSC-ECs show the capacity to incorporate acetylated LDL (red) and to bind endothelial-specific FITC-lectin (green). Cell nuclei were stained with DAPI (blue). OP9 cells served as negative control.

To analyze the angiogenic potential of maGSC-ECs, two in vitro functional assays (2D matrigel and 3D spheroid angiogenesis assays) were employed. When seeded on matrigel, maGSC-ECs formed tube-like networks within 8 hours (Figure 25, representative example).
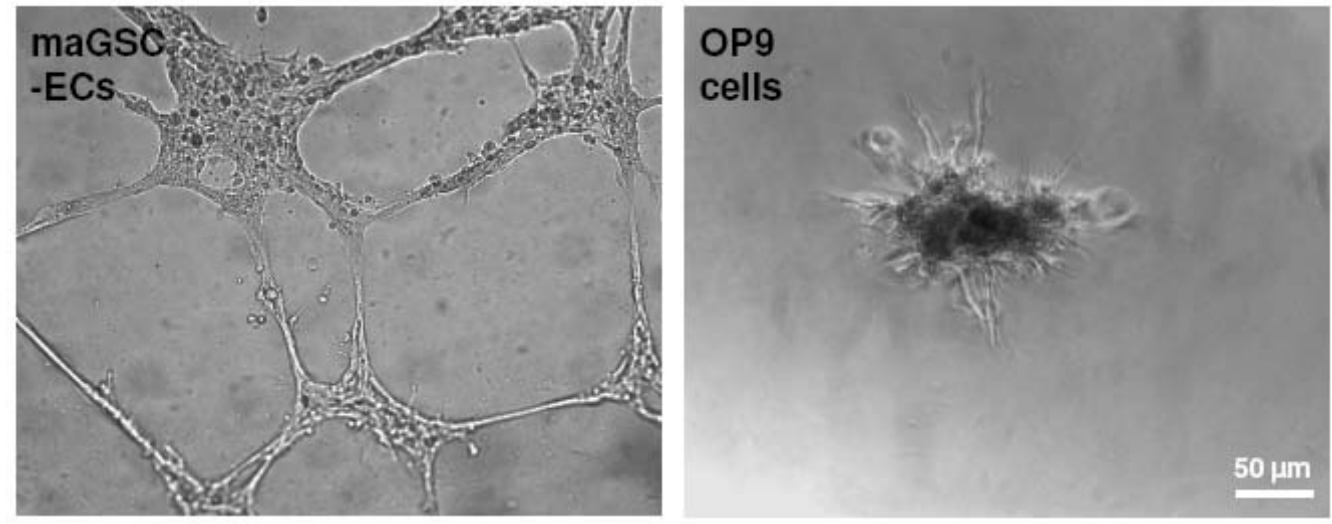

Figure 25. In vitro matrigel angiogenesis assay. MaGSC-ECs at passage 5-6 were subjected to the 2D matrigel angiogenesis assay. The cells form tube-like networks within 8 hours after being added to matrigel. OP9 stromal cells served as negative control. 
Analysis using the spheroid angiogenesis assay revealed that maGSC-ECs, similar to the murine endothelial cell line SVEC4-10 were able to sprout within 24 hours (Figure 26).
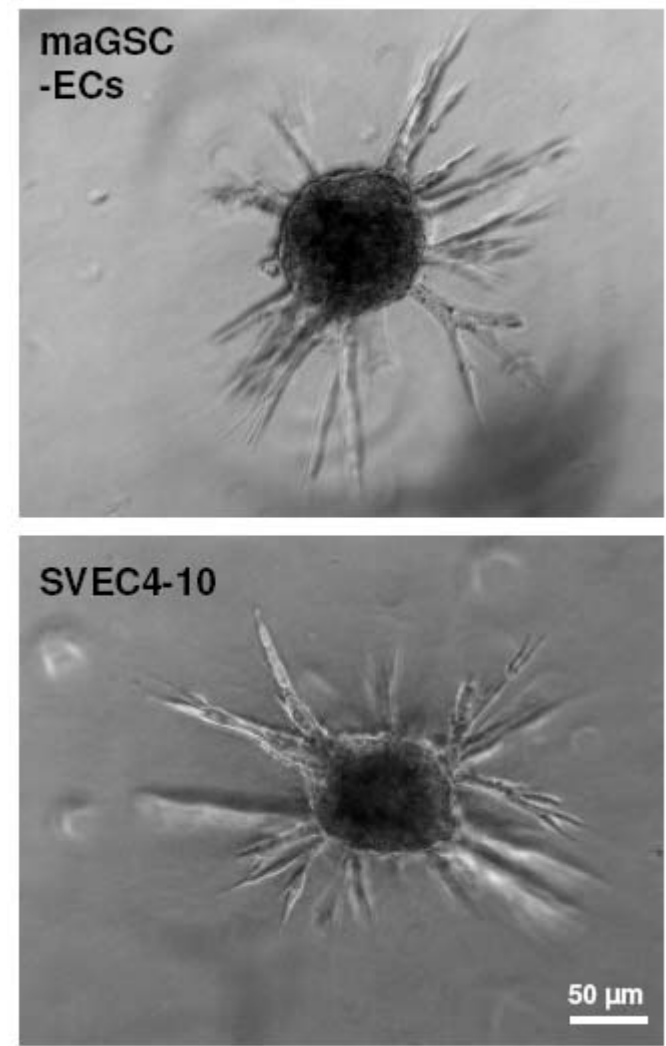

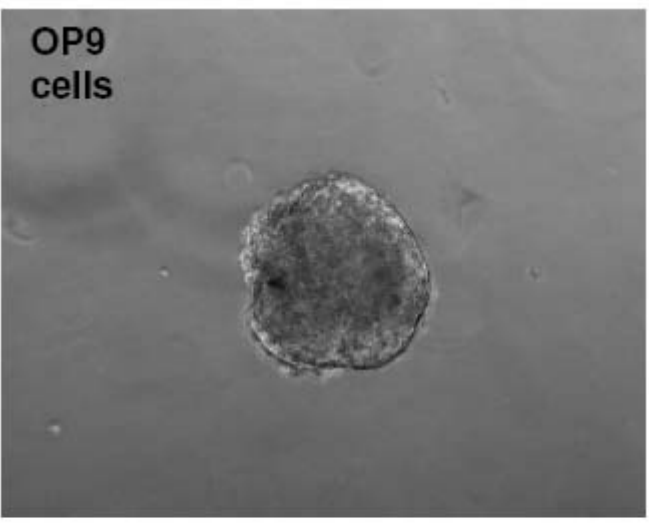

Figure 26. In vitro $3 \mathrm{D}$ spheroid angiogenesis assay. MaGSC-ECs at passage 5-6 were analyzed and show the ability to sprout from cell aggregates embedded in type I collagen. The murine endothelial cell line SVEC4-10 served as positive control, OP9 cells as negative control.

A colorimetric cell proliferation assay was used to measure cell proliferation of maGSC-ECs at passage 5-6. These analyses revealed that cells retained the ability to proliferate (Figure 27).

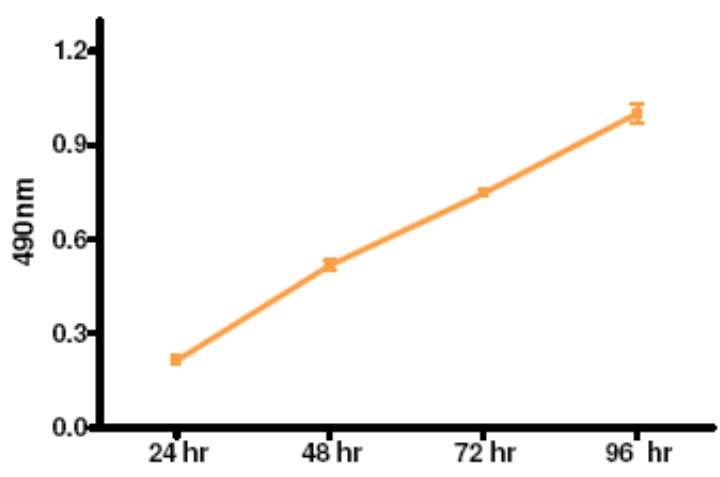

Figure 27. MaGSC-ECs can proliferate, as shown by the MTS assay. Passage 5-6 maGSC-ECs were used and absorbance at $490 \mathrm{~nm}$ after addition of MTS was recorded daily for 4 days. 
Taken together, Flk-1 ${ }^{+}$progenitor cells can be subsequently cultured in endothelial differentiation medium and give rise to functional and proliferating endotheliallike cells, as confirmed by their typical morphology, their gene and protein expression patterns, as well as in vitro functional assays.

\subsection{Functional evaluation of maGSC-ECs in vivo}

Although the above-mentioned in vitro studies demonstrate the functionality of maGSC-ECs, it is important to characterize their behavior in vivo, keeping in mind their potential future applications. Therefore, the murine matrigel plug model was employed and modified for the analyses of the angiogenic capacities of maGSCs-ECs in vivo. In this assay, matrigel alone and OP9 stromal cells were used as negative controls and the mouse EC line SVEC4-10 as positive control. Of note, all cells mixed with the matrigel (maGSCECs, SVEC4-10 and OP9 cells) were labelled with the fluorescent membrane dye CM-DiI to allow their detection and distinction from host cells. Additionally, in order to demonstrate that the newly formed vessels were functional and connected to the host circulatory system, mice were perfused with FITC-lectin before plug harvest, so that a green signal inside the matrigel plugs means the vessels have formed and are connected to the host circulation. As shown in Figure 28, there was scarce FITC-lectin signal in both negative control groups, indicating that only a few functional vessels had formed (Figure $28 \mathrm{~A}, \mathrm{~B})$.

In contrast, numerous and distinct FITC-lectin tube-like structures were observed within the matrigel plugs containing either the positive control cells (SVEC4-10) or maGSC-ECs. However, in both cases, the majority of CM-DiI-labelled cells did not colocalize with the tube-like structures (Figure $28 \mathrm{C}, \mathrm{D}$ ). 

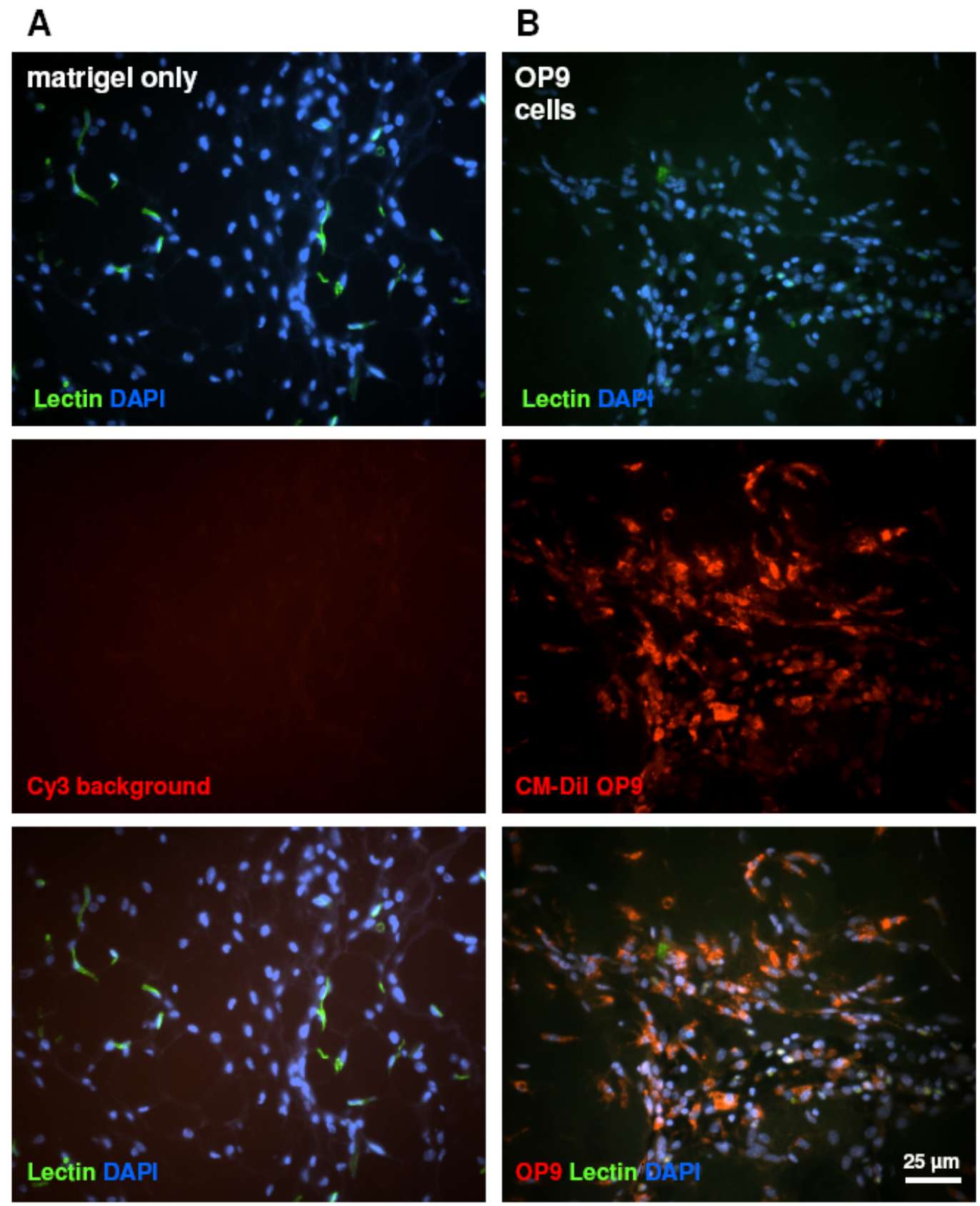

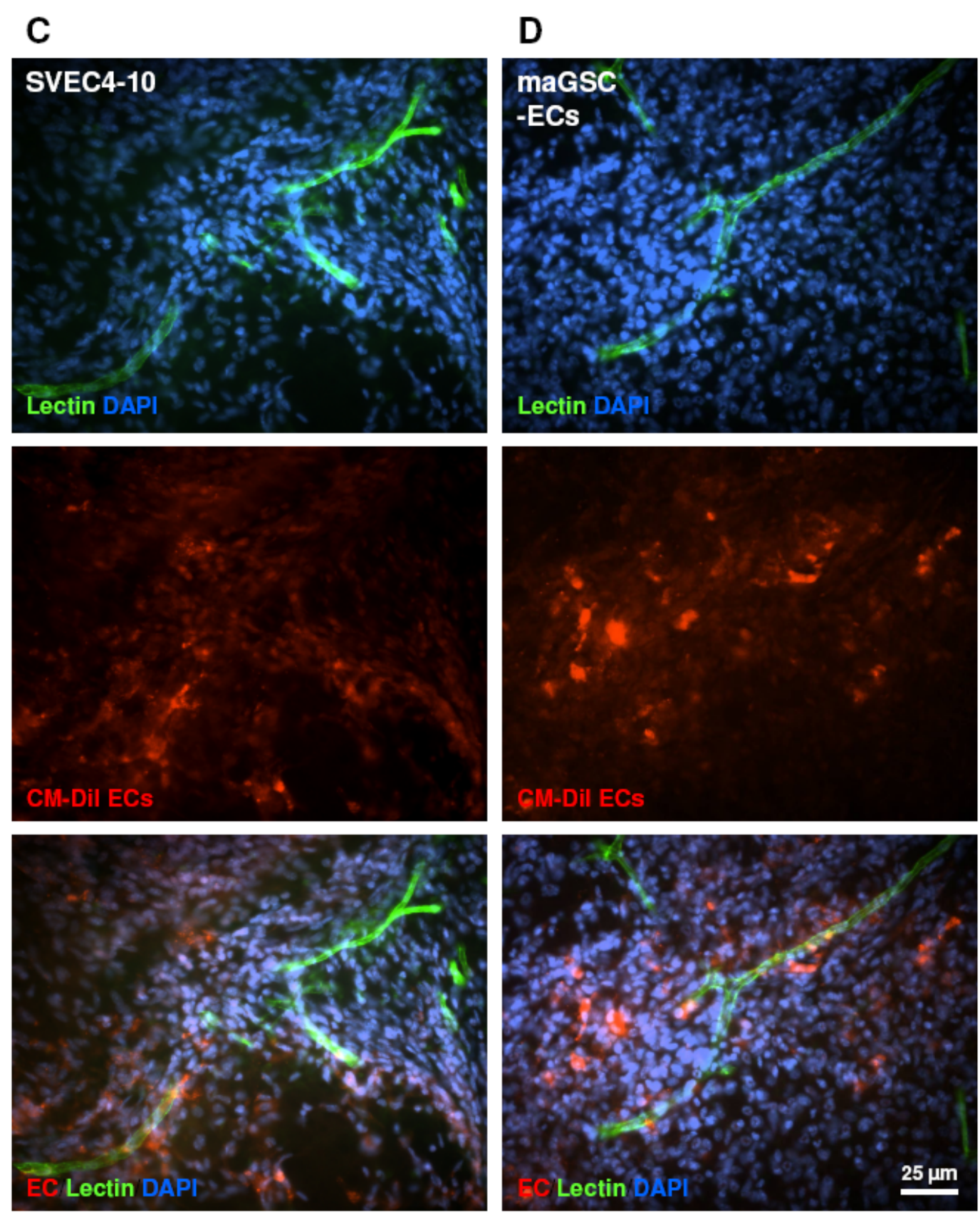

Figure 28. Evaluation of in vivo functions of maGSC-ECs. The murine matrigel plug assay was performed using CM-DiI labelled cells. A-B, There are few lectin positive signals in both negative control groups (matrigel alone and OP9 cells) when compared to $\mathbf{C}$, positive control SVEC4-10 as well as D, maGSC-ECs. Of note, only some of the CM-DiI labelled maGSC-ECs are found to be directly associated with FITC-lectin tube-like structures. Cell nuclei were stained with DAPI (blue).

At higher magnification, some co-localizations of delivered maGSC-ECs with the FITC-lectin positive tube-like structures were detected (Figure 29). Furthermore, 
quantification of the FITC-lectin signal revealed that maGSC-ECs promoted neovascularization (Figure 30).
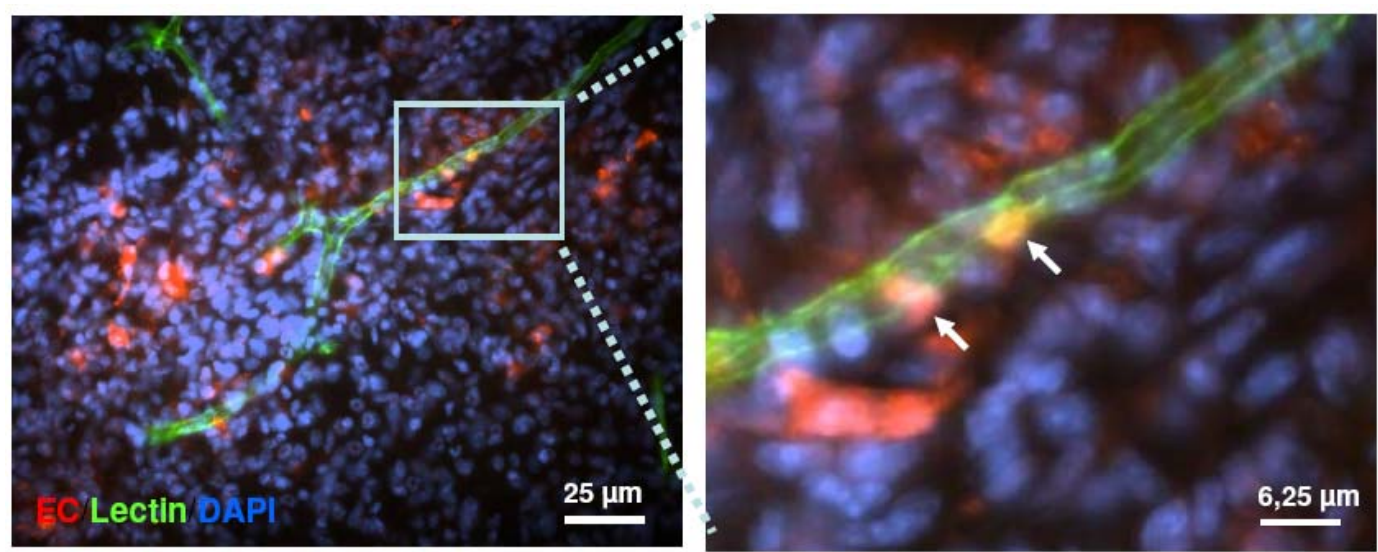

Figure 29. Evaluation of in vivo functions of maGSC-ECs. Matrigel plug assays were performed using CM-DiI-labelled cells. At higher magnification, co-localization (arrows) of delivered maGSC-ECs (red) and FITC-lectin positive endothelial cells (green) is observed. Cell nuclei were stained with DAPI (blue).
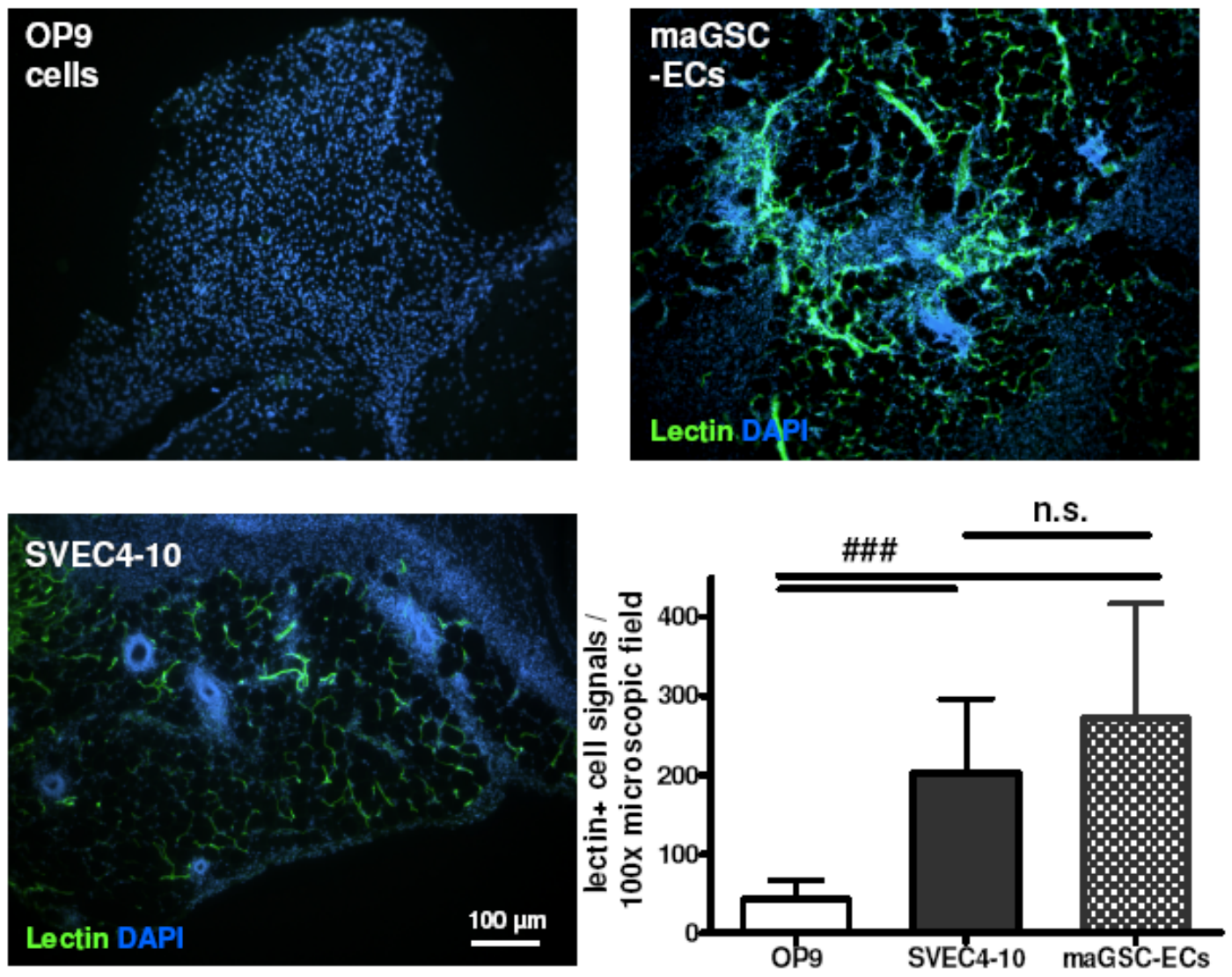

Figure 30. Enhanced neovascularization in vivo after maGSC-ECs delivery. The number of lectin-positive cells is significantly higher in matrigel plugs mixed with maGSC-ECs, when compared to negative control OP9 cells. SVEC4-10 cells served as positive control. Cell nuclei were stained with DAPI (blue). Data are shown as mean \pm S.D.; \#\#\# $\mathrm{P}<0.001 ; \mathrm{n}=3$ independent experiments. n.s., not significant. 
As shown in Figure 29, only some of the CM-DiI-labelled maGSC-ECs were found to be directly involved in the formation of new blood vessels perfused with FITClectin, whereas the majority of cells were located around it. To exclude the possibility that some of the transplanted cells may have been destroyed by the host immune system and to determine the tumorigenicity of maGSC-ECs, the in vivo matrigel plug assay was repeated using immunocompromised SCID mice. These analyses revealed massive tumor formation at the site of injection after 3 weeks in all of the mice $(n=7)$ treated with maGSCECs/matrigel, but not in those treated with SVEC4-10/matrigel $(n=3)$ or matrigel alone $(n=3)$. Tumors were harvested and subjected to fluorescence microscopy. CM-DiI-labelled maGSCs-ECs were found dispersed inside the tumor sections (Figure 31).
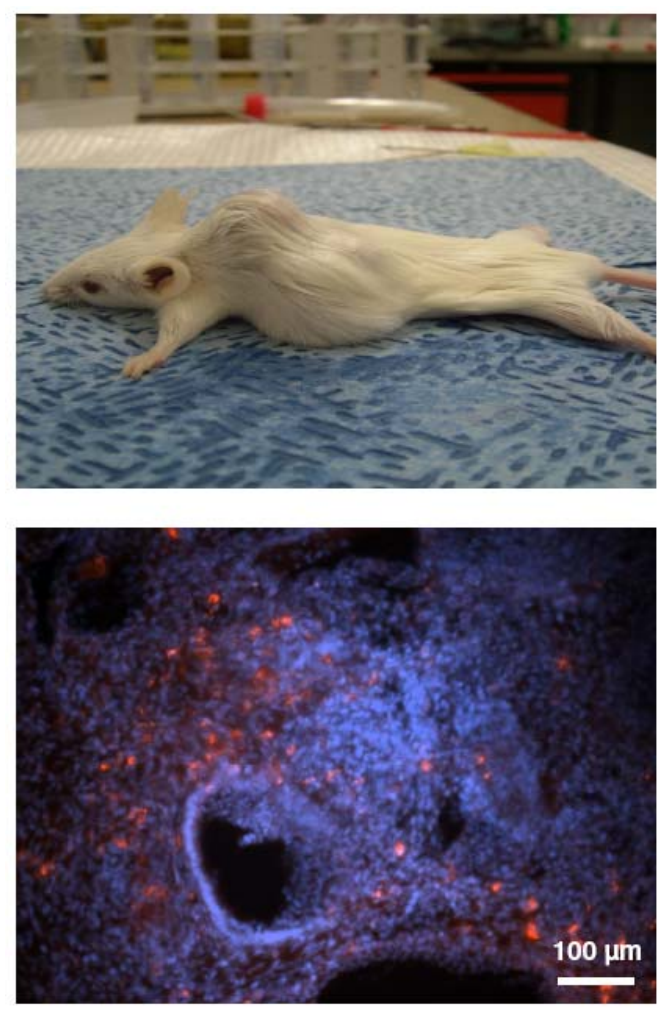

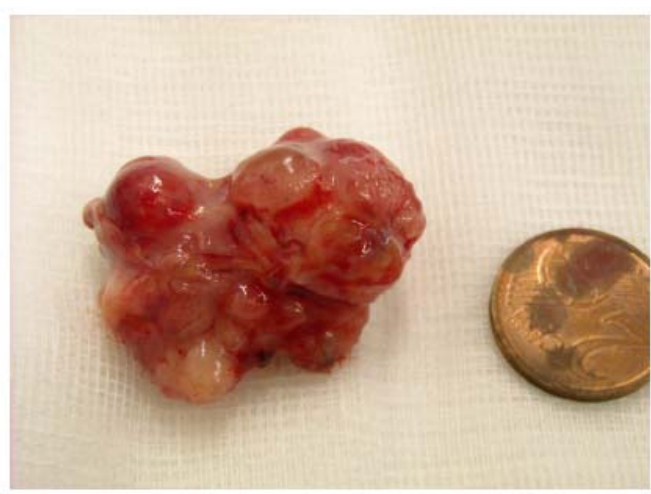

Figure 31. Tumor formation was found in SCID mice after maGSC-ECs transplantation. Tumors are found at the site of matrigel injection (upper left panel). A picture after excision of the tumor mass is also shown (upper right panel). Tumors were harvested and subjected to fluorescence microscopy. CM-DiI-labelled maGSC-ECs (red) are found inside the tumor sections. Cell nuclei were stained with DAPI (blue) (lower panel).

The sections of the tumors were further characterized by H\&E staining and morphologically identified as teratoma containing a wide variety of cell types, including cells derived from all three germ layers (Figure 32). 


\section{Epithelium}

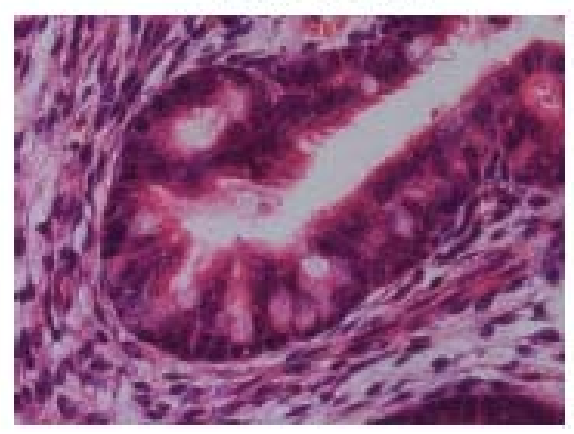

Cartilage

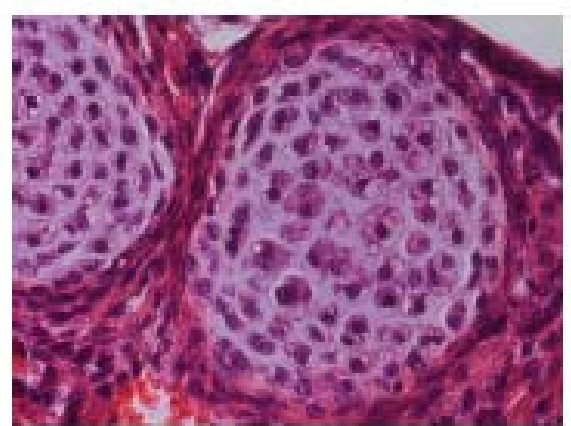

Muscle

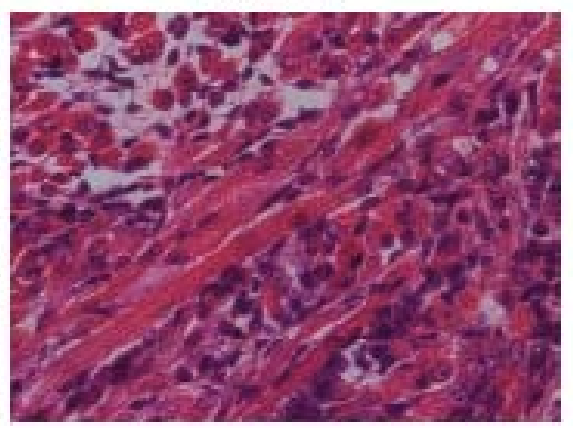

Neural tissue

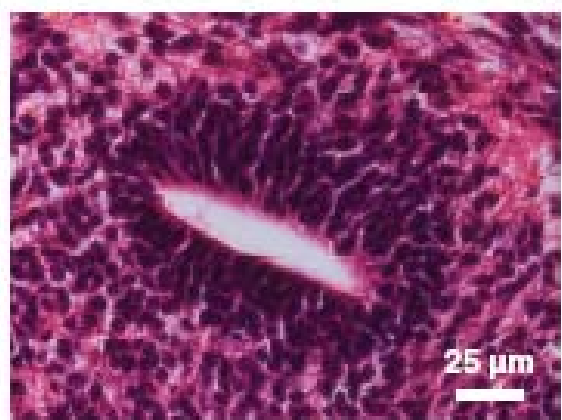

Figure 32. Histological analysis of teratoma formed after subcutaneous injection of matrigel plug containing maGSC-ECs into SCID mice. Three weeks after subcutaneous matrigel plug injection, tumors were sectioned and stained with hematoxylin and eosin. Shown are a variety of differentiated tissues. For example, epithelium formation from endoderm, muscle and cartilage derived from mesoderm and the neural tissue from ectoderm.

These findings indicated that the injected maGSC-ECs contained undifferentiated stem cells, which resulted in teratoma formation. Thus, it is necessary to generate longterm culture of cardiovascular progenitor cells, which maintain cardiovascular differentiation potential, but at the same time have lost their pluripotency. 


\subsection{Cultivation of Flk-1 ${ }^{+}$cardiovascular progenitor cells}

Flk- $1^{+}$progenitor cells can be generated from maGSCs in vitro. One of our interests was to establish a culture condition that would allow us to cultivate Flk-1 ${ }^{+}$ progenitor cells and expand them for longer periods.

\subsubsection{Screening culture conditions for long-term culture of Flk-1 progenitor cells}

MaGSC-derived Flk- $1^{+}$cardiovascular progenitor cells were isolated by FACS and cultured on COLIV-coated dishes in different serum concentration, i.e. serum free, $2 \%$ or $20 \%$ serum-containing media with or without N2B27 supplements. VEGF, bFGF and EGF at a final concentration of $10 \mathrm{ng} / \mathrm{ml}$ were included in all of the culture media. After several experiments, the culture conditions without serum and N2B27 were eliminated due to poor cell attachment. After cultivation for 7 days, the representative morphology of a colony is shown (Figure $33 \mathrm{~A}$ ) and the number of colonies was manually recorded. These analyses revealed that the highest number of colonies appeared after cultivation of Flk- $1^{+}$ progenitor cells in $2 \%$ FBS-containing medium supplemented with VEGF $10 \mathrm{ng} / \mathrm{ml}$ and N2B27 $(P<0.05$ vs. $2 \%$ or $20 \%$ FBS-containing medium supplemented with VEGF 20 ng/ml and N2B27; Figure 33 B).

A

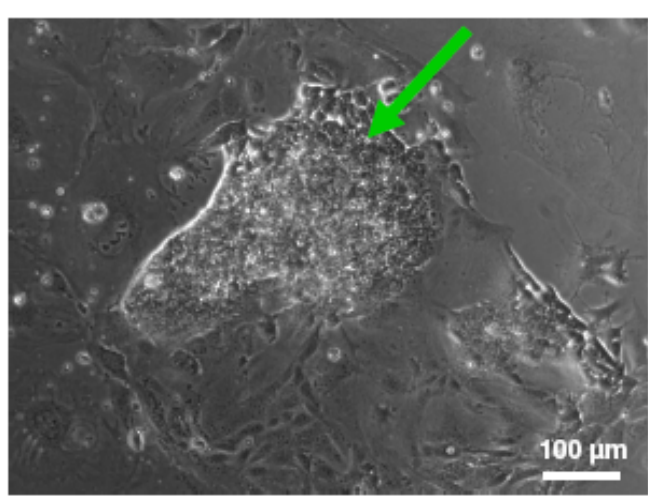

B

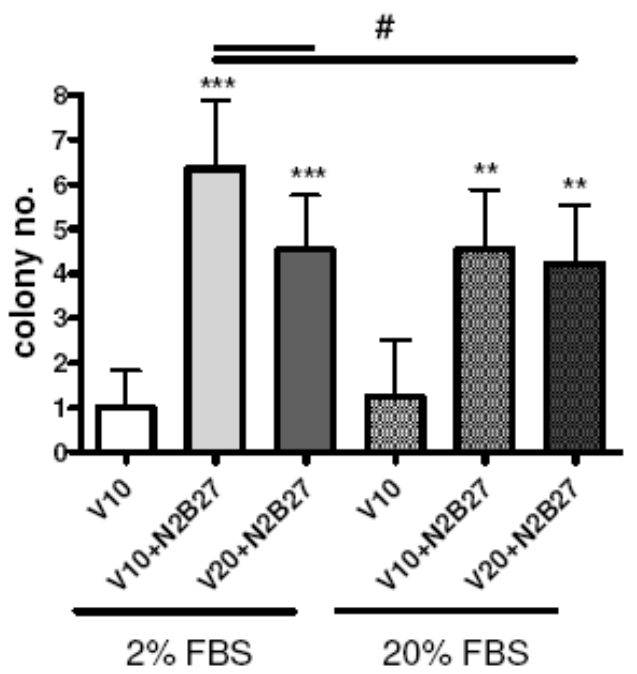

Figure 33. Morphology of Flk-1 ${ }^{+}$progenitor cell-derived colony and the number of colonies were recorded. A, Representative colony (arrow) of maGSC-derived Flk- $1^{+}$ progenitor cells at day $5+7$. B, The number of colonies was counted on day $5+7$ and found that the highest number of colonies appears in $2 \%$ FBS containing medium supplemented with VEGF $10 \mathrm{ng} / \mathrm{ml}$ and N2B27. Data are shown as mean \pm S.D.; \# $\mathrm{P}<0.05$, ** $\mathrm{P}<0.01$, *** $\mathrm{P}<0.001 ; \mathrm{n}=4$ independent experiments. 
In order to further determine which culture condition is optimal to support Flk-1 ${ }^{+}$ cardiovascular progenitor cell maintenance in a partially differentiated state, quantitative real-time PCR was used to compare the mRNA expression of the cardiovascular progenitor markers Flk-1 and Isl1, the endothelial differentiation marker, VE-cad and the undifferentiated stem cell marker, nanog among different culture conditions. Flk-1 ${ }^{+}$cells (day $5+0)$ were used immediately after FACS sorting and served as positive control. The expression of Flk-1 in cells cultured in $2 \%$ FBS-containing medium appeared to be maintained at a similar level when compared to Flk- $1^{+}$progenitor cells. The expression of Isl1 was downregulated in all conditions when compared to Flk- $1^{+}$progenitor cells, but to a lesser extent in 2\% FBS-containing medium with addition of VEGF (10 ng/ml). Additionally, the expression of Is11 in cells cultured in 2\% FBS-containing medium supplemented with VEGF $10 \mathrm{ng} / \mathrm{ml}$ was significantly higher when compared to those in both $20 \%$ FBS-containing media $(P<0.05)$. The expression of VE-cad and nanog appeared higher in $20 \%$ serum-containing medium, but the difference was not significant. These results suggest that $\mathrm{Flk}^{+} \mathrm{1}^{+}$progenitor cells may be better maintained under $2 \%$ FBScontaining medium with $10 \mathrm{ng} / \mathrm{ml}$ VEGF and N2B27 supplements, whereas cell cultured in $20 \%$ FBS-containing medium appeared to both enhance the number of EC-differentiated and undifferentiated cells (Figure 34). 
Flk-1

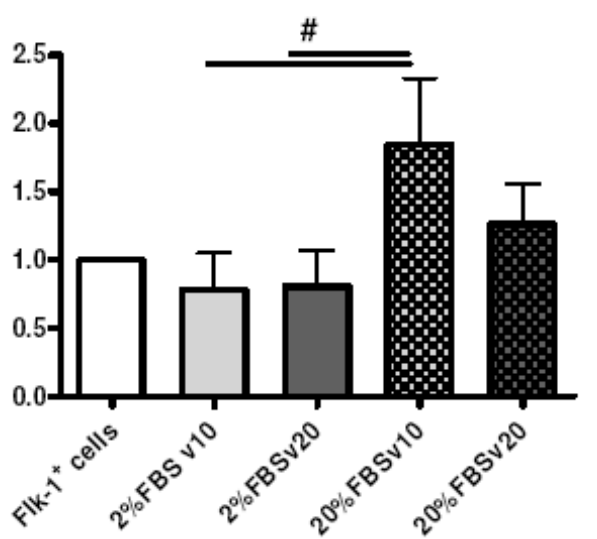

VE-cad

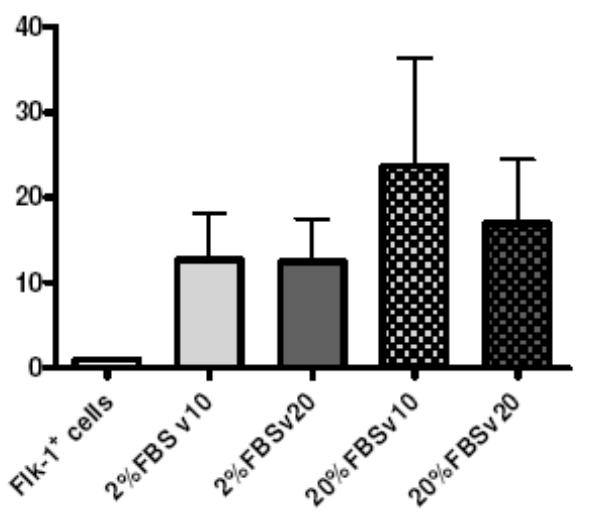

Isl1

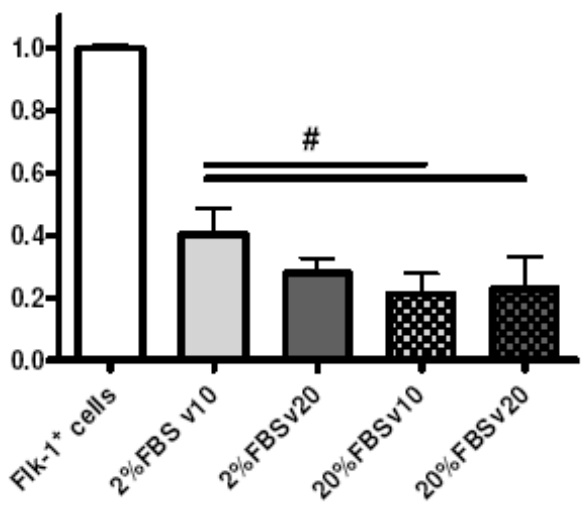

nanog

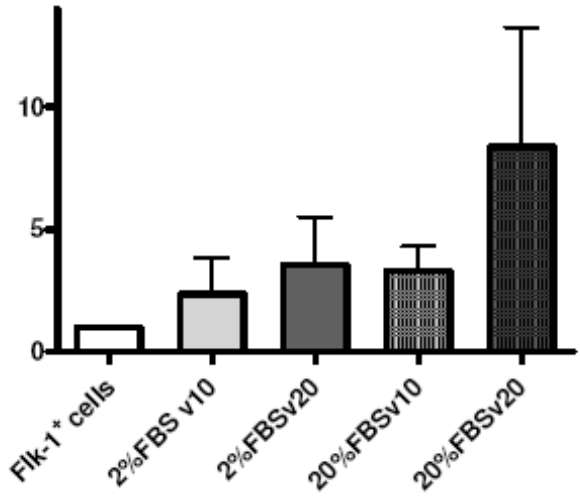

Figure 34. Quantitative real-time PCR analyses of gene expression in Flk- $\mathbf{1}^{+}$progenitor cells cultured under different culture conditions on day $\mathbf{5}+7$. The expression of Flk-1 in cells cultured in $2 \%$ FBS containing medium is maintained at a similar level when compared to $\mathrm{Flk}-1^{+}$progenitor cells. A higher expression of Isl1 appears in 2\% FBS containing medium with VEGF $10 \mathrm{ng} / \mathrm{ml}$ than in other three conditions. There is no significant difference in the expression of VE-cad and nanog among the groups. Data are shown as mean \pm S.D.; $\# \mathrm{P}<0.05 ; \mathrm{n}=3$ independent experiments. FACS sorted Flk $-1^{+}$cells at day $5+0$ served as positive control.

To determine whether the different culture conditions affect cell morphology, Flk- $1^{+}$cell-derived colonies were manually picked and subcultured under the same culture conditions. Of note, only the culture conditions with $10 \mathrm{ng} / \mathrm{ml}$ VEGF were tested based on the results from colony number (Figure $33 \mathrm{~B}$ ) and gene expression analyses (Figure 34). Distinctly different morphologies emerged in $2 \%$ and $20 \%$ FBS-containing medium. There were mainly $2 \mathrm{D}$ flat sheet-like cell clusters in $2 \%$ FBS-containing medium, which resemble the morphology of cardiac progenirtor cells (Moretti et al., 2006). On the other hand, 3D spheroid-like cell aggregates similar to EB were mainly found in 20\% FBS- 
containing medium. This could be the explanation of higher expression of nanog (Figure $35)$.
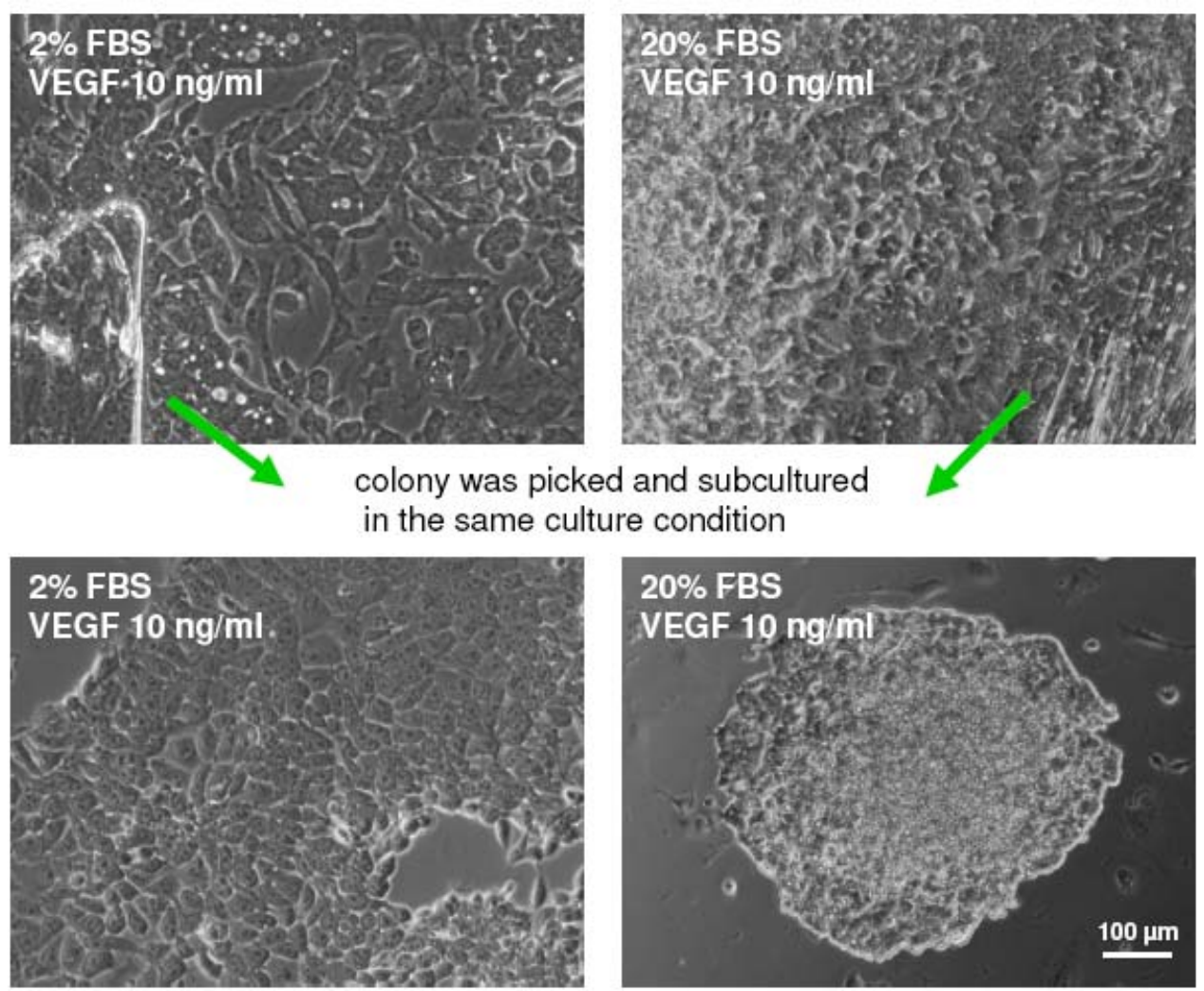

Figure 35. Effect of $2 \%$ and $20 \%$ serum concentration on Flk-1 ${ }^{+}$cell derived morphology. Cells were manually picked and replated in the same medium. 2D sheetlike cell clusters is observed in 2\% FBS-containing medium and 3D spheroid-like cell aggregates appear in $20 \%$ FBS-containing medium.

As shown in Figure 34, the expression of Is11 was lost in more than $50 \%$ of the cells, and therefore a second screening of culture conditions for long-term maintenance of Flk $-1^{+}$progenitor cells was performed by adding different growth factors, apart from VEGF, bFGF and EGF. Based on published protocols to maintain EPCs in culture (Marrotte et al., 2010; Santhanam et al., 2007), IGF-1, hydrocortisone, ascorbic acid and ECGS/H were added in different combinations to see whether these factors can recapitulate the progenitor property. The composition of the four different media used was as follows:

2\% FBS medium I: VEGF, bFGF and EGF $10 \mathrm{ng} / \mathrm{ml}$, N2B27 supplement, 1X 2\% FBS medium II: 2\% FBS medium I + IGF-1, $20 \mathrm{ng} / \mathrm{ml}$

$$
\text { Hydrocortisone, } 0.2 \square \mathrm{g} / \mathrm{ml}
$$


2\% FBS medium III: 2\% FBS medium II + ECGS/H, 0.4\%

$20 \%$ FBS medium III: same ingredients as $2 \%$ FBS medium III.

The cell number was recorded at day $5+7$, and data indicated a higher number of cell attachment when the cell culture medium was supplemented with $20 \%$ of serum. For example, cell number in $20 \%$ FBS medium III is significantly higher than in $2 \%$ FBS medium III $(P<0.001)$. Cell number in $2 \%$ FBS medium III is significantly higher than the cell cultured in $2 \%$ FBS medium II and I $(P<0.001$; Figure 36$)$.

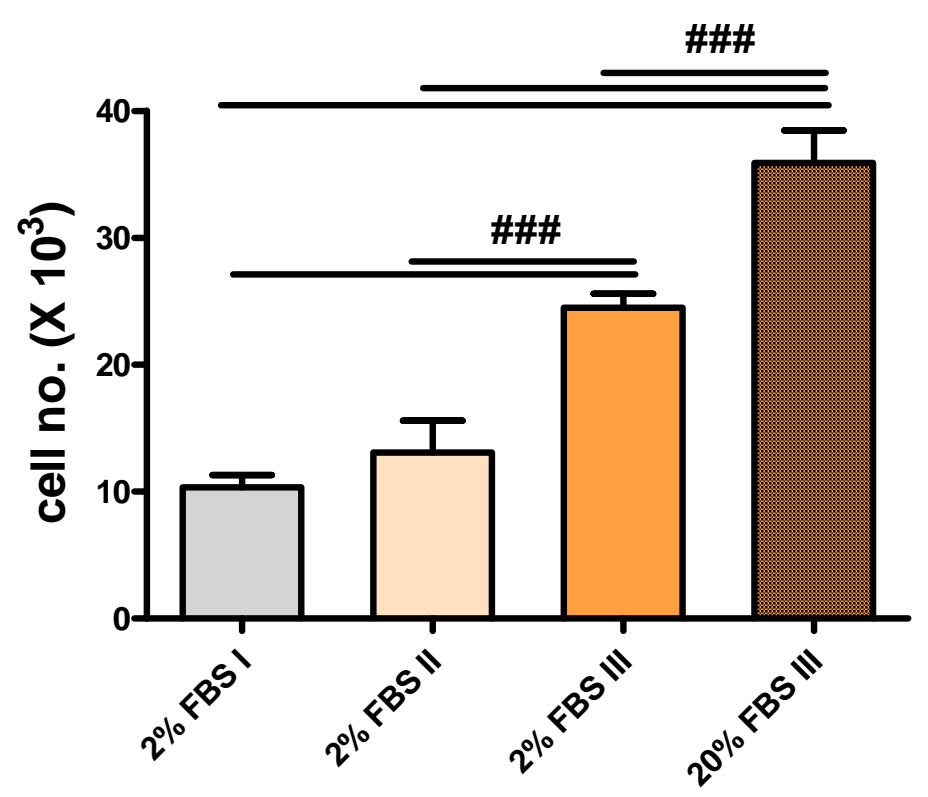

Figure 36. Effect of medium composition on the cell number. Cultures with addition of ECGS/H show significantly higher numbers of attached cells (medium III) and this finding is even more pronounced in the cells grown in $20 \%$ FBS medium III. Data are shown as mean \pm S.D, \#\#\# $\mathrm{P}<0.001, \mathrm{n}=3$ independent experiments.

On the morphological level, cells at passage 1 showed the ability to form colonies under all of the four culture conditions (Figure 37). The morphological difference is not obvious among three 2\% FBS-containing media, whereas the cells cultured in 20\% FBScontaining medium exhibited spheroid-like cell colonies as indicated by the lack of clear cell boundaries. 

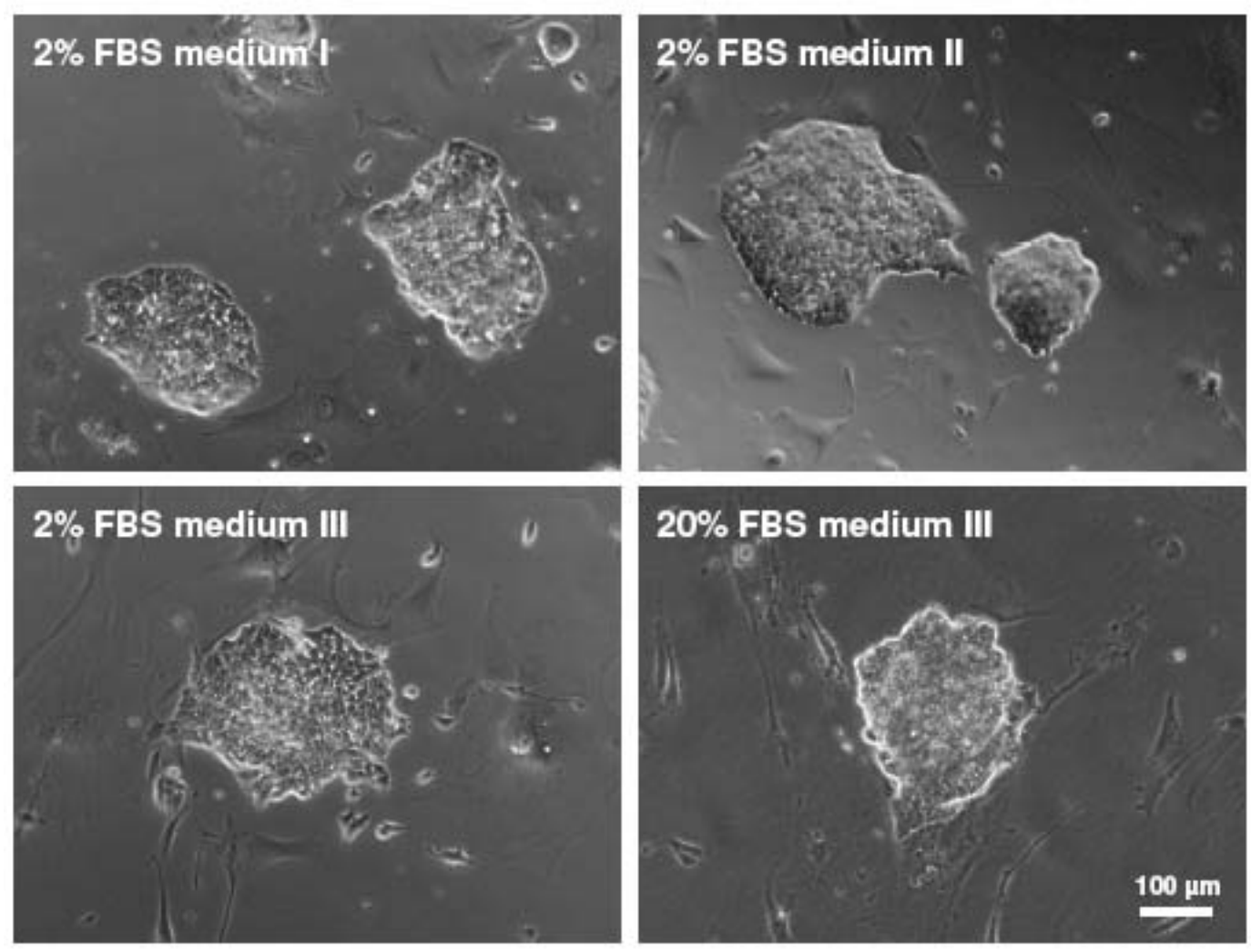

Figure 37. Analysis of the ability to form colonies. There is no obvious morphological difference among cultures in media containing $2 \%$ FBS. On the other hand, spheroid-like cell aggregates appear only in $20 \%$ medium III.

The mRNA expression was compared by semi-quantitative RT-PCR. Day 5+0 FACS-sorted Flk-1 ${ }^{+}$cardiovascular progenitor cells served as positive control. Cultures from passage 1, 4 and 8 were collected and examined for the expression of Flk-1 and Isl1. RT-PCR results indicated that the expression of Flk-1 and Is11 was better maintained in 2\% FBS medium III than those in other three conditions. For example, at passage 1, the expression of Flk-1 showed no significant difference among the four different culture media. On the other hand, the expression of Isl1 in the cells cultured in 2\% FBS medium III was maintained at similar level when compared to $\mathrm{Flk}-1^{+}$progenitor cells and significantly higher than the cells cultured in $2 \%$ FBS medium I and II $(P<0.05$; Figure 38). At passage 4, the expression of both Flk-1 and Isl1 was significantly higher in cells cultured in $2 \%$ FBS medium III (Figure 39) when compared to other media. The expression of Flk-1 and Isl1 was downregulated compared to earlier time points as the culture time increased. In particular, the expression of Isl1 reduced to $40 \%$ of the positive control at passage 8 (Figure 40). Hypothesizing that cells cultured under 2\% FBS medium III may be committed further towards the endothelial lineage, the expression of an early 
endothelial marker Tie-2 was examined. The results showed that the expression of Tie-2 was maintained at $80 \%$ level of the positive control, like Flk-1 at passage 8 (Figure 40).
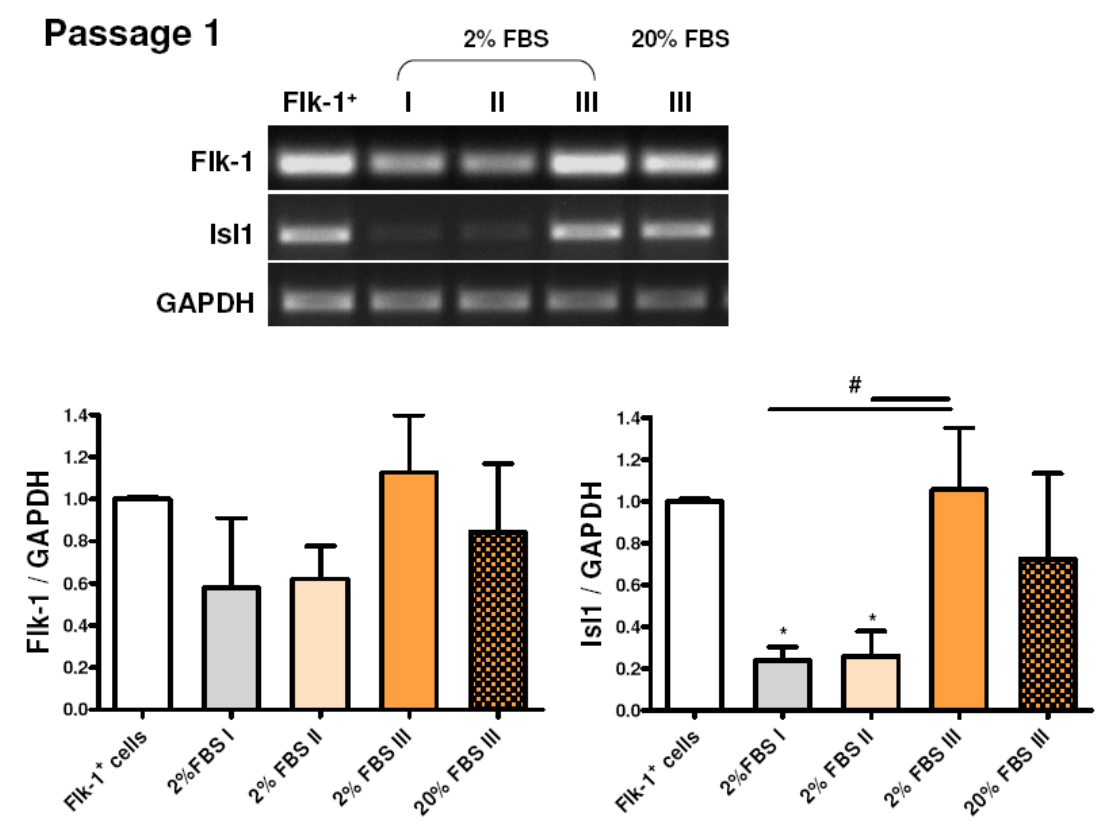

Figure 38. RNA expression of Flk-1 and Isl1 from cultures at passage 1. There is no significant difference in the expression of Flk-1 among all of the culture conditions. The cultures from $2 \%$ FBS medium III show significantly higher expression of Isl1 when compared to $2 \%$ medium I and II. Data are shown as mean \pm S.D.; * and \# $\mathrm{P}<0.05 ; \mathrm{n}=3$ independent experiments.
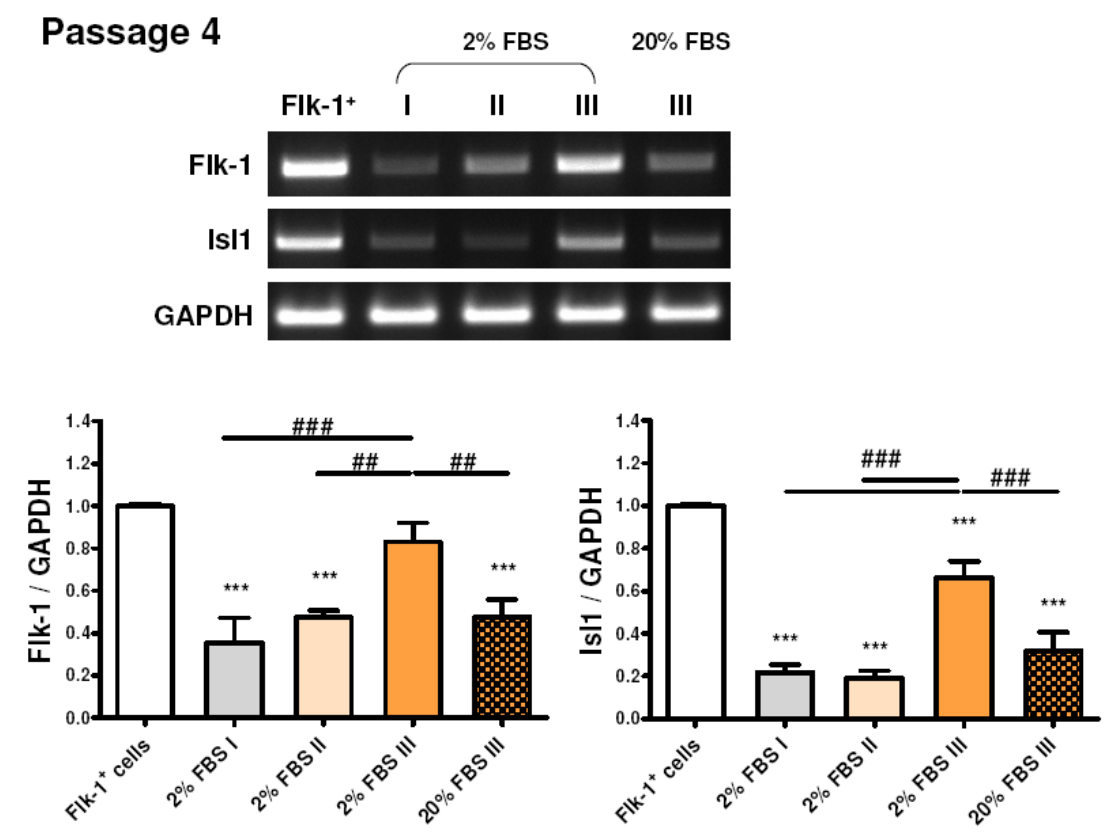

Figure 39. RNA expression of Flk-1 and Isl1 from cultures at passage 4. The cultures from $2 \%$ FBS medium III show significantly higher expression of Flk-1 and Isl1 when compared to other three conditions. Data are shown as mean \pm S.D.; ** and \#\# $\mathrm{P}<0.01,{ }^{* * *}$ and \#\#\# $\mathrm{P}<0.001 ; \mathrm{n}=3$ independent experiments. 


\section{Passage 8}
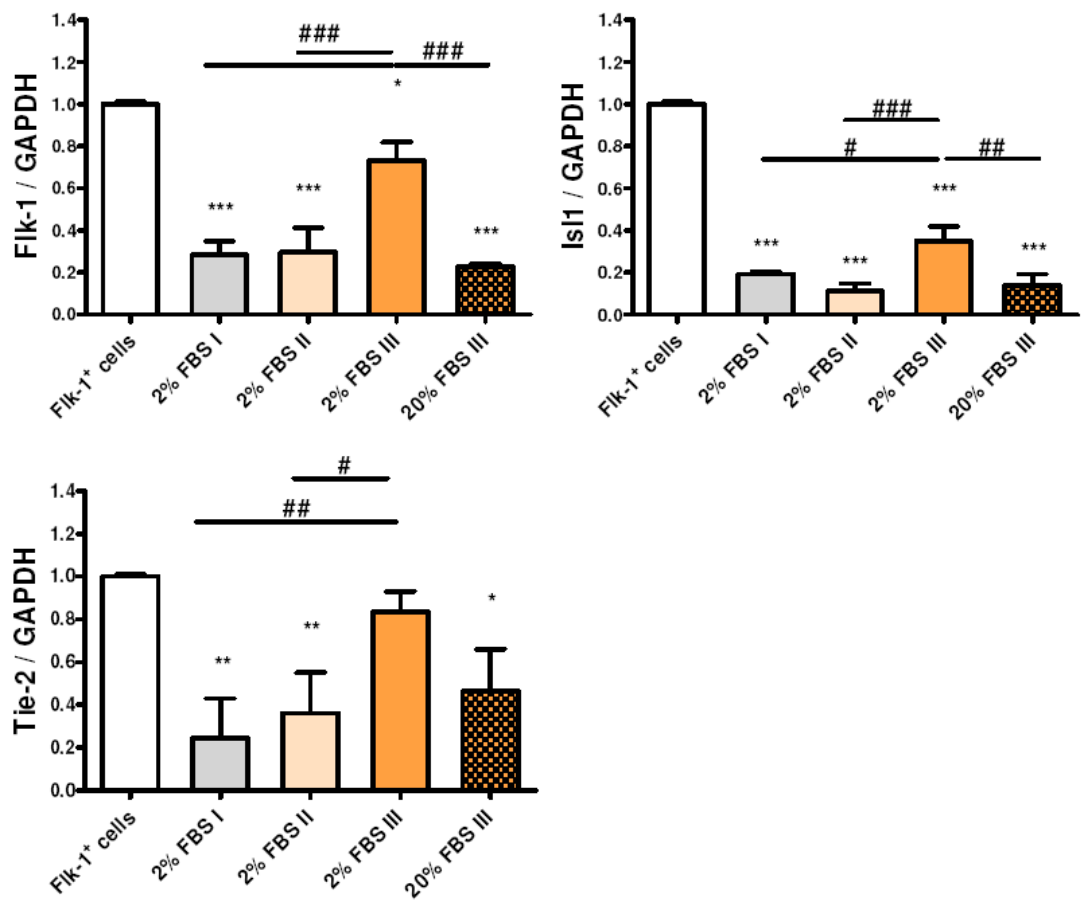

Figure 40. RNA expression of Flk-1, Isl1 and Tie-2 from cultures at passage 8. The cultures from $2 \%$ FBS medium III show significantly higher expression of Flk-1 and Isl1 when compared to other three conditions. The expression of Tie- 2 on the cells cultured in $2 \%$ medium III is significantly higher than those cultured in $2 \%$ medium I and II but is not significantly different from those cultured in $20 \%$ medium III. Data are shown as mean \pm S.D.; * and $\# \mathrm{P}<0.05$, ** and \#\# $\mathrm{P}<0.01, * * *$ and \#\#\# $\mathrm{P}<0.001 ; \mathrm{n}=3$ independent experiments. 


\subsubsection{In vitro characterization of long-term cultured Flk-1 ${ }^{+}$progenitor cells}

The finding that Flk-1 and Tie-2 were expressed in around $80 \%$ of Flk- $1^{+}$ progenitor cells at passage 8 indicate that these progenitor cells could be maintained to a certain extent. However, we could not exclude the possibility that the expression of Flk-1 and Tie-2 may have originated from differentiated ECs. Therefore, VE-cad and $\square$-SMA were used as markers to assess the presence of further differentiated vascular lineages beyond the progenitor state. Also, mesoderm posterior1 (Mesp1) was used as early cardiovascular marker (Saga et al., 2000) and nanog to visualize de-differentiated stem cells. Expression of both genes was examined in cells after culture in $2 \%$ FBS medium III until passage 12. The data showed that the expression of Flk-1 and Isl1 was detected, although a trend towards downregulated expression was observed. In addition, some cells appeared to have de-differentiated under the same culture conditions, as suggested by the upregulation of nanog expression over time. On the other hand, no expression of VE-cad and $\square$-SMA was detected indicating the absence of vascular differentiated cells (Figure
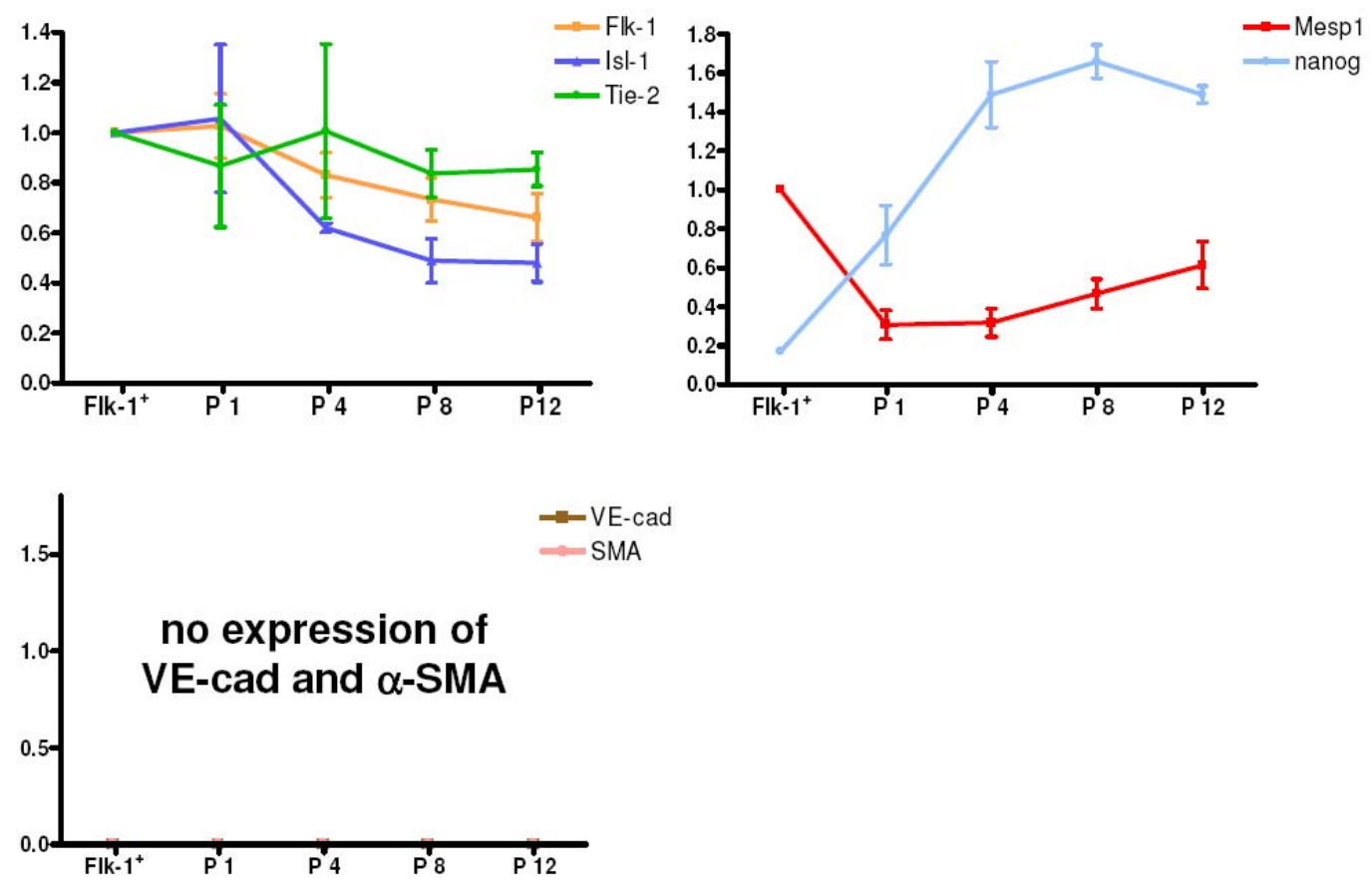

41). 
The upregulation of nanog RNA expression was further verified in protein level using flow cytometry. Around $5 \%$ of the presumptive Flk $-1^{+}$progenitor cells at passage 14-15 were $\mathrm{GFP}^{+}$cells (Figure 42).
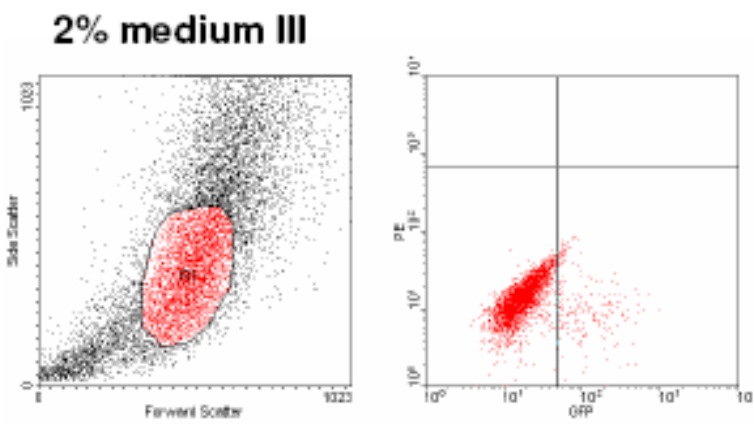

undifferentiated maGSCs
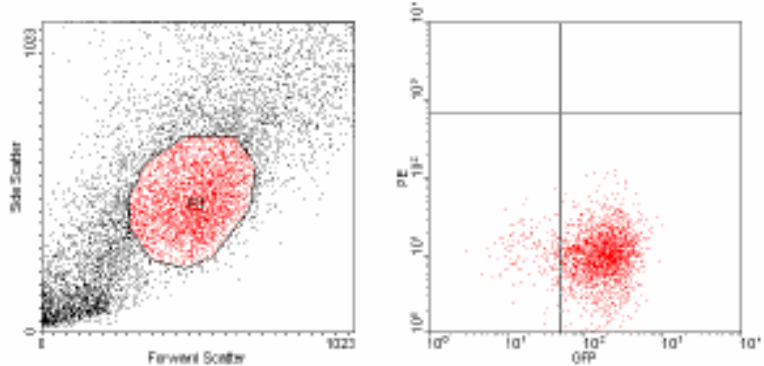

Figure 42. Analysis of GFP expression from cell cultures grown in $2 \%$ medium III by flow cytometry Around $5 \%$ of presumptive Flk- $1^{+}$progenitors cultured in $2 \%$ medium III are $\mathrm{GFP}^{+} \quad$ cells. Undifferentiated Stra8-EGFP ${ }^{+}$maGSCs served as positive control. $\mathrm{n}=3$ independent experiments.

To test whether long-term cultured cells grown in 2\% FBS medium III could maintain the distinct morphology of colony formation, the cell morphology was observed regularly. The cells exhibited 2D sheet-like clusters (Figure 43; representative findings in cells at passage 12 are shown), thus resembling the morphology of cardiac progenitor cells (Moretti et al., 2006).
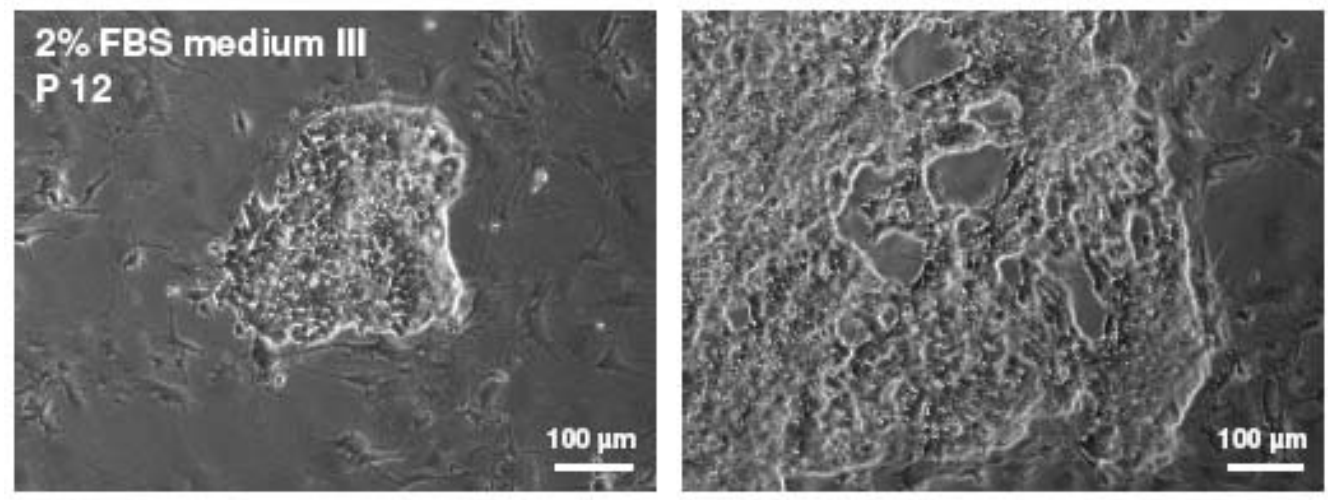

Figure 43. Morphology of Flk-1 ${ }^{+}$progenitors cells cultured in $2 \%$ FBS medium III at passage 12. The cells exhibit 2D sheet-like clusters. 
Presumptive $\mathrm{Flk}-1^{+}$progenitor cells were passaged every week and $1 \times 10^{4}$ cells were seeded in each well of 12-well plate. The cell numbers were recorded and showed the ability to proliferate (Figure 44).

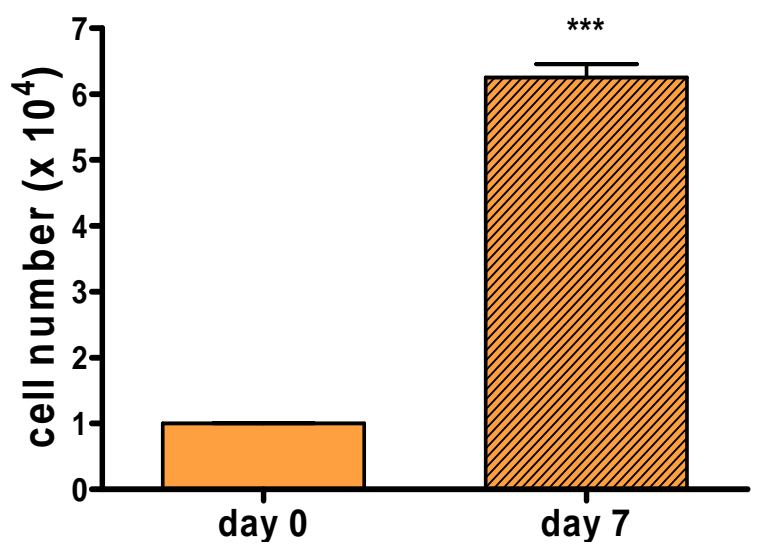

Figure 44. The presumptive Flk-1 ${ }^{+}$ progenitor cells can proliferate. Cell number was counted in every passage and found to increase approximately 6 times after 7 days of culture. Data are shown as mean \pm S.D., *** $\mathrm{P}<0.001$, $\mathrm{n}=3$ independent experiments.

\subsubsection{Protein expression of Flk-1 and Isl1 in long-term cultured Flk-1 ${ }^{+}$ progenitor cells}

According to the results shown in Figure 41, the mRNA expression of Flk-1 and Isl1 was gradually downregulated after long-term culture. To make sure these long-term cultured Flk-1 $1^{+}$progenitor cells still express the cardiovascular progenitor markers, the protein level of Flk-1 and Is11 in these cells was determined by flow cytometry. For this purpose, cells cultured in 2\% and 20\% FBS medium III at passage 13-15 were analyzed. Cells cultured in $20 \%$ FBS medium III at the same passages were selected as control because of the higher cell number that could be obtained when compared to the cells cultured in 2\% FBS medium I and II. Consistent with the above RNA expression profile, the results showed that approximately $70 \% \mathrm{Flk}-1^{+}$cells and $45 \% \mathrm{Is}^{+} 1^{+}$cells present in the cultures grown in $2 \%$ FBS medium III, which was significantly higher when compared to cells cultured in 20\% FBS medium III (Flk-1 expression, $70 \pm 7.1 \%$ in $2 \%$ medium III vs. $45.7 \pm 13.6 \%$ in $20 \%$ medium III, $P<0.001$; Isl1 expression, $39 \pm 9.2 \%$ in $2 \%$ medium III vs. $13.7 \pm 7.1 \%$ in $20 \%$ medium III, $P<0.01$, Figure 45$)$. These results indicate that a considerable number of progenitor cells were still present after 15 passages. 

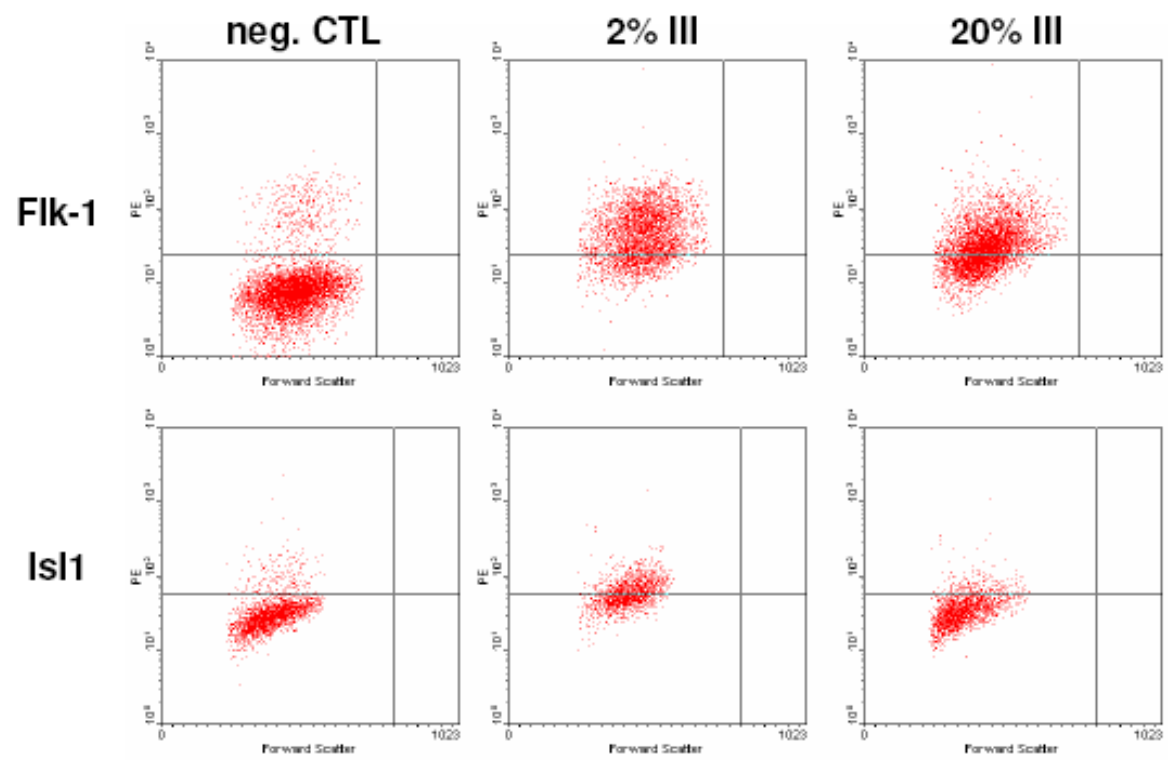

Is|1

Flk-1

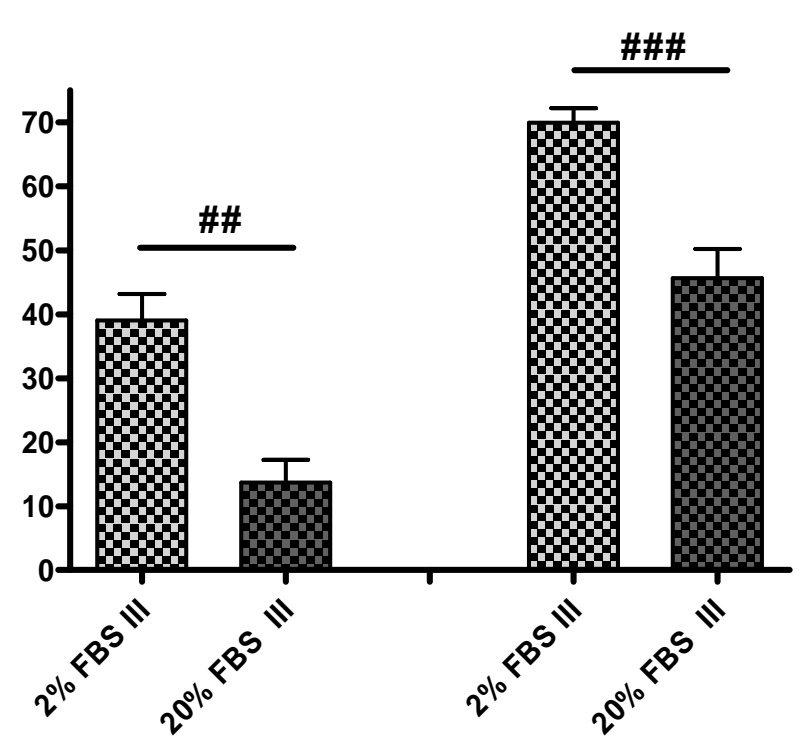

Figure 45. Comparison of Flk-1 and Isl1 expression from cell cultures grown in $2 \%$ and $20 \%$ FBS medium III by flow cytometry. Approximately $70 \%$ of cells express Flk-1 and $40 \%$ of cells express Isl1 when cultured in $2 \%$ FBS medium III at passage 13-15. The expression of both progenitor markers is significantly higher when compared to cells cultured in $20 \%$ FBS medium III. Data are shown as mean \pm S.D., \#\# $\mathrm{P}<0.01$, \#\#\# $\mathrm{P}<0.001, \mathrm{n}=3$ independent experiments. 


\subsubsection{Bipotency analysis of Flk-1 ${ }^{+}$progenitor cells}

To assess the bipotency of the long-term cultured presumptive Flk- $1^{+}$progenitor cells, cultures in 2\% FBS medium III at passage 12 were examined for their ability to give rise to vascular cells using the single cell assay. These immunocytochemical analyses revealed that cells derived from a single cell have the potential to express EC markers, e.g. VE-cad, as well as SMC markers, e.g. $\square$-SMA (Figure 46).
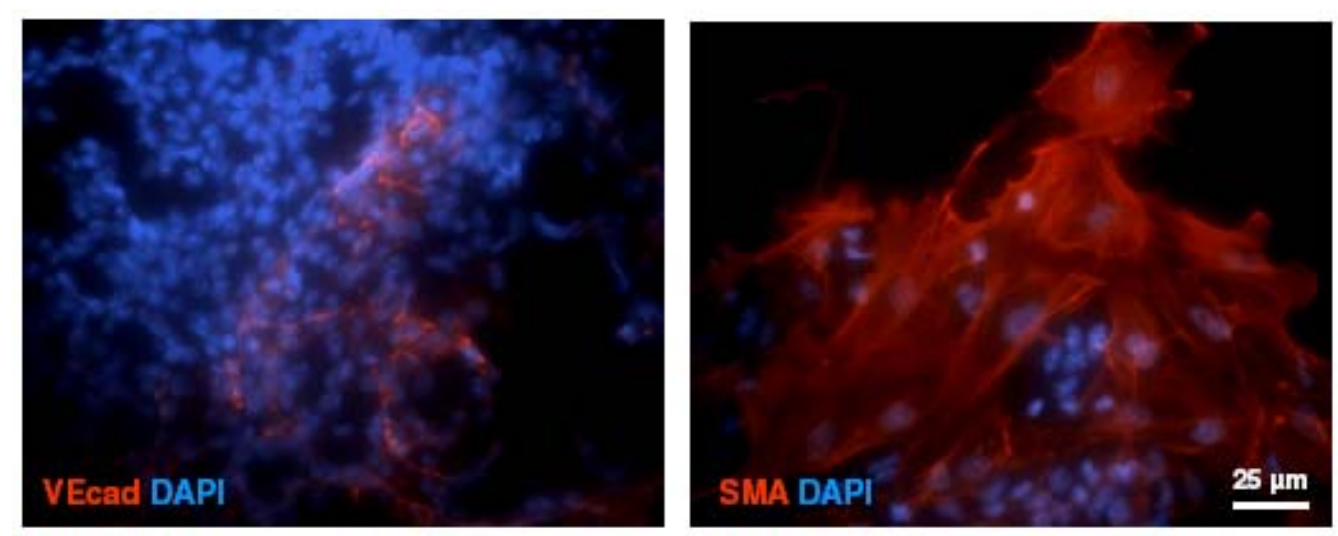

Figure 46. The presumptive Flk-1 ${ }^{+}$progenitor cells are bipotent. Cells originating from a single presumptive Flk- $1^{+}$progenitor cell express VE-cad and $\square \square$ SMA. Cell nuclei were stained with DAPI (blue).

\subsubsection{Angiogenic potential of the presumptive Flk-1 ${ }^{+}$progenitor cells}

To determine whether the presumptive $\mathrm{Flk}-1^{+}$progenitor cells have the potential to perform angiogenesis in vitro, cells cultured in 2\% FBS medium III at passage 13 were examined using the spheroid angiogenesis assay. Sprouting was observed 48 hours after culture in collagen type I (Figure 47).

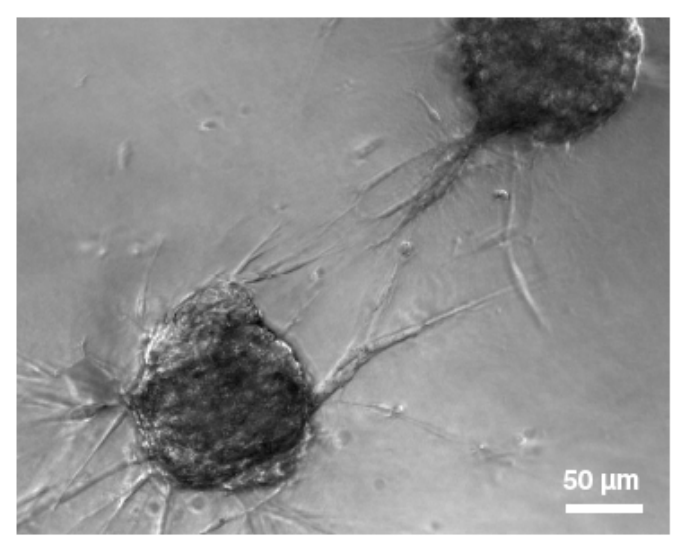

Figure 47. The presumptive Flk-1 ${ }^{+}$ progenitor cells are able to sprout. Cells cultured in $2 \%$ FBS medium III at passage 13 were used for 3D spheroid angiogenesis assay. Photos were taken 48 hours after culture in collagen type I. 


\subsubsection{Presumptive Flk-1 ${ }^{+}$progenitor cells spontaneously differentiate}

\section{into three cardiovascular lineages}

To evaluate the differentiation potential of long-term cultured presumptive Flk- $1^{+}$ progenitor cells, the cells at passage 13-15 were used for differentiation assay. Immunofluorescence analyses were performed 10-12 days after culture and demonstrated that presumptive $\mathrm{Flk}^{+} \mathrm{1}^{+}$progenitor cells give rise to three cardiovascular lineages: cardiomyocytes, ECs and SMCs (as shown by the expression of cardiac troponin $\mathrm{T}$ (cTNT), VE-cad and $\square$-SMA, respectively; Figure 48).
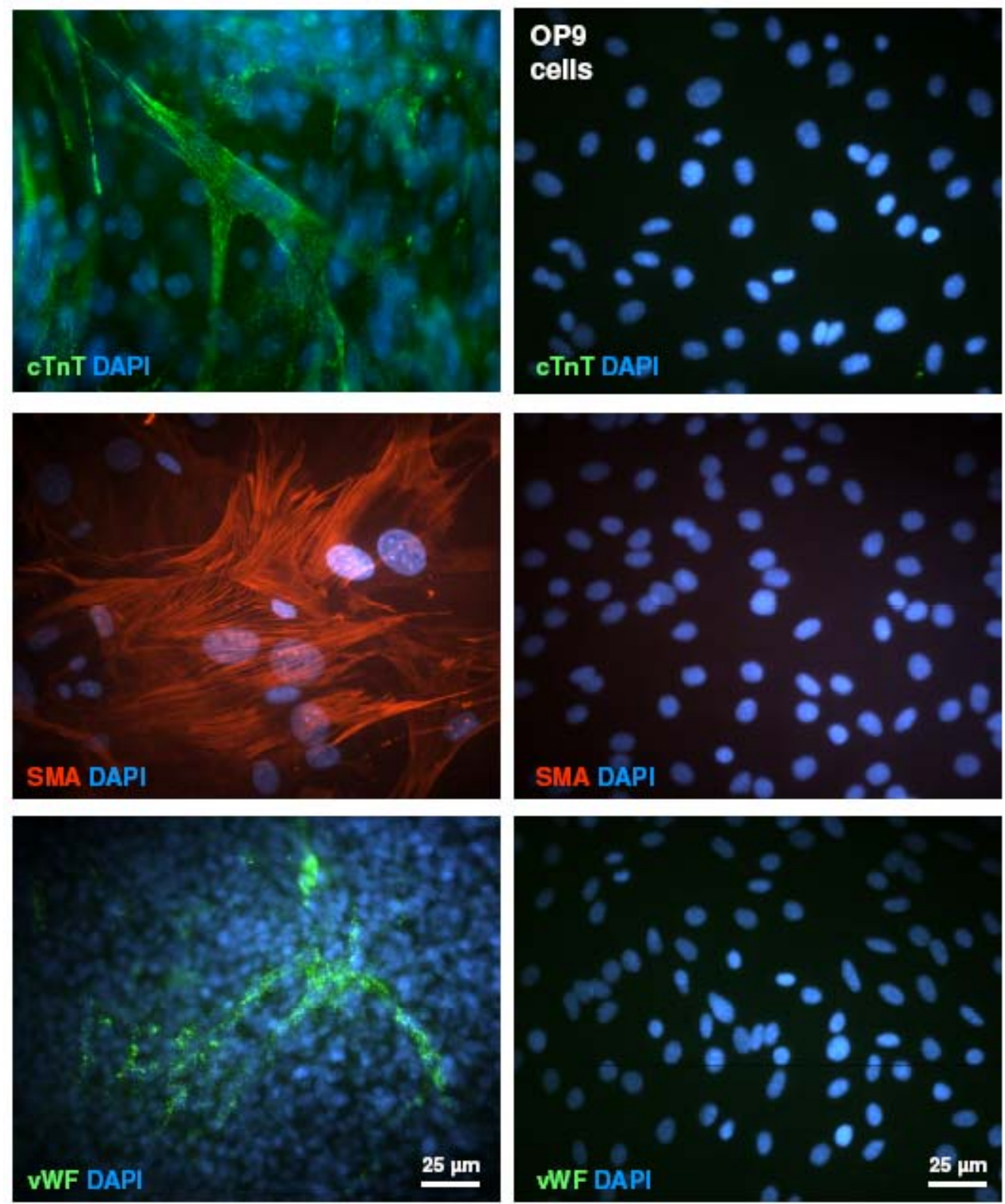

Figure 48. Immunostaining reveals that long term cultured presumptive Flk-1 $\mathbf{1}^{+}$ progenitors may give rise to three cardiovascular lineages. Spontaneous differentiation of Flk- $1^{+}$progenitor cells into cardiomyocytes, smooth muscle cells and endothelial cells in vitro, as assessed by expression of cTNT, $\square$-SMA and vWF, respectively. OP9 cells served as negative control (right column). Cell nuclei were stained with DAPI (blue). 
Taken together, Flk-1 ${ }^{+}$progenitor cells could be cultivated under culture condition of $2 \%$ FBS medium III, i.e. ECBM containing 2\% FBS, supplemented with VEGF, bFGF and EGF (10 ng/ml each), IGF-1, Hydrocortisone, Ascorbic acid, N2B27 and $\mathrm{ECGS} / \mathrm{H}$. These presumptive $\mathrm{Flk}-1^{+}$progenitor cells could be expanded with freezethaw cycles up to passage 15, and expression of the cardiovascular progenitor marker Flk-1 of approximately $70 \%$ could be maintained. Moreover, these presumptive Flk- $1^{+}$ progenitor cells were shown to possess bipotency as well as angiogenic potential and were able to spontaneously differentiate into three cardiovascular lineages in vitro. 


\section{Discussion}

Adult germline stem cells offer a novel route to cell-based therapy without immune rejection and ethical limitations. Cardiovascular progenitor cell- or EC-based therapy provides a strategy to improve tissue neovascularization for the treatment of cardiovascular diseases and an adequate amount of functional cells is required for this purpose. The present study showed the generation and expansion of Flk- $1^{+}$cardiovascular progenitor cells from mouse maGSCs as well as the differentiation of these cells into functional ECs in vitro and in vivo. First, we established a culture system that allows maGSC-derived Flk-1 ${ }^{+}$cells differentiating into functional ECs. These differentiated maGSC-ECs showed a typical endothelial morphology and gene expression patterns. In addition, they continued to proliferate and exhibit angiogenic potential both in vitro and in vivo. Second, we established a culture condition, under which cardiovascular progenitor cells proliferated rapidly and were maintained for at least 15 passages with freeze-thaw cycles. Under this culture condition, approximately $70 \%$ of cells retained Flk-1 expression and did not differentiate into vascular lineages. They were clonogenic and exhibited angiogenic potential in vitro. On the other hand, they were able to differentiate into all three cardiovascular lineages spontaneously when cultured on OP9 cells. This is the first study showing that cardiovascular progenitor cells can be expanded and maintained in vitro for long periods. However, the impurity, i.e. the continued existence of pluripotent stem cells, within cultures of both maGSC-ECs and long-term cultured Flk- $1^{+}$cardiovascular progenitor cells still limits their usefulness in clinical applications. Thus, future work in this area will have to focus on the purification of both cell types.

\subsection{MaGSCs may be useful as alternative cell source for the generation of cardiovascular progenitor and endothelial cells}

In the present study, we successfully generated Flk- $1^{+}$cardiovascular progenitor cells as well as functional ECs from mouse maGSCs. In previous studies, it has been demonstrated that maGSCs can be derived from adult SSCs under in vitro culture conditions. The generated maGSCs show similar properties to mouse ESCs (Guan et al., 
2006). It has been reported that maGSC culture could be established from adult human testis (Conrad et al., 2008). However, this was questioned by a recent study (Ko et al., 2010). If the technique could be transferred to human tissue, this could overcome problems associated with ethical concerns and immunorejection related to human ESCs, although this technology will only be available in males. So far, mouse maGSCs have been shown to be able to further differentiate into functional cardiomyocytes (Guan et al., 2007), neurons (Glaser et al., 2008; Streckfuss-Bomeke et al., 2009) and male germ cells (Nolte et al., 2010), whereas the generation of endothelial differentiation from maGSCs has not been systematically studied.

Generation of a differentiated cell type from pluripotent stem cells in vitro offers a powerful approach for studying lineage induction. Pluripotent stem cells are undoubtedly a promising source of progenitor cells or differentiated cells for cell-based therapy, as these "healthy" cells can repopulate the cell number and regenerate the function of defective or dysfunctional cells. A myriad of diseases, conditions and disabilities, among these diseases with a high morbidity and mortality such as diabetes, Parkinson's disease, ischemia and myocardial infarction, that result from cell loss or dysfunction are potential candidates for cell-based therapy. Several cell sources may be used for the in vitro differentiation into cardiovascular lineage. ESCs, adult stem cells, bone marrow or peripheral blood-derived EPCs (Figure 49) as well as a recent celebrity, induced pluripotent stem (iPS) cells. Their advantages and disadvantages will be discussed below.

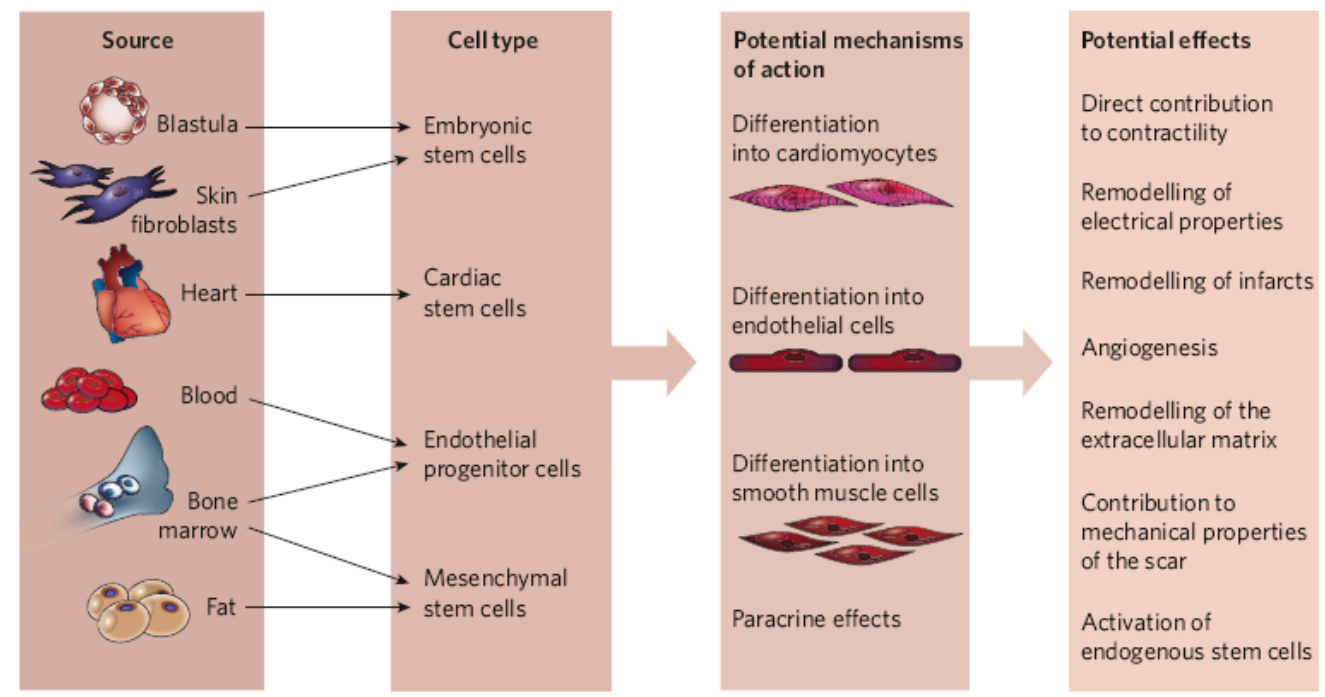

Figure 49. Different cell types that have been considered for cell-based therapy. Adapted from (Segers, 2008) 
ESCs are the most often used cell source for in vitro differentiation studies. ESCs possess multipotent differentiation potential of any cell type present in the adult organism. However, the pluripotency and fast growth kinetics of ESCs also are their major disadvantage, because these characteristics will produce undefined cell growth in vivo, giving rise to teratoma formation. Additionally, there are ethical concerns, and immunogenetic complications that need to be addressed before the cells can be clinically applied. In this regard, a graft immunogenic rejection may be avoided by using EPCs or iPS cells.

EPCs were first successfully isolated from human peripheral blood by Asahara in 1997 (Asahara et al., 1997), and his findings were a major milestone for cardiovascular regenerative medicine. Later studies have shown that EPCs can be isolated from bone marrow or peripheral blood and are a subpopulation of mononuclear cells. Numerous studies have shown that circulating EPCs isolated from adult peripheral blood were capable of differentiating into ECs in vitro and promoting neovascularization in vivo (Asahara et al., 1997; Kalka et al., 2000). However, the characterization of EPCs is not clearly defined, possibly due to the fact that there is no marker specific for EPCs. For example, uptake of acLDL and lectin binding ability are commonly used to identify EPCs, but this is also a phenotype observed in monocytes, macrophages and mature ECs (Schatteman et al., 2007). EPC-related nomenclature is often confusing, such as circulating angiogenic cells (CACs) are sometimes referred to as EPCs even though they most likely describe a different cell population with paracrine angiogenic activity (Kovacic et al., 2007; Shepherd et al., 2006). Besides, EPCs from patients with diabetes mellitus type II showed a decreased ability to proliferate and to form capillary tubes in vitro (Tepper et al., 2002). Moreover, EPCs expanded from the obese subjects showed reduced adhesive, migratory, and angiogenic capacity (Heida et al., 2010). Since cardiovascular risk factors have been shown to impair EPC functional capacities, their application and autologous transplantation for the regeneration of endothelial dysfunction or loss in patients suffering from these conditions may be limited.

iPS cells can be derived autologously but the high risk of teratoma formation remains. The iPS cells are generated by forced expression of four transcription factors via viral infection. For example, Oct4, Sox2, c-myc and Klf4 or Oct4, Sox2, nanog and lin-28 into adult human somatic cells (Takahashi et al., 2007; Yu et al., 2007); or in the mouse 
system (Yamanaka and Takahashi, 2006). However, these viral vectors which are inserted into the genome of the iPS cells could result in unpredictable genetic dysfunction and may be associated with tumor formation (Okita et al., 2007). The focus is now on adult stem cells, which allow that the cells to be transplanted are derived from the patient oneself (autologous transplantation) or from a healthy donor (allogeneic transplantation). In the case of allogeneic transplantation, HLA (human leukocyte antigen) matching between the donor and recipient is an important prerequisite for a successful application (Sloan, 1997). Unfortunately, HLA-matched donors are available only for a minority of patients.

Several studies have shown that multipotent Flk-1-positive or Isl1-positive cardiovascular progenitor cells can be generated from ESCs (Yang et al., 2008) and iPS cells (Moretti et al., 2010). They were able to differentiate into cardiomyocytes, ECs and SMCs under proper culture conditions. In this regard, no study has so far demonstrated the differentiation of cardiovascular progenitor cells from adult germline stem cells and also, the endothelial differentiation potential from these progenitor cells is unknown. The present study showed that $\mathrm{Flk}-1^{+}$cells can be generated from maGSCs indicating that maGSCs is an alternative cell source for the generation of cardiovascular progenitor cells and ECs.

\subsection{Collagen type IV is superior in supporting endothelial cell differentiation}

The present study showed that COLIV, compared to FN and GFR matrigel, is more suitable for supporting differentiation of maGSC-derived Flk- $1^{+}$progenitor cells into functional ECs.

There are at least two factors that govern endothelial function and maturation, i.e. soluble and insoluble factors (Ingber and Folkman, 1989). Soluble growth factors, such as VEGF, EGF and bFGF play an important role in both angiogenesis and the function of blood vessels (Pepper et al., 1996; Smith, 1995). Insoluble factors, including ECM proteins, promote capillary organization and direct the proliferation and differentiation of ECs in response to growth factors (Ingber and Folkman, 1989). Components of ECM proteins may also directly influence the differentiation potential of stem cells. For example, COLIV had been reported to direct mouse ESC differentiation to mesodermal (Yamashita 
et al., 2000) and trophoectodermal (Schenke-Layland et al., 2007) lineages. Collagen type VI may induce cardiac myofibroblast differentiation (Naugle et al., 2006).

COLIV has been extensively used to support both human (Gerecht-Nir et al., 2003) and mouse (Nishikawa et al., 1998; Schenke-Layland et al., 2008; Yamashita et al., 2000) ESC differentiation into mesodermal cell lineage. However, there is no study showing a significant difference between COLIV and other ECM proteins in the light of their mesodermal differentiation efficiency. To compare different coating matrices, COLIV was our first candidate. COLIV isolated from Engelbreth-Holm-Swarm (EHS) lathrytic mouse tumor has been often used for mesodermal differentiation. Of note, the COLIV used in the present study was obtained from human placenta. It remains to be determined in the future studies whether these different sources of collagen (human placenta and murine tumor) might have different effect on promoting Flk- $1^{+}$cell differentiation. On the other hand, the ability of COLIV extracted from mouse may be more compatible with ECMmediated differentiation to mouse derived germline stem cells.

FN was the second candidate because it is frequently used as a coating matrix for the culture of EPCs (Friedrich et al., 2006; Heida et al., 2010). EPCs are mostly defined as bone marrow or peripheral blood-derived mononuclear cells that can differentiate into ECs in vitro and induce neovascularization in vivo (Asahara et al., 1997; Asahara et al., 1999; Klein et al., 2010). Furthermore, one of the markers for EPCs is VEGFR2 (Friedrich et al., 2006; Hristov et al., 2003), which shows the resemblance to the cell we sought to obtain. Besides, FN has been shown to promote VEGF-induced differentiation of human EPCs into ECs (Wijelath et al., 2004).

GFR matrigel is a mixture consisting mainly COLIV and laminin. Laminin is a major structural protein of basement membrane and can induce endothelial differentiation into capillary-like structures (Kubota et al., 1988; Schnaper et al., 1993). Matrigel itself has been used to induce endothelial differentiation from murine embryonic yolk sac cells (Li et al., 1999) and ESCs (Yin et al., 2004). GFR matrigel is a variant of normal matrigel that contains a lower amount of growth factors such as EGF and IGF-1, which are also part of the growth factors used to induce endothelial differentiation. Thus, GFR matrigel in combination with growth factors were used for the screening of optimal ECM proteins. 
As mentioned previously, the majority of previous analyses have pointed to COLIV as a better choice for mesodermal lineage differentiation. Our studies also demonstrated that COLIV is a potent inducer of endothelial differentiation in vitro and are thus consistent with previous findings. Nishikawa et al. have compared dishes coated with gelatine, FN, collagen type I and IV according to their ability to differentiate ESCs to lateral mesodermal lineage and found that COLIV supports mesodermal lineage differentiation, although it should be kept in mind that they have used commercially coated dishes with COLIV extracted from mouse (Nishikawa et al., 1998). In present studies, COLIV was selected according to the expression of vascular-specific genes and proteins in differentiated cells as well as their angiogenic potentials. For example, COLIV exhibited the highest ability to support the growth of $\mathrm{Flk}-1^{+}$cells, induce EC proliferation, differentiation and exert higher angiogenic potential. However, according to the cell adhesion ability, we found that a significantly higher number of cells attached to GFR matrigel when compared to FN and COLIV. On the other hand, real-time PCR results suggest that cell types other than endothelial lineages might be responsible for these findings since the expression of endothelial markers, such as Flk-1, Tie-2 and VE-cad was significantly lower in cell grown on GFR matrigel. According to these findings, the different effects that these ECM proteins have on cell proliferation or differentiation can be applied in cell culture. Understanding the mechanism of certain ECM protein that drives the cells to proliferate or differentiate may allow us to use different ECM proteins according to the specific requirements during developmental period. For example, COLIV could be used initially to induce endothelial differentiation and later on, GFR matrigel may be used to support the expansion of more differentiated ECs. Of note, GFR matrigel is extracted from the EHS mouse tumor and its composition and quality may vary from batch to batch. These differences may cause inconsistent cellular responses and make any comparison difficult.

\subsection{VEGF promotes endothelial cell differentiation}

It has been previously shown that all three ECM proteins can induce endothelial differentiation (Li et al., 1999; Nishikawa et al., 1998; Wijelath et al., 2004). Similarly, our results showed that the expression of EC-related genes, such as Flk-1, Tie-2 and eNOS also occurred in the absence of VEGF supplementation in all three coating conditions, although to a lesser extent. In addition to the possibility of ECM-mediated or -induced 
differentiation, spontaneous differentiation may have also occurred during the culture. We have compared the culture condition with or without stimulation of VEGF during the screening of three ECM proteins. We found that the number of $\mathrm{Flk}^{+}{ }^{+}$cells was significantly reduced in cultures without addition of VEGF. Moreover, the formation of tube-like structures linked by vWF-positive cells also was only observed after addition of VEGF. Furthermore, we observed (using the spheroid angiogenesis assay) that the angiogenic potential exerted from $\mathrm{Flk}-1^{+}$progenitor cells was enhanced by the addition of VEGF. Taken together, these results confirm that VEGF is essential for endothelial differentiation and angiogenesis, and this observation is consistent with other groups. For example, it has been found that cultures without VEGF generated mostly mural cells and no ECs (Lanner et al., 2007; Yamashita et al., 2000).

Future studies will have to study in more detail how this endothelial differentiation process is controlled at the molecular level and how VEGF can promote endothelial lineage specification of Flk $-1^{+}$maGSCs. In this regard, the upstream cues to initiate VEGF/Flk-1 expression have not been specified in detail in this field. Also, downstream signalling pathways, such as the Ang/Tie and Notch signalling pathway, are known to play crucial roles in the remodelling of capillary plexi (Suri et al., 1996) and arterial endothelial differentiation (Fischer et al., 2004; Lanner et al., 2007; Lawson et al., 2002), respectively. Evidently, the formation of blood vessel involves multiple signalling pathways that communicate with one another in order to regulate gene expression during endothelial differentiation. As shown in Figure 50, several molecules have been shown to regulate the processes of vasculogenesis and angiogenesis. Among them, two subfamilies of mammalian receptor tyrosine kinase are introduced below due to their close relation to vascular development, namely the family of VEGFRs and Ang receptors. 


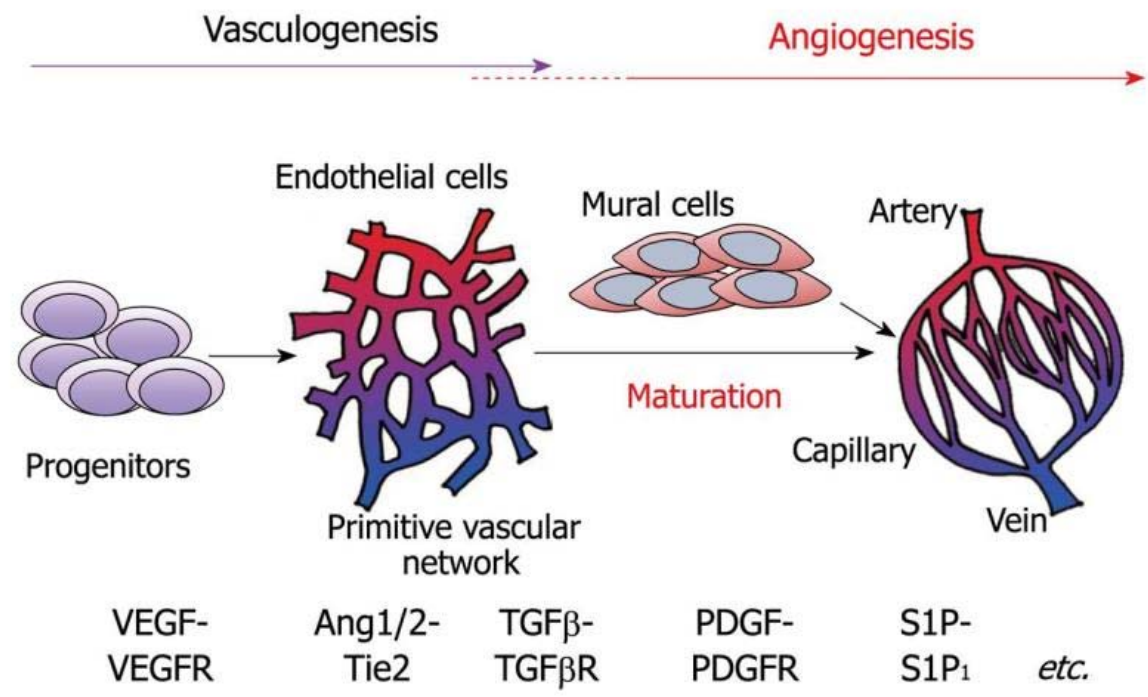

Figure 50. Various of growth factors and their receptors play important roles during vasculogenesis and angiogenesis. Adapted from (Takuwa, 2010)

VEGFRs are essential for vascular development. In mammals, there are five VEGF ligands which bind to three VEGFRs, known as VEGFR-1 (fumes-like tyrosine kinase, Flt-1), -2 (KDR/Flk-1, fetal liver kinase-1) and -3 (Flt-4), in an overlapping pattern (Olsson et al., 2006).

VEGFR-1 was the first receptor identified for VEGF (de et al., 1992). VEGFR-1 is expressed on angioblasts and vascular endothelium as well as on hematopoietic cells (Rafii et al., 2002). It is required for blood vessel morphogenesis. For example, homozygous deletion of VEGFR-1 results in severe malformation of the vasculature and mice die at embryonic day 8.5. Besides, ECs develop but do not organize into vascular channels (Fong et al., 1995; Fong et al., 1999).

VEGFR-2 marks a common mesodermal precursor and is the earliest differentiation marker of ECs (Yamaguchi et al., 1993). VEGFR2 expression is restricted to mesodermal precursors and ECs, and is downregulated in hematopoietic cells (Risau, 1997). Mice deficient in Flk-1 die between embryonic day 8.5 and 9.5, because they are unable to form yolk sac blood islands (Shelby et al., 1995). Furthermore, homozygous Flk$1^{-/-}$ESCs do not contribute to endothelial lineages and primitive hematopoiesis in chimeric 
yolk sacs or definitive hematopoiesis in adult chimeras and chimeric fetal livers (Shalaby et al., 1997). It also has been shown that VEGFR-2 is involved in the regulation of EC migration, proliferation, differentiation, survival and vessel permeability (Cebe-Suarez et al., 2006). VEGFR-2 mediated proliferation of ECs can be suppressed by VEGFR-1 (Rahimi et al., 2000; Zeng et al., 2001) indicating that VEGFR-1 is a regulator of VEGFR2.

VEGFR-3 plays a role in lymphangiogenesis. The expression of VEGFR-3 starts at mouse embryonic day 8.5 in all ECs and gradually becomes restricted to lymphatic endothelium during later development (Kaipainen et al., 1995). Dumont et al. used targeted inactivation of the gene encoding VEGFR-3 to determine its role and found defective blood vessel development in early mouse embryos. Vasculogenesis and angiogenesis occurred, but large vessels became abnormally organized with defective lumens leading to embryonic death at day 9.5 (Dumont et al., 1998).

Tie-2 is a receptor tyrosine kinase. There are four known angiopoietins (Ang), namely Ang1, 2, 3 and 4, all of which bind to Tie-2 (also called Tek). Tie-2 is expressed on ECs and hematopoietic stem cells (Dumont et al., 1992; Iwama et al., 1993; Sato et al., 1998). Tie-2 and Ang1 are both essential for blood vessel remodelling during embryonic angiogenesis (Eklund and Olsen, 2006; Suri et al., 1996). Targeted deletion of the Tie-2 gene results in early embryonic lethality because of vascular abnormalities (Sato et al., 1995). Tie-2 maintains vascular integrity by enhancing endothelial barrier function (Brindle et al., 2006; Gamble et al., 2000) and inhibiting apoptosis of ECs (Kwak et al., 1999; Papapetropoulos et al., 2000). Even though many genes involved in vessel formation have been identified, there are more to be discovered. In this study, Tie-2 was used to characterize endothelial lineage. Consistent with the expression of Flk-1, Tie-2 was only expressed in FACS sorted Flk- $1^{+}$cell population and its expression was progressively upregulated in endothelial differentiation culture, which is similar with other differentiated EC markers.

\subsection{In vitro endothelial differentiation from maGSCs}

ECs are one of the main cellular components involved in the formation of blood vessels. They can promote stem cell development and organ formation by exerting 
paracrine signals to surrounding cells (Coultas et al., 2005). Angiogenic therapy may be used to improve blood flow and function of ischemic tissues, and the generation of proliferating and functional ECs is essential for this purpose (Alaiti et al., 2010). In the last decade, accumulating evidence indicates that ES cells can differentiate into endothelial cells in vitro and in vivo (Balconi et al., 2000; Yin et al., 2004; Huang et al., 2010; Wang et al., 2007; Kaufman et al., 2004; Hirashima et al., 1999). Selection markers such as Flk-1 (Lanner et al., 2007; Li et al., 2007; McCloskey et al., 2003; Narazaki et al., 2008; Schenke-Layland et al., 2008; Yamashita et al., 2000), CD34 (Levenberg et al., 2010; Wang et al., 2007), VE-cad (Huang et al., 2010), vWF (Cho et al., 2007) and PECAM-1 (Levenberg et al., 2010; Yu et al., 2009) have been chosen by most groups.

Our data show that lineage selection is necessary. Day 5 predifferentiated maGSC contained around $35 \%$ of Flk- $1^{+}$progenitor cells. Without the selection of Flk-1 ${ }^{+}$cells, the number of Flk- $1^{+}$cells was reduced to $27 \%$, after cultivation on COLIV-coated culture dishes in the presence of VEGF. Direct transplantation of pluripotent cells could be therapeutic for angiogenic diseases if a sufficient degree of vascular differentiation can be reached spontaneously; however a more likely outcome is undirected differentiation (i.e. teratoma formation), as is observed after ESC transplantation (Nussbaum et al., 2007). Previous studies showed that 4 weeks after transplantation of undifferentiated maGSCs into the normal heart of immune-suppressed mouse, only few cells differentiated into vascular ECs and SMCs although no teratoma formation was observed (Guan et al., 2007). Therefore, protocols must be developed to establish lineage-selection before the use of pluripotent stem cells in organ regeneration strategies.

The two major challenges we faced during endothelial differentiation were obtaining a pure EC population as well as fully differentiated ECs. For example, in our results of in vitro EC characterization, around $15 \%$ of smooth muscle-like cells were present in the whole population. Previous studies suggest that second selection is necessary for obtaining pure endothelial population. One study used Flk-1 as the first and VE-cad as the second marker 4 days later and found that $95.9 \%$ of cells were positive for VE-cad, however, only $16.2 \%$ Flk $-1^{+}$cells were detected ( $\mathrm{Li}$ et al., 2007). McCloskey et al. sorted day 4 predifferentiated mouse ESCs with Flk-1, followed by the second manual selection based on the cobblestone-like endothelial morphology. They could obtain $96 \%$ of ECs, but may lack complete functional maturation in vitro (McCloskey et al., 2006). In this study, 
the manual selection as mentioned above was performed; however, the cells still appear heterogeneous later in the culture (data not shown). Thus, a second FACS sorting, for example with antibodies against PECAM-1 or VE-cad, should be considered for further purification of EC population. However, PECAM-1 is not endothelial-specific and may also be found in various cells of the haematopoietic lineage (Slieker et al., 1993; Watt et al., 1993). The measurement of VE-cad expression by FACS was not compatible with live cell staining, since cells needed to be fixed prior to staining with antibodies against VEcad.

Moreover, approximately $15 \%$ of cells at passage 6 were still positive for $\alpha$ SMA. The results indicate that Flk $-1^{+}$cells are able to differentiate into both endothelial and SMCs, and application of VEGF promote endothelial differentiation and inhibit SMC differentiation. Downregulation of $\square$-SMA expression at later time points suggests that cultivation for long periods may be necessary to increase the purity of cultures with respect to ECs. On the other hand, differentiation and cooperation of both endothelial and mural cells has been shown to be necessary for stable blood vessel maturation (Evensen et al., 2009). Moreover, previous studies using the murine hindlimb ischemia model have indicated that the combined transplantation of both ECs and mural cells was superior in achieving a significant augmentation of neovascularization when compared to ECs or mural cells alone (Yamahara et al., 2008).

Interestingly, the RNA expression of markers for vascular SMCs (e.g. $\square$-SMA) was found to be expressed at higher levels in the Flk-1 ${ }^{\text {low/- }}$ and undifferentiated $\mathrm{GFP}^{+}$cells compared to the $\mathrm{Flk}-1^{+}$cell population at early time points, and its expression was progressively downregulated during differentiation. Regarding the possibility that Flk-1 ${ }^{-}$ cells may possess the potential to differentiate into ECs, published previously (Schuh et al., 1999). Our RT-PCR results also suggest that Flk-1 ${ }^{\text {low/- }}$ and $\mathrm{GFP}^{+}$cells had the potential to differentiate into the endothelial lineage, although to a lesser extent, as suggested by the expression of EC-related markers, such as Tie-2 and vWF. The possible reason for this observation may be the secondary expression of Flk-1 that arose from initially Flk-1 ${ }^{-}$cells, as previously reported (Yang et al., 2008). Of note, only Flk-1 $1^{+}$, but neither Flk-1 ${ }^{\text {low/- }}$ and $\mathrm{GFP}^{+}$, nor OP9 cells were found to express Flk-1 immediately after FACS-mediated selection for Flk-1. 
The functional assays used in this study were 2D matrigel and 3D spheroid angiogenesis assay in vitro. The in vivo functional assay was based on spheroid formation. Vascular ECs can organize into capillary-like structures, and the 3D spheroid angiogenesis assay, in which ECs are cultured in 3D spheroids and embedded in collagen gels or matrigel, has been widely used to study the processes involved in the formation of capillary tubes in vitro (Korff et al., 2004) and in vivo (Alajati et al., 2008; Laib et al., 2009), respectively. Use of this two models revealed that $\mathrm{Flk}-1^{+}$cardiovascular progenitor cells and maGSC-ECs possess angiogenic potential. This ability to form capillary-like structures on matrigel or to sprout have been frequently used to characterize ECs (Li et al., 2007; Huang et al., 2010; Lanner et al., 2007; Nakahara et al., 2009). On the other hand, it is also important to remember that these cell culture systems are devoid of blood flow that mimics the in vivo authentic environment, which limits their usefulness in studying vessel formation.

\subsection{MaGSC-ECs are not yet clinically applicable in vivo}

One of the disadvantages of ESCs is their inherent potential of teratoma formation. Teratomas contain derivatives from all three germ layers, indicating or functionally proving the pluripotency of ESCs. The mechanisms behind teratoma formation arising from pluripotent stem cells are not exactly known. A study comparing the gene expression in undifferentiated human ESCs, teratomas and EBs found that the anti-apoptotic gene survivin (also called BIRC5, baculoviral inhibitor of apoptosis repeatcontaining 5) to be highly expressed in human ESCs and teratomas, but not in EBs (Blum et al., 2009). In our in vivo study, we found that maGSC-ECs promote neovascularization in immunocompetent CD1 mice, but induce teratoma formation after being injected in immunodeficient SCID mice. The formation of teratoma was also observed in other studies, in which differentiated ESCs were transplanted. For example, insulin-producing cells derived from mouse ESCs were used to reverse hyperglycemia in a STZ-induced diabetes NOD/scid mouse model, and teratoma formation was observed at each transplant site (Fujikawa et al., 2005).

The formation of teratoma in SCID mice indicated that the differentiation protocol is not able to achieve $100 \%$ efficiency. There are two possible causes underlying 
the observed teratoma formation: one is the presence of undifferentiated cells in the mixture of delivered cells, the other is that some of the delivered cells may have dedifferentiated under the in vivo conditions. The latter possibility is difficult to prove without lineage tracing. Also, it has been shown that teratoma formation caused by human ESCs may be enhanced in the presence of matrigel (Prokhorova et al., 2009).

Regarding the presence of undifferentiated cells, we noticed that a minority of Flk $-1^{+}$cells immediately after sorting were also $\mathrm{GFP}^{+}\left(9.7 \pm 4.1 \%\right.$ of the $\mathrm{Flk}-1^{+}$population and $3.5 \pm 1.5 \%$ of the total cell population, respectively). Even though immunocytochemistry analysis confirmed that most of Flk $-1^{+}$cells were negative for the pluripotency marker Oct4 (Kaiser, 2010), this method cannot be used for quantification of undifferentiated cells since the overall percentage of $\mathrm{Flk}-1^{+} / \mathrm{GFP}^{+}$cells was low (around $4 \%$ ). The identity of these two different cell populations, i.e. $\mathrm{Flk}-1^{+} / \mathrm{GFP}^{+}$and $\mathrm{Flk}-1^{+} / \mathrm{GFP}^{-}$ should be addressed in future studies.

The cascade of cellular differentiation most likely involves first undifferentiated $\mathrm{GFP}^{+}$cells, then Flk-1 ${ }^{+}$cells, and followed by Flk-1 ${ }^{\text {low/- }}$ cells, which are $\mathrm{GFP}^{-}$indicating that these cells have lost their pluripotency and have differentiated in lineages other than cardiovascular lineage. Flk-1 is transiently expressed in early mesoderm during development. In this regard, Flk- $1^{+} / \mathrm{GFP}^{+}$cells appeared earlier than Flk-1 ${ }^{+} / \mathrm{GFP}^{-}$cells. In agreement with a previous report, in which hemangioblast have been shown to express Flk1 as well as Oct3/4 (Furuta et al., 2006), the Flk-1 ${ }^{+} / \mathrm{GFP}^{+}$cell population could thus represent the in vitro counterpart of hemangioblasts and $\mathrm{Flk}-1^{+} / \mathrm{GFP}^{-}$cells are more likely the counterpart to angioblasts. Similar to our results, it has been reported that iPS cellsderived Flk- $1^{+}$cells contained $\operatorname{Nanog}^{+}$cells as well (Suzuki et al., 2010). Nevertheless, the possibility of $\mathrm{GFP}^{+}$undifferentiated cells exists. To clear this point, RNA expression patterns could be analyzed and compared in both $\mathrm{Flk}-1^{+} / \mathrm{GFP}^{+}$and $\mathrm{Flk}-1^{+} / \mathrm{GFP}^{-}$cell populations separated by FACS.

Before cell transplantation, maGSC-ECs at passage 6 were examined for GFP ${ }^{+}$ cells and for undifferentiated cell morphology using fluorescence microscopy, revealing approximately $4 \% \mathrm{GFP}^{+}$cells using flow cytometry (data not shown). Thus, negative sorting to remove $\mathrm{GFP}^{+}$cells before cell transplantation might be a useful strategy to avoid teratoma formation in the future. In any case, it is imperative to develop alternative 
protocols for the purpose of obtaining clinically useful ECs with pure cell population for use in therapeutic angiogenesis.

\subsection{In vivo detection system for tracking cell fate after transplantation}

Our results also suggest that it is necessary to track the delivered cells after cell transplantation. Thus, labelling cells prior to their delivery into the host would allow us to distinguish the delivered cells from host cells and track their fate.

There are many cell detection methods available. Radioactive probes like chromium-51 have been used for blood cell tracking (Dworkin et al., 2007). However, this procedure is toxic to the cells and also, uptake is poor (Horan et al., 1990). Chemical markers such as bisbenzimide (Hoechst 33342) and PKH26, similar to CM-DiI labelling used in the present study, have been used for cell labelling but their usefulness is limited to short-term applications (Mosahebi et al., 2000). Genetic labelling with either fluorescent proteins such as GFP or LacZ appears to be a relatively long-lasting method and was found not to be deleterious to the transduced cells (Dezawa et al., 2001). However, it is relatively time-consuming to prepare plasmids for GFP fusion and to establish stable transfection protocols. In the current cell transplantation study, CM-DiI was selected for labelling the cells before their transplantation in vivo. CM-DiI is a fluorescent lipophilic carbocyanine dye and incorporates into EC membranes upon contact. CM-DiI also stains membrane structures by lateral diffusion. CM-DiI has been widely used because it shows slow fading features and is relatively resistant to leakage to nearby cells ( $\mathrm{Li}$ et al., 2008). However, the membrane-bond fluorescence signal may be diluted once the cells proliferate. In matrigel plug in vivo assay, we only detected a few CM-DiI labelled maGSC-ECs, but also murine ECs (SVEC4-10) that were directly associated with FITC-lectin positive blood vessel formation, even though both maGSC-ECs and SVEC4-10 were both effective in promoting new vessel formation. Apart from the possibility that maGSC-ECs promote new vessel formation in a paracrine manner, a more probably explanation may be that the loss of detection may have resulted from dilution of the label during cell divisions. The ideal labelling to be used in future studies should thus be stable and efficient without changing cell viability, morphology and characteristics. 


\subsection{Long-term cultivation of Flk-1 ${ }^{+}$cardiovascular progenitor cells}

Previous studies have used Flk-1 as a marker for the isolation of multipotent cardiovascular progenitor cells (Kattman et al., 2006; Yang et al., 2008). Furthermore, lineage tracing of $\mathrm{Flk}-1^{+}$cells has demonstrated that these mesodermal progenitor cells contribute to both vascular endothelium and cardiac muscle (Coultas et al., 2005; Motoike et al., 2003). Surprisingly, there is no study regarding the methodology that can keep Flk$1^{+}$progenitor cells in culture for a long period. Disabilities like ischemic heart disease, characterized by reduced blood supply to the heart, are the major cause of death worldwide (Lopez et al., 2006; Segers and Lee, 2008). To replace and repair all types of damaged cells within the ischemic heart, progenitor cell therapy will be an appropriate and promising option.

The challenge is that the Flk-1 expression window is very narrow. A previous kinetic analysis indicated that BL-CFCs, the in vitro counterpart of hemangioblasts, are a transient population which persists for only a short period and are most abundant between day 2.75 and 3.25 of embryonic body development (Choi et al., 1998). Therefore, it is difficult to keep cells in an early mesodermal stage and to prevent their further differentiation into cardiovascular lineages or de-differentiation into undifferentiated stem cells.

A study published by the Chien group demonstrated that mouse postnatal Is $11^{+}$ cardiac progenitor cells could be expanded in vitro using a co-culture system with cardiac mesenchymal cells. The expression of Isl1 could be maintained and further differentiation was not detected (Moretti et al., 2006; Laugwitz et al., 2005). However, the characterization of long-term cultured Is $11^{+}$progenitor cells was not mentioned. Whether these progenitor cells can be passaged and whether they retain the same property after freeze-thaw cycles is not known. According to the above study, there are many common features in $\mathrm{Is} 11^{+}$and $\mathrm{Flk}-1^{+}$cardiovascular progenitor cells, even if they are not the same cells. For example, both cells express Flk-1, Is11 and Nkx2.5 and can spontaneously differentiate into three cardiovascular lineages. Thus, it is possible to maintain and expand Flk- $1^{+}$cardiovascular progenitor cells for a long time in vitro. 
Our results show that mouse maGSCs are similar to mouse ESCs according to the efficiency of Flk- $1^{+}$progenitor cell differentiation. When co-cultured with OP9 cells for 5 days, they differentiate into Flk- $1^{+}$cells $(35 \%)$ with an efficiency similar to that seen with ESCs. This is in line with the previous studies showing that mouse ESCs and iPS cells cultured on COLIV-coated culture dishes differentiate into Flk- $1^{+}$cells with an efficiency of $24 \%$ and $27 \%$, respectively (Narazaki et al., 2008; Suzuki et al., 2010). Similar to the previous studies (Narazaki et al., 2008), our FACS-sorted Flk- $1^{+}$cells express cardiovascular progenitor markers Isl-1, Nkx2.5 and brachyury. When FACS-sorted Flk-1 ${ }^{+}$ cells were cultured on OP9 cells, they were able to differentiate into beating cardiomyocytes as well as vascular ECs and SMCs (Kaiser, 2010). These data indicate that Flk- $1^{+}$cells derived from maGSCs in the present study are cardiovascular progenitors.

In the present study, we demonstrated that a single Flk- $1^{+}$progenitor cell was able to differentiate into both ECs and SMCs, as shown by the expression of VE-cad and SMA, respectively. Although beating cells were not observed during the single cell bipotency assay, possibly because the cells were cultured in endothelial differentiation medium or due to the short cultivation time. When these cells cultured on OP9 cells, were found to spontaneously differentiate into all three cardiovascular lineages, as detected by immunostaining. Although we have not been able to show the expression of other cell type markers by immunocytochemistry during spontaneous differentiation of the Flk- $1^{+}$ progenitor cells, different cell morphologies such as blood cell-like morphology were also detected during cultivation. In the future, the long-term cultured Flk- $1^{+}$cardiovascular progenitor cells should be transplanted into myocardial infarct mouse model to study their cardiovascular regeneration potential as well as their tumorigenicity.

Importantly, Flk-1 ${ }^{+}$progenitor cells can be generated reproducibly from the cultures on COLIV-coated culture dishes for a long period. However, these long-term cultured progenitor cells also are not a pure cell population. Gradually downregulated expression of progenitor markers and upregulation of stem cell marker was observed. Around $70 \%$ of the cells were Flk- $1^{+}$cardiovascular progenitor cells as shown by flow cytometry. Our date has shown that around $5 \%$ of the cells are $\mathrm{GFP}^{+}$. This leads to the question of the identity of the other $25 \%$ of cells. There was no expression of differentiated cell markers in the direction of vascular lineage meaning that these $25 \%$ of cells are not ECs or smooth muscles cells. However, we did not analyze the protein expression of 
cardiac and hematopoietic lineages by flow cytometry. Except for the typical 2D sheet-like cell clusters formed by Flk- $1^{+}$cardiovascular progenitor cells, other cells with different morphology were also observed throughout the culture periods. These cells could be differentiating cells that grew out of the sheet-like cell clusters or mesodermal-derived cells other than vascular lineage.

Multipotent $\mathrm{Flk}-1^{+}$cardiovascular progenitor cells capable of differentiating into cardiomyocytes, ECs and SMCs have been identified (Kattman et al., 2006). Additionally, BL-CFCs generated from Flk- ${ }^{+}$EB-derived population, that displays the ability to differentiate into hematopoietic, vascular endothelial and smooth muscle lineages, have been demonstrated (Choi et al., 1998; Fehling et al., 2003). Recently, endocardial cells have also been shown to be derived form $\mathrm{Flk}-1^{+}$cardiovascular progenitors (Figure 51)(Misfeldt et al., 2009).

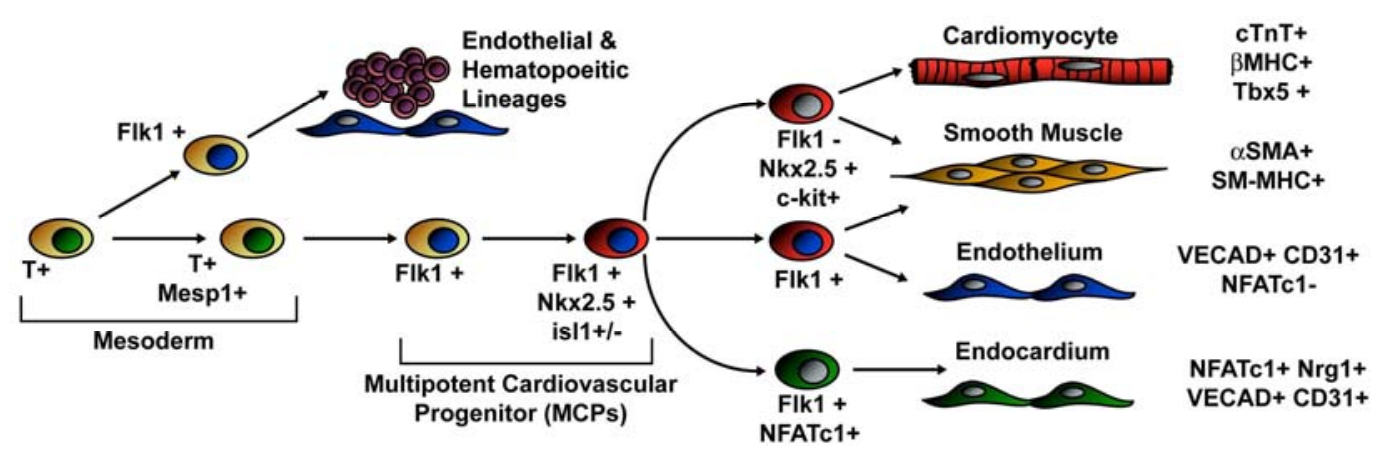

Figure 51. The cardiovascular lineage specification from multipotent Flk-1 ${ }^{+}$cardiovascular progenitor cells. Adapted from (Misfeldt et al., 2009)

Except the hypothesis of hemangioblast, a relatively younger theory suggests that hematopoietic stem cells derived from a subset of early ECs known as hemogenic endothelium. The relationship between hemangioblasts and hemogenic endothelium has not yet cleared (Yoshimoto and Yoder, 2009). Whether all these cell populations are the same cells or the subpopulation of these cells are overlapping is not known. In order to be clinically relevant, a detailed characterization should be done in the future. 


\subsection{Conclusion and future perspectives}

In conclusions, our findings suggest that maGSC-ECs can function in vitro and in vivo, but also they are tumorigenic if applied into immunodeficient mice. Flk- $1^{+}$ cardiovascular progenitor cells derived from adult mouse testis can be expanded and possess the potential for cardiovascular differentiation. However, their pluripotency potential continues to exist, as indicated by the presence of $\mathrm{GFP}^{+}$cells as well as upregulated expression of nanog. Although it is still too early for in vivo applications, the ability of maGSC-derived $\mathrm{Flk}-1^{+}$progenitor cells to sprout, branch and form vascular network-like structures may be useful for the establishment of in vitro model systems to further explore molecular events involved in the regulation of blood vessel formation. On the other hand, it is also important to remember that these cell culture systems are devoid of blood flow that mimics the in vivo authentic environment, which may limit their usefulness in studying vessel formation.

Taken together, we established a relatively simple protocol to generate functional endothelial cells from maGSCs, which has not been studied before. We could also present the first protocol regarding the cultivation of Flk- $1^{+}$progenitor cells in vitro for up to 15 passages. These in vitro model systems can be used to investigate the developmental steps of blood vessel formation and assist in studying the basic mechanisms in cardiovascular differentiation. Development of safe methodologies generating sufficient numbers of cardiovascular progenitors or ECs will be useful for future cell-based therapies. 


\section{Summary}

In previous studies, Guan et al. established multipotent adult germline stem cells (maGSCs) with similar characteristics with embryonic stem cells (ESCs) (Guan et al., 2006) and demonstrated that maGSCs can be differentiated into functional cardiomyocytes (Guan et al., 2007). Fetal liver kinase-1 (Flk-1) ${ }^{+}$progenitor cells have been identified as cardiovascular progenitor cells using both human (Yang et al., 2008) and mouse ESCs (Kattman et al., 2006). This current study extends these findings in two major directions: 1) to obtain Flk-1 ${ }^{+}$progenitor cells from maGSCs and further differentiate them into functional endothelial cells (ECs), and 2) to establish a culture condition that allows the cultivation of Flk- $1^{+}$progenitor cells in vitro for long periods. By using a co-culture system with OP9 stromal cells, approximately $35 \%$ of Flk- $1^{+}$progenitor cells were generated. The generated Flk- $1^{+}$cells were able to differentiate into proliferating and functional ECs. For the in vitro characterization of both cell types, we examined the mRNA and protein expression of different progenitor or EC markers and performed two in vitro angiogenesis assays to assess their functional properties. We also performed in vivo matrigel plug assay to evaluate the potential of maGSC-ECs to participate in the formation of functional, i.e. perfused new vasculature. Furthermore, our findings suggest that collagen type IV (COLIV) is superior in facilitating maGSCs-derived endothelial differentiation in the presence of vascular endothelial growth factor (VEGF) compared to fibronectin (FN) or growth factor reduced (GFR) matrigel. MaGSC-ECs show typical endothelial morphology, express endothelial specific genes and acquire the ability to sprout and to form tube-like network in vitro. Moreover, maGSC-ECs participate and promote neovascularization in vivo. However, transplantation of maGSC-ECs into immunodeficient mice resulted in teratoma formation strongly suggesting that the current protocol needs to be further optimized in order to reduce or eliminate the presence of undifferentiated cells. We also show that maGSCs-derived Flk- $1^{+}$cardiovascular progenitor cells can be cultivated in vitro with repeated freeze-thaw cycles, if cultivated in low (i.e. 2\%) serum-containing medium with addition of N2B27, without further vascular lineage differentiation. After 15 passages, $70 \%$ of presumptive progenitor cells continue to express Flk-1, possess bipotency as well as angiogenic potential in vitro. Moreover, they spontaneously differentiate into all three cardiovascular lineages when cultured on OP9 cells. Taken together, we established a 
protocol for the isolation and differentiation of endothelial-like cells from maGSCs, which will make them a useful source for studying basic mechanisms in vascular differentiation. The establishment of long-term culture of $\mathrm{Flk}-1^{+}$progenitor cells may be valuable for progenitor cell-based therapy in cardiovascular diseases. However, further optimization steps are needed to minimize the risk of tumor formation before they can be therapeutically and safely applied in patients. 


\section{References}

Adams,I.R. and McLaren,A. (2002). Sexually dimorphic development of mouse primordial germ cells: switching from oogenesis to spermatogenesis. Development 129, 11551164 .

Alaiti,M.A., Ishikawa,M., and Costa,M.A. (2010). Bone marrow and circulating stem/progenitor cells for regenerative cardiovascular therapy. Transl. Res. 156, 112129.

Alajati,A., Laib,A.M., Weber,H., Boos,A.M., Bartol,A., Ikenberg,K., Korff,T., Zentgraf,H., Obodozie,C., Graeser,R., Christian,S., Finkenzeller,G., Stark,G.B., Heroult,M., and Augustin,H.G. (2008). Spheroid-based engineering of a human vasculature in mice. Nat. Methods 5, 439-445.

Alsberg,E., von Recum,H.A., and Mahoney,M.J. (2006). Environmental cues to guide stem cell fate decision for tissue engineering applications. Expert. Opin. Biol. Ther. 6, 847866.

Andrew H. Fischer, Kenneth A. Jacobson, Jack Rose, and Rolf Zeller (2008). Preparation of Slides and Coverslips for Microscopy. This protocol was adapted from "Preparation of Cells and Tissues for Fluorescence Microscopy," Chapter 4, in Basic Methods in Microscopy.

Asahara,T., Masuda,H., Takahashi,T., Kalka,C., Pastore,C., Silver,M., Kearne,M., Magner,M., and Isner,J.M. (1999). Bone marrow origin of endothelial progenitor cells responsible for postnatal vasculogenesis in physiological and pathological neovascularization. Circ. Res. 85, 221-228.

Asahara,T., Murohara,T., Sullivan,A., Silver,M., van der,Z.R., Li,T., Witzenbichler,B., Schatteman,G., and Isner,J.M. (1997). Isolation of putative progenitor endothelial cells for angiogenesis. Science 275, 964-967.

Augustin,H.G., Koh,G.Y., Thurston,G., and Alitalo,K. (2009). Control of vascular morphogenesis and homeostasis through the angiopoietin-Tie system. Nat. Rev. Mol. Cell Biol. 10, 165-177.

Baatout,S. (1997). Endothelial differentiation using Matrigel (review). Anticancer Res. 17, 451-455.

Baba,S., Heike,T., Umeda,K., Iwasa,T., Kaichi,S., Hiraumi,Y., Doi,H., Yoshimoto,M., Kanatsu-Shinohara,M., Shinohara,T., and Nakahata,T. (2007). Generation of cardiac and endothelial cells from neonatal mouse testis-derived multipotent germline stem cells. Stem Cells 25, 1375-1383.

Balconi,G., Spagnuolo,R., and Dejana,E. (2000). Development of endothelial cell lines from embryonic stem cells: A tool for studying genetically manipulated endothelial cells in vitro. Arterioscler. Thromb. Vasc. Biol. 20, 1443-1451. 
Blum,B., Bar-Nur,O., Golan-Lev,T., and Benvenisty,N. (2009). The anti-apoptotic gene survivin contributes to teratoma formation by human embryonic stem cells. Nat. Biotechnol. 27, 281-287.

Brindle,N.P., Saharinen,P., and Alitalo,K. (2006). Signaling and functions of angiopoietin1 in vascular protection. Circ. Res. 98, 1014-1023.

Brinster,R.L. (2002). Germline stem cell transplantation and transgenesis. Science 296, 2174-2176.

Brinster,R.L. and Zimmermann,J.W. (1994). Spermatogenesis following male germ-cell transplantation. Proc. Natl. Acad. Sci. U. S. A 91, 11298-11302.

Bull,N.D. and Bartlett,P.F. (2005). The adult mouse hippocampal progenitor is neurogenic but not a stem cell. J. Neurosci. 25, 10815-10821.

Buttke,T.M., McCubrey,J.A., and Owen,T.C. (1993). Use of an aqueous soluble tetrazolium/formazan assay to measure viability and proliferation of lymphokinedependent cell lines. J. Immunol. Methods 157, 233-240.

Cai,C.L., Liang,X., Shi,Y., Chu,P.H., Pfaff,S.L., Chen,J., and Evans,S. (2003). Is11 identifies a cardiac progenitor population that proliferates prior to differentiation and contributes a majority of cells to the heart. Dev. Cell 5, 877-889.

Caires,K., Broady,J., and McLean,D. (2010). Maintaining the male germline: regulation of spermatogonial stem cells. J. Endocrinol. 205, 133-145.

Carmeliet,P. (2003). Angiogenesis in health and disease. Nat. Med. 9, 653-660.

Carmeliet,P. (2005). Angiogenesis in life, disease and medicine. Nature 438, 932-936.

Carmeliet,P., Ferreira,V., Breier,G., Pollefeyt,S., Kieckens,L., Gertsenstein,M., Fahrig,M., Vandenhoeck,A., Harpal,K., Eberhardt,C., Declercq,C., Pawling,J., Moons,L., Collen,D., Risau,W., and Nagy,A. (1996). Abnormal blood vessel development and lethality in embryos lacking a single VEGF allele. Nature 380, 435-439.

Cebe-Suarez,S., Zehnder-Fjallman,A., and Ballmer-Hofer,K. (2006). The role of VEGF receptors in angiogenesis; complex partnerships. Cell Mol. Life Sci. 63, 601-615.

Cho,S.W., Moon,S.H., Lee,S.H., Kang,S.W., Kim,J., Lim,J.M., Kim,H.S., Kim,B.S., and Chung,H.M. (2007). Improvement of postnatal neovascularization by human embryonic stem cell derived endothelial-like cell transplantation in a mouse model of hindlimb ischemia. Circulation 116, 2409-2419.

Choi,K., Kennedy,M., Kazarov,A., Papadimitriou,J.C., and Keller,G. (1998). A common precursor for hematopoietic and endothelial cells. Development 125, 725-732.

Cleaver,O. and Melton,D.A. (2003). Endothelial signaling during development. Nat. Med. 9, 661-668.

Conrad,S., Renninger,M., Hennenlotter,J., Wiesner,T., Just,L., Bonin,M., Aicher,W., Buhring,H.J., Mattheus,U., Mack,A., Wagner,H.J., Minger,S., Matzkies,M., Reppel,M., 
Hescheler,J., Sievert,K.D., Stenzl,A., and Skutella,T. (2008). Generation of pluripotent stem cells from adult human testis. Nature 456, 344-349.

Cory,A.H., Owen,T.C., Barltrop,J.A., and Cory,J.G. (1991). Use of an aqueous soluble tetrazolium/formazan assay for cell growth assays in culture. Cancer Commun. 3, 207212.

Couffinhal,T., Dufourcq,P., Barandon,L., Leroux,L., and Duplaa,C. (2009). Mouse models to study angiogenesis in the context of cardiovascular diseases. Front Biosci. 14, 33103325 .

Coultas,L., Chawengsaksophak,K., and Rossant,J. (2005). Endothelial cells and VEGF in vascular development. Nature 438, 937-945.

Cox,C.M. and Poole,T.J. (2000). Angioblast differentiation is influenced by the local environment: FGF-2 induces angioblasts and patterns vessel formation in the quail embryo. Dev. Dyn. 218, 371-382.

Czyz,J., Wiese,C., Rolletschek,A., Blyszczuk,P., Cross,M., and Wobus,A.M. (2003). Potential of embryonic and adult stem cells in vitro. Biol. Chem. 384, 1391-1409.

Dai,J. and Rabie,A.B. (2007). VEGF: an essential mediator of both angiogenesis and endochondral ossification. J. Dent. Res. 86, 937-950.

Darland,D.C. and D'Amore,P.A. (1999). Blood vessel maturation: vascular development comes of age. J. Clin. Invest 103, 157-158.

De,V.S. and Black,B.L. (2009). Transcriptional control of endothelial cell development. Dev. Cell 16, 180-195.

de,V.C., Escobedo,J.A., Ueno,H., Houck,K., Ferrara,N., and Williams,L.T. (1992). The fms-like tyrosine kinase, a receptor for vascular endothelial growth factor. Science 255, 989-991.

DeLisser,H.M., Newman,P.J., and Albelda,S.M. (1994). Molecular and functional aspects of PECAM-1/CD31. Immunol. Today 15, 490-495.

Dezawa,M., Takahashi,I., Esaki,M., Takano,M., and Sawada,H. (2001). Sciatic nerve regeneration in rats induced by transplantation of in vitro differentiated bone-marrow stromal cells. Eur. J. Neurosci. 14, 1771-1776.

Ding,B.S., Dziubla,T., Shuvaev,V.V., Muro,S., and Muzykantov,V.R. (2006). Advanced drug delivery systems that target the vascular endothelium. Mol. Interv. 6, 98-112.

Drake,C.J. (2003). Embryonic and adult vasculogenesis. Birth Defects Res. C. Embryo. Today 69, 73-82.

Drake,C.J., Hungerford,J.E., and Little,C.D. (1998). Morphogenesis of the first blood vessels. Ann. N. Y. Acad. Sci. 857, 155-179.

Dumont,D.J., Jussila,L., Taipale,J., Lymboussaki,A., Mustonen,T., Pajusola,K., Breitman,M., and Alitalo,K. (1998). Cardiovascular failure in mouse embryos deficient in VEGF receptor-3. Science 282, 946-949. 
Dumont,D.J., Yamaguchi,T.P., Conlon,R.A., Rossant,J., and Breitman,M.L. (1992). tek, a novel tyrosine kinase gene located on mouse chromosome 4, is expressed in endothelial cells and their presumptive precursors. Oncogene 7, 1471-1480.

Dworkin,H.J., Premo,M., and Dees,S. (2007). Comparison of red cell and whole blood volume as performed using both chromium-51-tagged red cells and iodine-125-tagged albumin and using I-131-tagged albumin and extrapolated red cell volume. Am. J. Med. Sci. 334, 37-40.

Eckfeldt,C.E., Mendenhall,E.M., and Verfaillie,C.M. (2005). The molecular repertoire of the 'almighty' stem cell. Nat. Rev. Mol. Cell Biol. 6, 726-737.

Eichmann,A., Corbel,C., Nataf,V., Vaigot,P., Breant,C., and Le Douarin,N.M. (1997). Ligand-dependent development of the endothelial and hemopoietic lineages from embryonic mesodermal cells expressing vascular endothelial growth factor receptor 2. Proc. Natl. Acad. Sci. U. S. A 94, 5141-5146.

Eklund,L. and Olsen,B.R. (2006). Tie receptors and their angiopoietin ligands are contextdependent regulators of vascular remodeling. Exp. Cell Res. 312, 630-641.

Evans,M.J. and Kaufman,M.H. (1981). Establishment in culture of pluripotential cells from mouse embryos. Nature 292, 154-156.

Evensen,L., Micklem,D.R., Blois,A., Berge,S.V., Aarsaether,N., Littlewood-Evans,A., Wood,J., and Lorens,J.B. (2009). Mural cell associated VEGF is required for organotypic vessel formation. PLoS. One. 4, e5798.

Fehling,H.J., Lacaud,G., Kubo,A., Kennedy,M., Robertson,S., Keller,G., and Kouskoff,V. (2003). Tracking mesoderm induction and its specification to the hemangioblast during embryonic stem cell differentiation. Development 130, 4217-4227.

Ferrara,N., Carver-Moore,K., Chen,H., Dowd,M., Lu,L., O'Shea,K.S., Powell-Braxton,L., Hillan,K.J., and Moore,M.W. (1996). Heterozygous embryonic lethality induced by targeted inactivation of the VEGF gene. Nature 380, 439-442.

Fischer,A., Schumacher,N., Maier,M., Sendtner,M., and Gessler,M. (2004). The Notch target genes Hey1 and Hey2 are required for embryonic vascular development. Genes Dev. 18, 901-911.

Flamme,I., Frolich,T., and Risau,W. (1997). Molecular mechanisms of vasculogenesis and embryonic angiogenesis. J. Cell Physiol 173, 206-210.

Folkman,J. and D'Amore,P.A. (1996). Blood vessel formation: what is its molecular basis? Cell 87, 1153-1155.

Fong,G.H., Rossant,J., Gertsenstein,M., and Breitman,M.L. (1995). Role of the Flt-1 receptor tyrosine kinase in regulating the assembly of vascular endothelium. Nature $376,66-70$.

Fong,G.H., Zhang,L., Bryce,D.M., and Peng,J. (1999). Increased hemangioblast commitment, not vascular disorganization, is the primary defect in flt-1 knock-out mice. Development 126, 3015-3025. 
Friedrich,E.B., Walenta,K., Scharlau,J., Nickenig,G., and Werner,N. (2006). CD34/CD133+/VEGFR-2+ endothelial progenitor cell subpopulation with potent vasoregenerative capacities. Circ. Res. 98, e20-e25.

Fujikawa,T., Oh,S.H., Pi,L., Hatch,H.M., Shupe,T., and Petersen,B.E. (2005). Teratoma formation leads to failure of treatment for type I diabetes using embryonic stem cellderived insulin-producing cells. Am. J. Pathol. 166, 1781-1791.

Furuta,C., Ema,H., Takayanagi,S., Ogaeri,T., Okamura,D., Matsui,Y., and Nakauchi,H. (2006). Discordant developmental waves of angioblasts and hemangioblasts in the early gastrulating mouse embryo. Development 133, 2771-2779.

Gamble,J.R., Drew,J., Trezise,L., Underwood,A., Parsons,M., Kasminkas,L., Rudge,J., Yancopoulos,G., and Vadas,M.A. (2000). Angiopoietin-1 is an antipermeability and anti-inflammatory agent in vitro and targets cell junctions. Circ. Res. 87, 603-607.

Gerber,H.P., McMurtrey,A., Kowalski,J., Yan,M., Keyt,B.A., Dixit,V., and Ferrara,N. (1998). Vascular endothelial growth factor regulates endothelial cell survival through the phosphatidylinositol 3'-kinase/Akt signal transduction pathway. Requirement for Flk-1/KDR activation. J. Biol. Chem. 273, 30336-30343.

Gerecht-Nir,S., Ziskind,A., Cohen,S., and Itskovitz-Eldor,J. (2003). Human embryonic stem cells as an in vitro model for human vascular development and the induction of vascular differentiation. Lab Invest 83, 1811-1820.

Giglio,S., Monis,P.T., and Saint,C.P. (2003). Demonstration of preferential binding of SYBR Green I to specific DNA fragments in real-time multiplex PCR. Nucleic Acids Res. 31, e136.

Ginsburg,D., Handin,R.I., Bonthron,D.T., Donlon,T.A., Bruns,G.A., Latt,S.A., and Orkin,S.H. (1985). Human von Willebrand factor (vWF): isolation of complementary DNA (cDNA) clones and chromosomal localization. Science 228, 1401-1406.

Glaser,T., Opitz,T., Kischlat,T., Konang,R., Sasse,P., Fleischmann,B.K., Engel,W., Nayernia,K., and Brustle,O. (2008). Adult germ line stem cells as a source of functional neurons and glia. Stem Cells 26, 2434-2443.

Guan,K., Nayernia,K., Maier,L.S., Wagner,S., Dressel,R., Lee,J.H., Nolte,J., Wolf,F., Li,M., Engel,W., and Hasenfuss,G. (2006). Pluripotency of spermatogonial stem cells from adult mouse testis. Nature 440, 1199-1203.

Guan,K., Wagner,S., Unsold,B., Maier,L.S., Kaiser,D., Hemmerlein,B., Nayernia,K., Engel,W., and Hasenfuss, G. (2007). Generation of functional cardiomyocytes from adult mouse spermatogonial stem cells. Circ. Res. 100, 1615-1625.

Haar,J.L. and Ackerman,G.A. (1971). Ultrastructural changes in mouse yolk sac associated with the initiation of vitelline circulation. Anat. Rec. 170, 437-455.

Heida,N.M., Muller,J.P., Cheng,I.F., Leifheit-Nestler,M., Faustin,V., Riggert,J., Hasenfuss,G., Konstantinides,S., and Schafer,K. (2010). Effects of obesity and weight loss on the functional properties of early outgrowth endothelial progenitor cells. J. Am. Coll. Cardiol. 55, 357-367. 
Herbert,S.P., Huisken,J., Kim,T.N., Feldman,M.E., Houseman,B.T., Wang,R.A., Shokat,K.M., and Stainier,D.Y. (2009). Arterial-venous segregation by selective cell sprouting: an alternative mode of blood vessel formation. Science 326, 294-298.

Herzenberg,L.A., Parks,D., Sahaf,B., Perez,O., Roederer,M., and Herzenberg,L.A. (2002). The history and future of the fluorescence activated cell sorter and flow cytometry: a view from Stanford. Clin. Chem. 48, 1819-1827.

Hibino,N., Shin'oka,T., Matsumura,G., Ikada,Y., and Kurosawa,H. (2005). The tissueengineered vascular graft using bone marrow without culture. J. Thorac. Cardiovasc. Surg. 129, 1064-1070.

Hirashima,M., Kataoka,H., Nishikawa,S., Matsuyoshi,N., and Nishikawa,S. (1999). Maturation of embryonic stem cells into endothelial cells in an in vitro model of vasculogenesis. Blood 93, 1253-1263.

His, W., (1900). Lecithoblast und angioblast der Wirbeltiere. Abh. Math. Phys. Kl Saechs Ges. 26, pp. 171-328.

Horan,P.K., Melnicoff,M.J., Jensen,B.D., and Slezak,S.E. (1990). Fluorescent cell labeling for in vivo and in vitro cell tracking. Methods Cell Biol. 33, 469-490.

Hristov,M., Erl,W., and Weber,P.C. (2003). Endothelial progenitor cells: isolation and characterization. Trends Cardiovasc. Med. 13, 201-206.

Huang,N.F., Niiyama,H., Peter,C., De,A., Natkunam,Y., Fleissner,F., Li,Z., Rollins,M.D., Wu,J.C., Gambhir,S.S., and Cooke,J.P. (2010). Embryonic stem cell-derived endothelial cells engraft into the ischemic hindlimb and restore perfusion. Arterioscler. Thromb. Vasc. Biol. 30, 984-991.

Huber,T.L., Kouskoff,V., Fehling,H.J., Palis,J., and Keller,G. (2004). Haemangioblast commitment is initiated in the primitive streak of the mouse embryo. Nature 432, 625630 .

Ingber,D.E. and Folkman,J. (1989). How does extracellular matrix control capillary morphogenesis? Cell 58, 803-805.

Iwama,A., Hamaguchi,I., Hashiyama,M., Murayama,Y., Yasunaga,K., and Suda,T. (1993). Molecular cloning and characterization of mouse TIE and TEK receptor tyrosine kinase genes and their expression in hematopoietic stem cells. Biochem. Biophys. Res. Commun. 195, 301-309.

Jilani,S.M., Murphy,T.J., Thai,S.N., Eichmann,A., Alva,J.A., and Iruela-Arispe,M.L. (2003). Selective binding of lectins to embryonic chicken vasculature. J. Histochem. Cytochem. 51, 597-604.

Jussila,L. and Alitalo,K. (2002). Vascular growth factors and lymphangiogenesis. Physiol Rev. 82, 673-700.

Kaipainen,A., Korhonen,J., Mustonen,T., van,H., V, Fang,G.H., Dumont,D., Breitman,M., and Alitalo,K. (1995). Expression of the fms-like tyrosine kinase 4 gene becomes restricted to lymphatic endothelium during development. Proc. Natl. Acad. Sci. U. S. A 92, 3566-3570. 
Kaiser, D. (2010). Der Einfluss mechanischer Last auf das Potential multipotenter adulter Keimbahnstammzellen zur kardialen Regeneration.

Kalka,C., Masuda,H., Takahashi,T., Kalka-Moll,W.M., Silver,M., Kearney,M., Li,T., Isner,J.M., and Asahara,T. (2000). Transplantation of ex vivo expanded endothelial progenitor cells for therapeutic neovascularization. Proc. Natl. Acad. Sci. U. S. A 97, 3422-3427.

Kallianpur,A.R., Jordan,J.E., and Brandt,S.J. (1994). The SCL/TAL-1 gene is expressed in progenitors of both the hematopoietic and vascular systems during embryogenesis. Blood 83, 1200-1208.

Kanatsu-Shinohara,M., Inoue,K., Lee,J., Yoshimoto,M., Ogonuki,N., Miki,H., Baba,S., Kato,T., Kazuki,Y., Toyokuni,S., Toyoshima,M., Niwa,O., Oshimura,M., Heike,T., Nakahata,T., Ishino,F., Ogura,A., and Shinohara,T. (2004). Generation of pluripotent stem cells from neonatal mouse testis. Cell 119, 1001-1012.

Kattman,S.J., Huber,T.L., and Keller,G.M. (2006). Multipotent flk-1+ cardiovascular progenitor cells give rise to the cardiomyocyte, endothelial, and vascular smooth muscle lineages. Dev. Cell 11, 723-732.

Kaufman,D.S., Lewis,R.L., Hanson,E.T., Auerbach,R., Plendl,J., and Thomson,J.A. (2004). Functional endothelial cells derived from rhesus monkey embryonic stem cells. Blood 103, 1325-1332.

Kelly,M.A. and Hirschi,K.K. (2009). Signaling hierarchy regulating human endothelial cell development. Arterioscler. Thromb. Vasc. Biol. 29, 718-724.

Kennedy,M., Firpo,M., Choi,K., Wall,C., Robertson,S., Kabrun,N., and Keller,G. (1997). A common precursor for primitive erythropoiesis and definitive haematopoiesis. Nature 386, 488-493.

Klein,D., Hohn,H.P., Kleff,V., Tilki,D., and Ergun,S. (2010). Vascular wall-resident stem cells. Histol. Histopathol. 25, 681-689.

Ko,K., rauzo-Bravo,M.J., Tapia,N., Kim,J., Lin,Q., Bernemann,C., Han,D.W., Gentile,L., Reinhardt,P., Greber,B., Schneider,R.K., Kliesch,S., Zenke,M., and Scholer,H.R. (2010). Human adult germline stem cells in question. Nature 465, E1.

Korff,T. and Augustin,H.G. (1998). Integration of endothelial cells in multicellular spheroids prevents apoptosis and induces differentiation. J. Cell Biol. 143, 1341-1352.

Korff,T., Kimmina,S., Martiny-Baron,G., and Augustin,H.G. (2001). Blood vessel maturation in a 3-dimensional spheroidal coculture model: direct contact with smooth muscle cells regulates endothelial cell quiescence and abrogates VEGF responsiveness. FASEB J. 15, 447-457.

Korff,T., Krauss,T., and Augustin,H.G. (2004). Three-dimensional spheroidal culture of cytotrophoblast cells mimics the phenotype and differentiation of cytotrophoblasts from normal and preeclamptic pregnancies. Exp. Cell Res. 297, 415-423.

Kovacic,J.C., Harvey,R.P., and Dimmeler,S. (2007). Cardiovascular regenerative medicine: digging in for the long haul. Cell Stem Cell 1, 628-633. 
Kubo,H. and Alitalo,K. (2003). The bloody fate of endothelial stem cells. Genes Dev. 17, 322-329.

Kubota,Y., Kleinman,H.K., Martin,G.R., and Lawley,T.J. (1988). Role of laminin and basement membrane in the morphological differentiation of human endothelial cells into capillary-like structures. J. Cell Biol. 107, 1589-1598.

Kwak,H.J., So,J.N., Lee,S.J., Kim,I., and Koh,G.Y. (1999). Angiopoietin-1 is an apoptosis survival factor for endothelial cells. FEBS Lett. 448, 249-253.

Laib,A.M., Bartol,A., Alajati,A., Korff,T., Weber,H., and Augustin,H.G. (2009). Spheroidbased human endothelial cell microvessel formation in vivo. Nat. Protoc. 4, 1202-1215.

Lampugnani,M.G., Resnati,M., Raiteri,M., Pigott,R., Pisacane,A., Houen,G., Ruco,L.P., and Dejana,E. (1992). A novel endothelial-specific membrane protein is a marker of cell-cell contacts. J. Cell Biol. 118, 1511-1522.

Lanner,F., Sohl,M., and Farnebo,F. (2007). Functional arterial and venous fate is determined by graded VEGF signaling and notch status during embryonic stem cell differentiation. Arterioscler. Thromb. Vasc. Biol. 27, 487-493.

Laugwitz,K.L., Moretti,A., Lam,J., Gruber,P., Chen,Y., Woodard,S., Lin,L.Z., Cai,C.L., Lu,M.M., Reth,M., Platoshyn,O., Yuan,J.X., Evans,S., and Chien,K.R. (2005). Postnatal is $11+$ cardioblasts enter fully differentiated cardiomyocyte lineages. Nature 433, 647653.

Lawson,N.D., Vogel,A.M., and Weinstein,B.M. (2002). sonic hedgehog and vascular endothelial growth factor act upstream of the Notch pathway during arterial endothelial differentiation. Dev. Cell 3, 127-136.

LePecq,J.B. and Paoletti,C. (1967). A fluorescent complex between ethidium bromide and nucleic acids. Physical-chemical characterization. J. Mol. Biol. 27, 87-106.

Levenberg,S., Ferreira,L.S., Chen-Konak,L., Kraehenbuehl,T.P., and Langer,R. (2010). Isolation, differentiation and characterization of vascular cells derived from human embryonic stem cells. Nat. Protoc. 5, 1115-1126.

Li,J., Wei,Y., and Wagner,T.E. (1999). In vitro endothelial differentiation of long-term cultured murine embryonic yolk sac cells induced by matrigel. Stem Cells 17, 72-81.

Li,Y., Song,Y., Zhao,L., Gaidosh,G., Laties,A.M., and Wen,R. (2008). Direct labeling and visualization of blood vessels with lipophilic carbocyanine dye DiI. Nat. Protoc. 3, 1703-1708.

Li,Z., Wu,J.C., Sheikh,A.Y., Kraft,D., Cao,F., Xie,X., Patel,M., Gambhir,S.S., Robbins,R.C., Cooke,J.P., and Wu,J.C. (2007). Differentiation, survival, and function of embryonic stem cell derived endothelial cells for ischemic heart disease. Circulation 116, I46-I54.

Livak,K.J. and Schmittgen,T.D. (2001). Analysis of relative gene expression data using real-time quantitative PCR and the 2(-Delta Delta C(T)) Method. Methods 25, 402-408. 
Lopez,A.D., Mathers,C.D., Ezzati,M., Jamison,D.T., and Murray,C.J. (2006). Global and regional burden of disease and risk factors, 2001: systematic analysis of population health data. Lancet 367, 1747-1757.

Marrotte,E.J., Chen,D.D., Hakim,J.S., and Chen,A.F. (2010). Manganese superoxide dismutase expression in endothelial progenitor cells accelerates wound healing in diabetic mice. J. Clin. Invest.

Martin,G.R. (1981). Isolation of a pluripotent cell line from early mouse embryos cultured in medium conditioned by teratocarcinoma stem cells. Proc. Natl. Acad. Sci. U. S. A 78, 7634-7638.

McClay,D.R. and Logan,C.Y. (1996). Regulative capacity of the archenteron during gastrulation in the sea urchin. Development 122, 607-616.

McCloskey,K.E., Lyons,I., Rao,R.R., Stice,S.L., and Nerem,R.M. (2003). Purified and proliferating endothelial cells derived and expanded in vitro from embryonic stem cells. Endothelium 10, 329-336.

McCloskey,K.E., Smith,D.A., Jo,H., and Nerem,R.M. (2006). Embryonic stem cellderived endothelial cells may lack complete functional maturation in vitro. J. Vasc. Res. 43, 411-421.

McCloskey,K.E., Stice,S.L., and Nerem,R.M. (2006). In vitro derivation and expansion of endothelial cells from embryonic stem cells. Methods Mol. Biol. 330, 287-301.

McKay,R. (2000). Stem cells [mdash] hype and hope. Nature 406, 361-364.

McLaren,A. and Southee,D. (1997). Entry of mouse embryonic germ cells into meiosis. Dev. Biol. 187, 107-113.

Misfeldt,A.M., Boyle,S.C., Tompkins,K.L., Bautch,V.L., Labosky,P.A., and Baldwin,H.S. (2009). Endocardial cells are a distinct endothelial lineage derived from Flk1+ multipotent cardiovascular progenitors. Dev. Biol. 333, 78-89.

Moretti,A., Bellin,M., Jung,C.B., Thies,T.M., Takashima,Y., Bernshausen,A., Schiemann,M., Fischer,S., Moosmang,S., Smith,A.G., Lam,J.T., and Laugwitz,K.L. (2010). Mouse and human induced pluripotent stem cells as a source for multipotent Is11+ cardiovascular progenitors. FASEB J. 24, 700-711.

Moretti,A., Caron,L., Nakano,A., Lam,J.T., Bernshausen,A., Chen,Y., Qyang,Y., Bu,L., Sasaki,M., Martin-Puig,S., Sun,Y., Evans,S.M., Laugwitz,K.L., and Chien,K.R. (2006). Multipotent embryonic isl1+ progenitor cells lead to cardiac, smooth muscle, and endothelial cell diversification. Cell 127, 1151-1165.

Mosahebi,A., Woodward,B., Green,C., Martin,R., and Terenghi,G. (2000). Long-term effect of vital labelling on mixed Schwann cell cultures. Histochem. J. 32, 337-343.

Motoike,T., Markham,D.W., Rossant,J., and Sato,T.N. (2003). Evidence for novel fate of Flk1+ progenitor: contribution to muscle lineage. Genesis. 35, 153-159.

Murray, P. D. F. (1932). The development in vitro of the blood of the early chick embryo. Proc. Roy. Soc. London. 11, 497-521. 
Nakahara,M., Nakamura,N., Matsuyama,S., Yogiashi,Y., Yasuda,K., Kondo,Y., Yuo,A., and Saeki,K. (2009). High-efficiency production of subculturable vascular endothelial cells from feeder-free human embryonic stem cells without cell-sorting technique. Cloning Stem Cells 11, 509-522.

Nakano,T., Kodama,H., and Honjo,T. (1994). Generation of lymphohematopoietic cells from embryonic stem cells in culture. Science 265, 1098-1101.

Narazaki,G., Uosaki,H., Teranishi,M., Okita,K., Kim,B., Matsuoka,S., Yamanaka,S., and Yamashita,J.K. (2008). Directed and systematic differentiation of cardiovascular cells from mouse induced pluripotent stem cells. Circulation 118, 498-506.

Naugle,J.E., Olson,E.R., Zhang,X., Mase,S.E., Pilati,C.F., Maron,M.B., Folkesson,H.G., Horne,W.I., Doane,K.J., and Meszaros,J.G. (2006). Type VI collagen induces cardiac myofibroblast differentiation: implications for postinfarction remodeling. Am. J. Physiol Heart Circ. Physiol 290, H323-H330.

Nishikawa,S.I., Nishikawa,S., Hirashima,M., Matsuyoshi,N., and Kodama,H. (1998). Progressive lineage analysis by cell sorting and culture identifies FLK1+VE-cadherin+ cells at a diverging point of endothelial and hemopoietic lineages. Development 125, 1747-1757.

Noden,D.M. (1988). Interactions and fates of avian craniofacial mesenchyme. Development 103 Suppl, 121-140.

Nolte,J., Michelmann,H.W., Wolf,M., Wulf,G., Nayernia,K., Meinhardt,A., Zechner,U., and Engel,W. (2010). PSCDGs of mouse multipotent adult germline stem cells can enter and progress through meiosis to form haploid male germ cells in vitro. Differentiation 80, 184-194.

Norrby,K. (2006). In vivo models of angiogenesis. J. Cell Mol. Med. 10, 588-612.

Nussbaum,J., Minami,E., Laflamme,M.A., Virag,J.A., Ware,C.B., Masino,A., Muskheli,V., Pabon,L., Reinecke,H., and Murry,C.E. (2007). Transplantation of undifferentiated murine embryonic stem cells in the heart: teratoma formation and immune response. FASEB J. 21, 1345-1357.

O'Connell,K.A. and Edidin,M. (1990). A mouse lymphoid endothelial cell line immortalized by simian virus 40 binds lymphocytes and retains functional characteristics of normal endothelial cells. J. Immunol. 144, 521-525.

Okamoto,T. and Okabe,S. (2000). Ultraviolet absorbance at 260 and $280 \mathrm{~nm}$ in RNA measurement is dependent on measurement solution. Int. J. Mol. Med. 5, 657-659.

Okano,H. (2002). [Neural stem cells: their identification, isolation and potential therapeutic application]. Seikagaku 74, 17-26.

Okita,K., Ichisaka,T., and Yamanaka,S. (2007). Generation of germline-competent induced pluripotent stem cells. Nature 448, 313-317.

Olsson,A.K., Dimberg,A., Kreuger,J., and Claesson-Welsh,L. (2006). VEGF receptor signalling - in control of vascular function. Nat. Rev. Mol. Cell Biol. 7, 359-371. 
Oulad-Abdelghani,M., Bouillet,P., Decimo,D., Gansmuller,A., Heyberger,S., Dolle,P., Bronner,S., Lutz,Y., and Chambon,P. (1996). Characterization of a premeiotic germ cell-specific cytoplasmic protein encoded by Stra8, a novel retinoic acid-responsive gene. J. Cell Biol. 135, 469-477.

Palis,J. and Yoder,M.C. (2001). Yolk-sac hematopoiesis: the first blood cells of mouse and man. Exp. Hematol. 29, 927-936.

Papapetropoulos,A., Fulton,D., Mahboubi,K., Kalb,R.G., O'Connor,D.S., Li,F., Altieri,D.C., and Sessa,W.C. (2000). Angiopoietin-1 inhibits endothelial cell apoptosis via the Akt/survivin pathway. J. Biol. Chem. 275, 9102-9105.

Passaniti,A., Taylor,R.M., Pili,R., Guo,Y., Long,P.V., Haney,J.A., Pauly,R.R., Grant,D.S., and Martin,G.R. (1992). A simple, quantitative method for assessing angiogenesis and antiangiogenic agents using reconstituted basement membrane, heparin, and fibroblast growth factor. Lab Invest 67, 519-528.

Patan,S. (2004). Vasculogenesis and angiogenesis. Cancer Treat. Res. 117, 3-32.

Pepper,M.S., Mandriota,S.J., Vassalli,J.D., Orci,L., and Montesano,R. (1996). Angiogenesis-regulating cytokines: activities and interactions. Curr. Top. Microbiol. Immunol. 213 ( Pt 2), 31-67.

Ponchel,F., Toomes,C., Bransfield,K., Leong,F.T., Douglas,S.H., Field,S.L., Bell,S.M., Combaret,V., Puisieux,A., Mighell,A.J., Robinson,P.A., Inglehearn,C.F., Isaacs,J.D., and Markham,A.F. (2003). Real-time PCR based on SYBR-Green I fluorescence: an alternative to the TaqMan assay for a relative quantification of gene rearrangements, gene amplifications and micro gene deletions. BMC. Biotechnol. 3, 18.

Prokhorova,T.A., Harkness,L.M., Frandsen,U., Ditzel,N., Schroder,H.D., Burns,J.S., and Kassem,M. (2009). Teratoma formation by human embryonic stem cells is site dependent and enhanced by the presence of Matrigel. Stem Cells Dev. 18, 47-54.

Rafii,S. and Lyden,D. (2003). Therapeutic stem and progenitor cell transplantation for organ vascularization and regeneration. Nat. Med. 9, 702-712.

Rafii,S., Heissig,B., and Hattori,K. (2002). Efficient mobilization and recruitment of marrow-derived endothelial and hematopoietic stem cells by adenoviral vectors expressing angiogenic factors. Gene Ther. 9, 631-641.

Rahimi,N., Dayanir,V., and Lashkari,K. (2000). Receptor chimeras indicate that the vascular endothelial growth factor receptor-1 (VEGFR-1) modulates mitogenic activity of VEGFR-2 in endothelial cells. J. Biol. Chem. 275, 16986-16992.

Ramiya,V.K., Maraist,M., Arfors,K.E., Schatz,D.A., Peck,A.B., and Cornelius,J.G. (2000). Reversal of insulin-dependent diabetes using islets generated in vitro from pancreatic stem cells. Nat. Med. 6, 278-282.

Risau,W. (1997). Mechanisms of angiogenesis. Nature 386, 671-674.

Risau,W. and Flamme,I. (1995). Vasculogenesis. Annu. Rev. Cell Dev. Biol. 11, 73-91. 
Risau,W. and Lemmon,V. (1988). Changes in the vascular extracellular matrix during embryonic vasculogenesis and angiogenesis. Dev. Biol. 125, 441-450.

Risau,W., Sariola,H., Zerwes,H.G., Sasse,J., Ekblom,P., Kemler,R., and Doetschman,T. (1988). Vasculogenesis and angiogenesis in embryonic-stem-cell-derived embryoid bodies. Development 102, 471-478.

Robey,P.G. (2000). Stem cells near the century mark. J. Clin. Invest 105, 1489-1491.

Rondaij,M.G., Bierings,R., Kragt,A., van Mourik,J.A., and Voorberg,J. (2006). Dynamics and plasticity of Weibel-Palade bodies in endothelial cells. Arterioscler. Thromb. Vasc. Biol. 26, 1002-1007.

Sabin, F.R. (1920). Studies on the origin of blood vessels and of red corpuscles as seen in the living blastoderm of the chick during the second day of incubation. Contributions to Embryology. 9, 213-262.

Saga,Y., Kitajima,S., and Miyagawa-Tomita,S. (2000). Mesp1 expression is the earliest sign of cardiovascular development. Trends Cardiovasc. Med. 10, 345-352.

Santhanam,A.V., Smith,L.A., He,T., Nath,K.A., and Katusic,Z.S. (2007). Endothelial progenitor cells stimulate cerebrovascular production of prostacyclin by paracrine activation of cyclooxygenase-2. Circ. Res. 100, 1379-1388.

Sato,A., Iwama,A., Takakura,N., Nishio,H., Yancopoulos,G.D., and Suda,T. (1998). Characterization of TEK receptor tyrosine kinase and its ligands, Angiopoietins, in human hematopoietic progenitor cells. Int. Immunol. 10, 1217-1227.

Sato,T.N., Tozawa,Y., Deutsch,U., Wolburg-Buchholz,K., Fujiwara,Y., GendronMaguire,M., Gridley,T., Wolburg,H., Risau,W., and Qin,Y. (1995). Distinct roles of the receptor tyrosine kinases Tie-1 and Tie-2 in blood vessel formation. Nature 376, 70-74.

Schatteman,G.C., Dunnwald,M., and Jiao,C. (2007). Biology of bone marrow-derived endothelial cell precursors. Am. J. Physiol Heart Circ. Physiol 292, H1-18.

Schenke-Layland,K., Angelis,E., Rhodes,K.E., Heydarkhan-Hagvall,S., Mikkola,H.K., and MacLellan,W.R. (2007). Collagen IV induces trophoectoderm differentiation of mouse embryonic stem cells. Stem Cells 25, 1529-1538.

Schenke-Layland,K., Rhodes,K.E., Angelis,E., Butylkova,Y., Heydarkhan-Hagvall,S., Gekas,C., Zhang,R., Goldhaber,J.I., Mikkola,H.K., Plath,K., and Maclellan,W.R. (2008). Reprogrammed mouse fibroblasts differentiate into cells of the cardiovascular and hematopoietic lineages. Stem Cells 26, 1537-1546.

Schnaper,H.W., Kleinman,H.K., and Grant,D.S. (1993). Role of laminin in endothelial cell recognition and differentiation. Kidney Int. 43, 20-25.

Schuh,A.C., Faloon,P., Hu,Q.L., Bhimani,M., and Choi,K. (1999). In vitro hematopoietic and endothelial potential of flk-1(-/-) embryonic stem cells and embryos. Proc. Natl. Acad. Sci. U. S. A 96, 2159-2164.

Schwartz,R.S. (1998). Pathophysiology of restenosis: interaction of thrombosis, hyperplasia, and/or remodeling. Am. J. Cardiol. 81, 14E-17E. 
Segers,V.F. and Lee,R.T. (2008). Stem-cell therapy for cardiac disease. Nature 451, 937942.

Seifalian,A.M., Tiwari,A., Hamilton,G., and Salacinski,H.J. (2002). Improving the clinical patency of prosthetic vascular and coronary bypass grafts: the role of seeding and tissue engineering. Artif. Organs 26, 307-320.

Shalaby,F., Ho,J., Stanford,W.L., Fischer,K.D., Schuh,A.C., Schwartz,L., Bernstein,A., and Rossant,J. (1997). A requirement for Flk1 in primitive and definitive hematopoiesis and vasculogenesis. Cell 89, 981-990.

Shalaby,F., Rossant,J., Yamaguchi,T.P., Gertsenstein,M., Wu,X.F., Breitman,M.L., and Schuh,A.C. (1995). Failure of blood-island formation and vasculogenesis in Flk-1deficient mice. Nature 376, 62-66.

Shepherd,R.M., Capoccia,B.J., Devine,S.M., Dipersio,J., Trinkaus,K.M., Ingram,D., and Link,D.C. (2006). Angiogenic cells can be rapidly mobilized and efficiently harvested from the blood following treatment with AMD3100. Blood 108, 3662-3667.

Skalli,O., Pelte,M.F., Peclet,M.C., Gabbiani,G., Gugliotta,P., Bussolati,G., Ravazzola,M., and Orci,L. (1989). Alpha-smooth muscle actin, a differentiation marker of smooth muscle cells, is present in microfilamentous bundles of pericytes. J. Histochem. Cytochem. 37, 315-321.

Slieker,W.A., de Rijk-de Bruijn MF, Leenen,P.J., and van,E.W. (1993). ER-MP12 antigen, a new cell surface marker on mouse bone marrow cells with thymus-repopulating ability: I. Intrathymic repopulating ability of ER-MP12-positive bone marrow cells. Int. Immunol. 5, 1093-1098.

Sloan,S.R. (1997). Diseases associated with the major histocompatibility complex. West J. Med. 167, 36-37.

Smith,S.K. (1995). Angiogenic growth factor expression in the uterus. Hum. Reprod. Update. 1, 162-172.

Soker,S., Machado,M., and Atala,A. (2000). Systems for therapeutic angiogenesis in tissue engineering. World J. Urol. 18, 10-18.

Sone,M., Itoh,H., Yamahara,K., Yamashita,J.K., Yurugi-Kobayashi,T., Nonoguchi,A., Suzuki,Y., Chao,T.H., Sawada,N., Fukunaga,Y., Miyashita,K., Park,K., Oyamada,N., Sawada,N., Taura,D., Tamura,N., Kondo,Y., Nito,S., Suemori,H., Nakatsuji,N., Nishikawa,S., and Nakao,K. (2007). Pathway for differentiation of human embryonic stem cells to vascular cell components and their potential for vascular regeneration. Arterioscler. Thromb. Vasc. Biol. 27, 2127-2134.

Stanley,E.G., Biben,C., Elefanty,A., Barnett,L., Koentgen,F., Robb,L., and Harvey,R.P. (2002). Efficient Cre-mediated deletion in cardiac progenitor cells conferred by a 3'UTR-ires-Cre allele of the homeobox gene Nkx2-5. Int. J. Dev. Biol. 46, 431-439.

Staton,C.A., Stribbling,S.M., Tazzyman,S., Hughes,R., Brown,N.J., and Lewis,C.E. (2004). Current methods for assaying angiogenesis in vitro and in vivo. Int. J. Exp. Pathol. 85, 233-248. 
Streckfuss-Bomeke,K., Vlasov,A., Hulsmann,S., Yin,D., Nayernia,K., Engel,W., Hasenfuss,G., and Guan,K. (2009). Generation of functional neurons and glia from multipotent adult mouse germ-line stem cells. Stem Cell Res. 2, 139-154.

Suri,C., Jones,P.F., Patan,S., Bartunkova,S., Maisonpierre,P.C., Davis,S., Sato,T.N., and Yancopoulos,G.D. (1996). Requisite role of angiopoietin-1, a ligand for the TIE2 receptor, during embryonic angiogenesis. Cell 87, 1171-1180.

Suzuki,H., Shibata,R., Kito,T., Ishii,M., Li,P., Yoshikai,T., Nishio,N., Ito,S., Numaguchi,Y., Yamashita,J.K., Murohara,T., and Isobe,K. (2010). Therapeutic angiogenesis by transplantation of induced pluripotent stem cell-derived Flk-1 positive cells. BMC. Cell Biol. 11, 72.

Takahashi,K., Tanabe,K., Ohnuki,M., Narita,M., Ichisaka,T., Tomoda,K., and Yamanaka,S. (2007). Induction of pluripotent stem cells from adult human fibroblasts by defined factors. Cell 131, 861-872.

Takuwa, Y., Du, W., Qi, X., Okamoto Y., Takuwa N., and Yoshioka K. (2010). Roles of sphingosine-1-phosphate signaling in angiogeneis. World J Biol Chem. 1(10), 298-306

Tam,P.P. and Beddington,R.S. (1987). The formation of mesodermal tissues in the mouse embryo during gastrulation and early organogenesis. Development 99, 109-126.

Tam,P.P. and Behringer,R.R. (1997). Mouse gastrulation: the formation of a mammalian body plan. Mech. Dev. 68, 3-25.

Tammela,T., Enholm,B., Alitalo,K., and Paavonen,K. (2005). The biology of vascular endothelial growth factors. Cardiovasc. Res. 65, 550-563.

Tepper,O.M., Galiano,R.D., Capla,J.M., Kalka,C., Gagne,P.J., Jacobowitz,G.R., Levine,J.P., and Gurtner,G.C. (2002). Human endothelial progenitor cells from type II diabetics exhibit impaired proliferation, adhesion, and incorporation into vascular structures. Circulation 106, 2781-2786.

Theise,N.D., Saxena,R., Portmann,B.C., Thung,S.N., Yee,H., Chiriboga,L., Kumar,A., and Crawford,J.M. (1999). The canals of Hering and hepatic stem cells in humans. Hepatology 30, 1425-1433.

van der,K.D. and Weiss,S. (2000). Why stem cells? Science 287, 1439-1441.

Velazquez,O.C. (2007). Angiogenesis and vasculogenesis: inducing the growth of new blood vessels and wound healing by stimulation of bone marrow-derived progenitor cell mobilization and homing. J. Vasc. Surg. 45 Suppl A, A39-A47.

Vestweber,D. (2008). VE-cadherin: the major endothelial adhesion molecule controlling cellular junctions and blood vessel formation. Arterioscler. Thromb. Vasc. Biol. 28, 223-232.

Vodyanik,M.A., Bork,J.A., Thomson,J.A., and Slukvin,I.I. (2005). Human embryonic stem cell-derived CD34+ cells: efficient production in the coculture with OP9 stromal cells and analysis of lymphohematopoietic potential. Blood 105, 617-626. 
Voyta,J.C., Via,D.P., Butterfield,C.E., and Zetter,B.R. (1984). Identification and isolation of endothelial cells based on their increased uptake of acetylated-low density lipoprotein. J. Cell Biol. 99, 2034-2040.

Vukicevic,S., Kleinman,H.K., Luyten,F.P., Roberts,A.B., Roche,N.S., and Reddi,A.H. (1992). Identification of multiple active growth factors in basement membrane Matrigel suggests caution in interpretation of cellular activity related to extracellular matrix components. Exp. Cell Res. 202, 1-8.

Wake,H., Mori,S., Liu,K., Takahashi,H.K., and Nishibori,M. (2009). High mobility group box 1 complexed with heparin induced angiogenesis in a matrigel plug assay. Acta Med. Okayama 63, 249-262.

Wang,Z.Z., Au,P., Chen,T., Shao,Y., Daheron,L.M., Bai,H., Arzigian,M., Fukumura,D., Jain,R.K., and Scadden,D.T. (2007). Endothelial cells derived from human embryonic stem cells form durable blood vessels in vivo. Nat. Biotechnol. 25, 317-318.

Watt,F.M. and Hogan,B.L. (2000). Out of Eden: stem cells and their niches. Science 287, 1427-1430.

Watt,S.M., Williamson,J., Genevier,H., Fawcett,J., Simmons,D.L., Hatzfeld,A., Nesbitt,S.A., and Coombe,D.R. (1993). The heparin binding PECAM-1 adhesion molecule is expressed by CD34+ hematopoietic precursor cells with early myeloid and B-lymphoid cell phenotypes. Blood 82, 2649-2663.

Wijelath,E.S., Rahman,S., Murray,J., Patel,Y., Savidge,G., and Sobel,M. (2004). Fibronectin promotes VEGF-induced CD34 cell differentiation into endothelial cells. J. Vasc. Surg. 39, 655-660.

Wolins,N.E., Quaynor,B.K., Skinner,J.R., Tzekov,A., Park,C., Choi,K., and Bickel,P.E. (2006). OP9 mouse stromal cells rapidly differentiate into adipocytes: characterization of a useful new model of adipogenesis. J. Lipid Res. 47, 450-460.

Yamaguchi,T.P., Dumont,D.J., Conlon,R.A., Breitman,M.L., and Rossant,J. (1993). flk-1, an flt-related receptor tyrosine kinase is an early marker for endothelial cell precursors. Development 118, 489-498.

Yamahara,K., Sone,M., Itoh,H., Yamashita,J.K., Yurugi-Kobayashi,T., Homma,K., Chao,T.H., Miyashita,K., Park,K., Oyamada,N., Sawada,N., Taura,D., Fukunaga,Y., Tamura,N., and Nakao,K. (2008). Augmentation of neovascularization [corrected] in hindlimb ischemia by combined transplantation of human embryonic stem cells-derived endothelial and mural cells. PLoS. One. 3, e1666.

Yamanaka,S. and Takahashi,K. (2006). [Induction of pluripotent stem cells from mouse fibroblast cultures]. Tanpakushitsu Kakusan Koso 51, 2346-2351.

Yamashita,J., Itoh,H., Hirashima,M., Ogawa,M., Nishikawa,S., Yurugi,T., Naito,M., Nakao,K., and Nishikawa,S. (2000). Flk1-positive cells derived from embryonic stem cells serve as vascular progenitors. Nature 408, 92-96.

Yang,L., Soonpaa,M.H., Adler,E.D., Roepke,T.K., Kattman,S.J., Kennedy,M., Henckaerts,E., Bonham,K., Abbott,G.W., Linden,R.M., Field,L.J., and Keller,G.M. 
(2008). Human cardiovascular progenitor cells develop from a KDR+ embryonic-stemcell-derived population. Nature 453, 524-528.

Yin,Y., Que,J., Teh,M., Cao,W.P., El Oakley,R.M., and Lim,S.K. (2004). Embryonic cell lines with endothelial potential: an in vitro system for studying endothelial differentiation. Arterioscler. Thromb. Vasc. Biol. 24, 691-696.

Yoshida,H., Hayashi,S., Kunisada,T., Ogawa,M., Nishikawa,S., Okamura,H., Sudo,T., Shultz,L.D., and Nishikawa,S. (1990). The murine mutation osteopetrosis is in the coding region of the macrophage colony stimulating factor gene. Nature 345, 442-444.

Yoshimoto,M. and Yoder,M.C. (2009). Developmental biology: Birth of the blood cell. Nature 457, 801-803.

Yu,J., Vodyanik,M.A., Smuga-Otto,K., ntosiewicz-Bourget,J., Frane,J.L., Tian,S., Nie,J., Jonsdottir,G.A., Ruotti,V., Stewart,R., Slukvin,I.I., and Thomson,J.A. (2007). Induced pluripotent stem cell lines derived from human somatic cells. Science 318, 1917-1920.

Yu,J., Huang,N.F., Wilson,K.D., Velotta,J.B., Huang,M., Li,Z., Lee,A., Robbins,R.C., Cooke,J.P., and Wu,J.C. (2009). nAChRs mediate human embryonic stem cell-derived endothelial cells: proliferation, apoptosis, and angiogenesis. PLoS. One. 4, e7040

Zech, N. H. (2004). Adult stem cell manipulation and possible clinical perspectives. J Reproduktionsmed Endokronol. 1(2):91-99.

Zeng,H., Dvorak,H.F., and Mukhopadhyay,D. (2001). Vascular permeability factor (VPF)/vascular endothelial growth factor (VEGF) peceptor-1 down-modulates VPF/VEGF receptor-2-mediated endothelial cell proliferation, but not migration, through phosphatidylinositol 3-kinase-dependent pathways. J. Biol. Chem. 276, 2696926979.

Zhang,W.J., Park,C., Arentson,E., and Choi,K. (2005). Modulation of hematopoietic and endothelial cell differentiation from mouse embryonic stem cells by different culture conditions. Blood 105, 111-114. 


\section{$7 \quad$ Acknowledgements}

Dr. Katrin Schäfer and Dr. Kaomei Guan are the first I would like to thank to. Thank you for providing me with this wonderful opportunity to be part of your lab. I am grateful to have you as supervisors during my $\mathrm{PhD}$ period. Thank you for the keen supervisions and warm encouragements. I thank all the lab members for creating a homey atmosphere and being so nice and friendly. This work would not be possible without each one of you.

I would like to thank Prof. Wolfgang Engel and Prof. Sigrid Hoyer-Fender. Thank you for your patience, suggestions and ideas during scientific discussions.

I would love to extend the warmest thanks to my family. My grandparents are the most important families in my life for now and ever. Thank you for being so kind and generous. You will always be my role models. In addition, thank my parents, sisters and numerous family members. Your love and care is the force I can keep going.

At last but never the least, I want to express the love and appreciation especially to my dearest husband, Vijayakumar Muppala and our two lovely kids, Vivin and Nitin. You enrich my life and make my career thrive. All the credits are bound to be shared with you.

I would not have made it without all of you!

Thanks! 


\section{Curriculum Vitae}

Name: $\quad$ I-Fen Cheng

Nationality: $\quad$ Taiwan, R.O.C

E-mail: $\quad$ bukki1977@,hotmail.com

Address: $\quad$ Albrecht-Thaer-Weg 24E/ Zimmer 11, 37075, Goettingen, Germany

Education

07/99-06/01 M.Sc., Cell Biology Program, Institute of Biology,

Grade

National Defence University, Taipei, Taiwan

A

09/95-06/99 B.Sc., Department of Food Nutrition, Shih-Chien

A

University, Taipei, Taiwan.

Research Experience

12/06-12/10 PhD in biology (GAUSS program)

Department of Cardiology and Pulmonary Medicine, Georg-AugustUniversity, Goettingen.

08/04-10/05 JRF-Research assistant,

Stem cell program, The Genomic Research Center, Academia Sinica, Taiwan

01/02-08/03 JRF-Research assistant,

Institute of Biological Chemistry, Academia Sinica, Taiwan

\section{Publications}

1. I-Fen Cheng, Diana Kaiser, Wolfgang Engel, Gerd Hasenfuss, Kaomei Guan and Katrin Schaefer. Differentiation of Multipotent Adult Germline Stem Cells Derived from Mouse Testis into Endothelial cells. 2010 (Manuscript in preparation) 
2. I-Fen Cheng, Gerd Hasenfuss, Katrin Schaefer and Kaomei Guan. Long-term Cultivation of Multipotent Flk- $1^{+}$Cardiovascular Progenitor Cells Derived from Adult Mouse Germline Stem Cells. (Manuscript in preparation)

3. Heida,N.M.; Leifheit-Nestler,M.; Schroeter,M.R.; Muller,J.P.; Cheng, IF.; Henkel,S.; Limbourg,A.; Limbourg,F.P.; Alves,F.; Quigley,J.P.; Ruggeri,Z.M.; Hasenfuss,G.; Konstantinides,S.; Schafer,K. Leptin enhances the potency of circulating angiogenic cells via src kinase and integrin (alpha)vbeta5: implications for angiogenesis in human obesity. 2010, Arterioscler.Thromb.Vasc.Biol.

4. Heida NM, Müller JP, Cheng IF, Leifheit-Nestler M, Faustin V, Riggert J, Hasenfuss G, Kondtantinides S, Schäfer K. Effects of obesity and weight loss on the functional properties of early outgrowth endothelial progenitor cells. 2010, J Am Coll Cardiol.

5. I-Fen Cheng. 2001, The effect of Salvianolic acid B in hypertension development of spontaneously hypertensive rats. National Defence University Master Thesis.

\section{Abstract/Posters}

1. I-Fen Cheng, Diana Kaiser, Gerd Hasenfuß, Katrin Schäfer and Kaomei Guan. 2010. $2^{\text {nd }}$ Eugeneheart PhD Student Exchange Meeting, London, UK. Cultivation of Flk-1 Positive Cardiovascular Progenitor Cells Derived from Multipotent Adult Germline Stem Cells.

2. I-Fen Cheng, Diana Kaiser, Nana-Maria Heida, Wolfgang Engel, Gerd Hasenfuß, Katrin Schäfer and Kaomei Guan. 2010. $1^{\text {st }}$ Eugeneheart PhD Student Exchange Meeting, Göttingen, Germany. Differentiation of Multipotent Adult Germline Stem Cells Derived from Mouse Testis into Endothelial Cells in vitro and in vivo.

3. I-Fen Cheng, Katrin Schäfer, Wolfgang Engel, Gerd Hasenfuß, Kaomei Guan. 2009.7th Dutch-German Joint Meeting of the Molecular Cardiology Groups, Hamburg, Germany. Differentiation of Multipotent Adult Germline Stem Cells into Vascular Endothelial Cells in vitro.

4. N.-M. Heida, M. Schroeter, I.-F. Cheng, M. Leifheit, J.-P. Müller, G.

Hasenfuß, S. Konstantinides, K. Schäfer. 2008. German congress of cardiology, Mannheim, Germany. Leptin potentiates angiogenic properties of endothelial progenitor cells in vitro and in vivo. 
5. N.-M. Heida, J.-P. Müller, I.-F. Cheng, G. Hasenfuß, S. Konstantinides, K. Schäfer. 2008 German congress of cardiology, Mannheim, Germany. Effects of obesity and weight loss on the functional properties of endothelial progenitor cells.

6. K. Guan, B. Unsöld, D. Kaiser, I.-F. Cheng, K. Schäfer, G. Hasenfuß. 2008. German congress of cardiology, Mannheim, Germany. Spermatogonial stem cells for cardiac and vascular regeneration.

7. M. Leifheit, G. Conrad, N.-M. Heida, I.-F. Cheng, S. Konstantinides, K. Schäfer. 2008. German congress of cardiology, Mannheim, Germany. Overexpression of integrin beta5 isoform enhances the proangiogenic properties of human endothelial progenitor cells.

8. I-Fen Cheng, Wei-Chuan Lin, David Tosh and Chia-Ning Shen. 2005. The $21^{\text {st }}$ joint annual conference of biomedical sciences. Taipei, Taiwan. Role of HNF-4 $\square$ and epithelial morphogenesis in cellular transdifferentiation of pancreas to liver. 